Portland State University

PDXScholar

Spring 5-17-2017

\title{
Responses of Aquatic Non-Native Species to Novel Predator Cues and Increased Mortality
}

Brian Christopher Turner

Portland State University

Follow this and additional works at: https://pdxscholar.library.pdx.edu/open_access_etds

Part of the Terrestrial and Aquatic Ecology Commons

Let us know how access to this document benefits you.

\section{Recommended Citation}

Turner, Brian Christopher, "Responses of Aquatic Non-Native Species to Novel Predator Cues and Increased Mortality" (2017). Dissertations and Theses. Paper 3620.

https://doi.org/10.15760/etd.5512

This Dissertation is brought to you for free and open access. It has been accepted for inclusion in Dissertations and Theses by an authorized administrator of PDXScholar. Please contact us if we can make this document more accessible: pdxscholar@pdx.edu. 
Responses of Aquatic Non-Native Species to

Novel Predator Cues and Increased Mortality

by

Brian Christopher Turner

A dissertation submitted in partial fulfillment of the requirements for the degree of

Doctor of Philosophy

in

Environmental Sciences and Resources

Dissertation Committee:

Catherine E. de Rivera, Chair

Edwin D. Grosholz

Michael T. Murphy

Greg M. Ruiz

Ian R. Waite

Portland State University

2017 


\begin{abstract}
Lethal biotic interactions strongly influence the potential for aquatic non-native species to establish and endure in habitats to which they are introduced. Predators in the recipient area, including native and previously established non-native predators, can prevent establishment, limit habitat use, and reduce abundance of non-native species. Management efforts by humans using methods designed to cause mass mortality (e.g., trapping, biocide applications) can reduce or eradicate non-native populations. However, the impacts of predator and human induced mortality may be mitigated by the behavior or population-level responses of a given non-native species.

My dissertation examined the responses of non-native aquatic species to the risk of predation by novel (i.e., no previous exposure) predators in the recipient community and indicators of potential compensatory responses by non-native populations to increased mortality resulting from removal efforts. My dissertation addresses four primary questions. 1) Can first generation, naïve invaders recognize and defend against predators found within the region of invasion through the expression of inducible defenses? 2) Can the overcompensatory potential of a population be predicted though examinations of intraspecific interactions of individuals from the population? 3) What is the relationship between removal effort outcome (i.e., successful or unsuccessful reduction of the target population) and compensatory population responses? 4) Is there a relationship between characteristics of removal efforts that are typically available to managers (e.g., target area size, target area connectivity, removal methodology) and
\end{abstract}


compensatory population responses that could indicate the relative likelihood of compensation resulting from removal efforts?

An invading species should be more likely to establish if it can successfully identify and defend against predators in the recipient range, such as through the expression of inducible defenses. Inducible defenses are behavioral or physiological changes that reduce an organism's susceptibility to predation. Through a series of laboratory experiments, I tested whether inducible defenses, in the form of increased burrowing depth, may have benefited the early stage of invasion of Nuttallia obscurata (purple varnish clam), an established Northeast Pacific invader. Specimens of $N$. obscurata were collected from introduced populations in the Northeast Pacific and from a native population in Japan. The clams were exposed to chemical and physical cues from Northeast Pacific crab predators, including the native Metacarcinus magister (Dungeness crab), an abundant and frequent predator of $N$. obscurata. While introduced $N$. obscurata increased their burrowing depth in the physical presence of $M$. magister, clams collected from their native range showed no such response. This lack of increased burrowing depth by naïve clams in response to a predator native to the newly invaded range, but a significant increase in depth for clams from populations established in the range suggests that while inducible defenses likely did not contribute to the initial establishment of $N$. obscurata in the Northeast Pacific, they may contribute to their continued persistence and expansion in their introduced range.

Some efforts to reduce invasive populations have paradoxically led to population increases. This phenomenon, referred to as overcompensation, occurs when strong 
negative density-dependent interactions are reduced through increased mortality within a population, resulting in an increase in the population's recruitment rate sufficient to increase the population's overall abundance. Increases in a population's recruitment rate can result from reduced cannibalism of juveniles resulting in lower mortality of new recruits, from increased adult reproductive output, which increases the number of potential recruits, or from reductions in size and/or age at maturity of the unharvested population, which increases the number of reproductive individuals. I predicted the overcompensatory potential of a population of Carcinus maenas (European green crab) in Bodega Harbor, California, using a series of laboratory and field experiments examining intraspecific pressures of adults on juveniles in the population. This measure of intraspecific pressure was used to predict the overcompensatory potential of the population in response to increased mortality from ongoing removal efforts. This prediction was then assessed using pre- and post-removal surveys of juvenile recruitment in Bodega Harbor compared to nearby populations, testing for evidence of overcompensation. While adult C. maenas in Bodega Harbor had limited negative impacts on juveniles, I concluded it was unlikely to result in overcompensation. Relative juvenile abundance did not statistically increase in removal compared to reference populations, consistent with my conclusion from the experiments.

Increases in recruitment rates can occur as a result of efforts to remove non-native species. This increase in recruitment can result in overcompensation, but more commonly results in compensation, where recruitment rates increase relative to pre-removal recruitment but does not result in in the population's abundance exceeding pre-removal 
levels. However, a detailed and accurate prediction of the response of a population to harvest is time consuming and data intensive. This is not feasible for most efforts to eradicate non-native species, which have the greatest chance of success when enacted rapidly after detection. For my final chapter, I performed a literature review and accompanying statistical analysis to determine if typically available information related to the removal effort (site size, site connectivity, and removal technique) could be used to determine increased risk of compensation for a given effort to remove aquatic invasive species. Compensation was closely linked to unsuccessful removal efforts and was observed only among efforts utilizing physical removal methods. However, the frequency with which compensation occurred varied with the exact technique employed, occurring most frequently in removal utilizing electrofishing. Additionally, evidence of compensation was more frequent among larger removal areas with variable connectivity. While other predictors (temperature, effort, etc) might add to the predicative power, the findings of the review provide criteria for managers to determine the relative risk of compensation prior to the start of removal.

Further understanding of how invasive species respond to lethal biotic interactions, including anthropogenically mediated control measures, can aid in assessing the risk of invasion for a given species and inform managers of the risk of complications resulting from removal efforts. While inducible defenses may contribute to the long-term success of an introduced species in their recipient range, my findings did not support the idea that inducible defenses triggered by predator cues contributed to their initial introduction in this case. However, research on other non-native species and offspring of 
previously naïve prey would allow for a clearer picture of the role of inducible defenses in the invasion process. Compensation resulting from removal efforts does not guarantee failure, and certain characteristics of removal efforts seem to indicate increased risk of compensation. Together these components help identify how biotic interactions surrounding mortality risk of an invading species help shape the trajectory of invasion. 


\section{Acknowledgements}

First and foremost, I thank my advisor, Catherine de Rivera. Without her guidance, insight, support and patience I could never have made it this far. My deepest thanks to my committee members Ted Grosholz, Michael T. Murphy, Greg Ruiz and Ian Waite for their advice, insight and that most precious gift to all scientists, time. For their generous hospitality and invaluable help during collection efforts in Japan and Canada, I

would like to thank Takao Suzuki and Rick Harbo. They could not have been kinder to a complete stranger in need of clams. For their help tackling that most daunting of challenges, statistical analyses, I would like to thank Chris Parker, Brian Steves and Yangdong Pan. For her invaluable work as a lab intern and clam co-conspirator, I would like to thank Marie Hepner. Thanks to Mark Sytsma, for giving me invaluable work experience and advice. Thanks to John Reuter for letting me live in his garage for a few weeks and for helping me throughout my days at Portland State.

A huge thank you to these and all fellow de Rivera lab mates past and present for their advice, support and friendship: Tim Davidson, Leslie Bliss-Ketchum, Inez Lawson, Whitney McClees, Sydney Gonsalves, Amy Truitt, Erin Kincaid, Aileen Miller, Jalene Littlejohn, Sarah Henderson, and Andrew McCandles. To Christa von Behren, Sarah Kidd, Christine Kendrick, Amy Larson, and Joey Peters: thank you for your science help and friendship. Thanks to Rosa Mallorson and Stephanie Harger for their expert clam tethering assistance. Many thanks to Andrew Harwood, Vanessa Robertson-Rojas, Marko Bradley, Basma Mohammad, Melinda Essig, Jessica Miller, Chris Bell, Benjamin Bell-de 
Rivera, and all of the Clamstravaganza crew. And thank you to my Bodega Marine Lab field buddies Amanda Newsom, Blythe Marshman, Sukkrit Nimitkul and Seth Koetke.

Eric Sanford, Steven Morgan, and Jay Stachowicz: thank you for cultivating my love of marine invertebrates and for starting me on my path to becoming a scientist. A special thanks to Lynn Kimsey and Steve Heydon at the Bohart Museum of Entomology for being great role models as scientists, awesome bug folks and for fostering my interest in science outreach.

For his support and faith that I wouldn't screw up too much as an assistant, thank you to Patrick Edwards. Thanks also to Nicole Alfafara and Amie Martin for being awesome EPP cohorts. Thank you to the staffs of the Bodega Marine Laboratory, the Department of Environmental Science and Management at Portland State University and the Portland State Library. I extend my deepest thanks to Sherie Huffman and Teri McKenzie, without whom I would have never navigated the maze that is Portland State bureaucracy.

For their generous financial support of my work, I would like to thank the National Science Foundation's Gk-12 Program (\# 0948041), the Pacific Marine Fisheries Commission and NOAA (\#\# NA06OA R4170261, NA06OAR4170159, NA07OAR4170501, NA08OA R4170927), the Alaska Department of Fish and Game (\#IHP- 07-146), the American Malacological Society, the Bushby Travel and Graduate scholarship programs and the backers of my crowd funding project "A Pacific Northwest Clamtastrophe!" through Experimnet.com. 
To my many non-science friends, thank you for your continued support and friendship. You all mean the world to me.

Thank you to whole family for their love and support. I would especially like to thank my sister Laura and her husband Garrett for their moral support, help in the field and gentle prodding on progress. To my parents, George and Alice: I could not have asked for more supportive parents and I could not have accomplished this without all you have done for me. Though he is no longer with us, I owe a great debt to my grandfather Ellsworth, as my earliest memories of the ocean are walking with him along Wright's Beach in California.

For keeping me company via my headphones for countless hours spent driving, digging for clams, tethering invertebrates and entering data, thank you to James Marsters, Jim Butcher, John Oliver, Andy Zaltzman, Scott Aukerman, Paul F. Tompkins, Patton Oswald, Matt Gourley, Mark Mcconville, David Bowie, Jonathan Coulton and Muse. Also thanks to Winston P. Turner for being a good boy. And just for fun, thanks to my favorite fictional doctors: Mordin Solus, John A. Zoidberg and Bunsen Honeydew.

Finally, and most importantly, thank you to my beautiful wife, Crystal. She loves me, believes in me, listened to countless talks, proofread papers, dealt with me when stressed and even tolerated live crabs in the house. What can I say? She's the best. 


\section{Table of Contents}

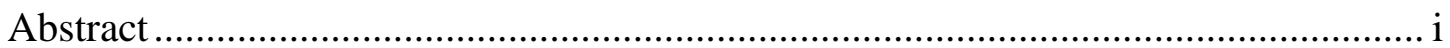

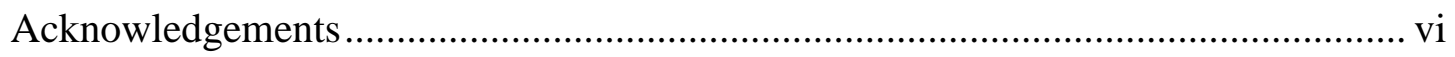

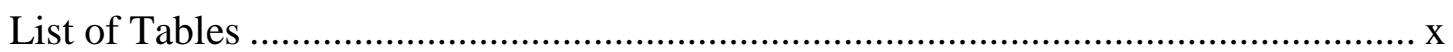

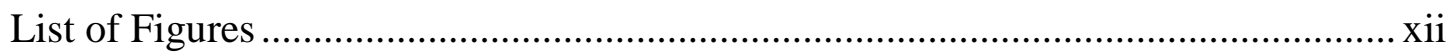

Introduction: Responses of introduced species to lethal biotic interactions and their

influence on invasion success ........................................................................... 1

Chapter 1: Examining inducible defenses to novel predators across native and

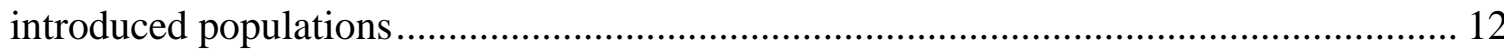

Chapter 2: Assessing population increase as a possible outcome to management of

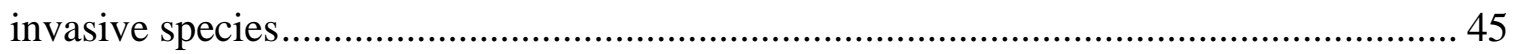

Chapter 3: Outcomes of aquatic invasive species management efforts help determine

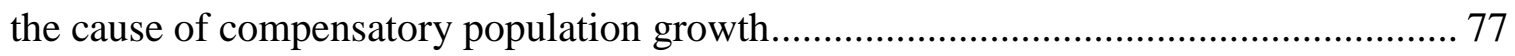

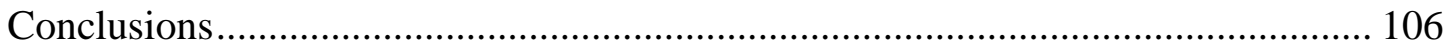

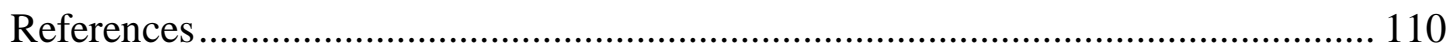

Appendix A: Supplemental tables and figures, R-scripts with additional output for Chapter 1

Appendix B: Carcinus maenas survey data, R scripts with additional output, and

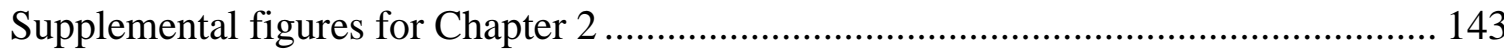


Appendix C: Supplemental tables and R-scripts with additional output for Chapter 3

Appendix D: Cascades to Coast GK-12 Curriculum ............................................ 158 


\section{List of Tables}

Table 1.1 Studies that found an inducible response by non-native species to the presence of recipient range predators, including estimated minimum period of interaction of the two species in the recipient range and the response of the non-native species .......15

Table 1.2 Mean \pm SE burrowing depth of Nuttallia obscurata and generalized linear mixed effect model estimated model coefficients \pm SE, test statistic and probability for risk cue treatments relative to control treatments in Experiment 1

Table 1.3 Mean \pm SE burrowing depth of Nuttallia obscurata and generalized linear mixed effect model estimated model coefficients \pm SE, test statistic and probability for risk cue treatments relative to control treatments in Experiment 2

Table 1.4 Mean \pm SE burrowing depth of Nuttallia obscurata, generalized linear mixed effect model estimated model coefficients \pm SE and statistical output for risk cue treatments relative to the USA N. obscurata, Control treatment in Experiment 3

Table 2.1 Maturation and fecundity data for Carcinus maenas and for fish species that showed signs of overcompensation in response to removal efforts

Table 3.1 Case studies included in the literature review with site description, species targeted for removal, and outcome of the examination for evidence of compensation

Table 3.2 Cases with or without evidence that compensation occurred for each of two possible outcomes from removal efforts.

Table 3.3 Cases or versus without evidence that compensation occurred for each of four possible removal methods

Table 3.4 Cases with or without evidence that compensation occurred for physical removal technique, removal site connectivity, removal area size and their corresponding levels

Table 3.5 Statistical output of multiple comparisons analysis for frequency with which evidence of compensation was detected across physical removal technique, removal site connectivity, and removal area. 


\section{List of Figures}

Figure 1.1 Average burrowing depth (mean $\pm 1 \mathrm{SE}$ ) of Nuttallia obscurata collected in Oregon exposed to combinations of risk cues in Experiment 1

Figure 1.2 Average burrowing depth (mean $\pm 1 \mathrm{SE}$ ) of Nuttallia obscurata collected in Oregon exposed to individual risk cues in Experiment 2 ..........................................31

Figure 1.3 Average burrowing depth (mean $\pm 1 \mathrm{SE}$ ) of Nuttallia obscurata from two regions it has invaded (USA and Canada) and one to which it is native (Japan) exposed to individual risk cues in Experiment 3

Figure 1.4 Average burrowing depth (mean $\pm 95 \%$ CI) of Oregon Nuttallia obscurata in tanks at two different locations in the Marine Ecology Research Lab at Portland State University

Figure 2.1 Number of tethered juvenile ( $<30 \mathrm{~mm}$ width) Carcinus maenas that were presumed eaten (confirmed eaten or missing) across adult Carcinus densities

Figure 2.2 Average (mean $\pm 1 \mathrm{SE}$ ) percent mass increases of juvenile Carcinus for each treatment

Figure 2.3 Average Carcinus daily catch per unit effort (CPUE) per site during annual systematic survey events at Removal (Bodega Harbor) and Reference (Elkhorn Slough, Tomales Bay) bays 


\section{Introduction: Responses of introduced species to lethal biotic interactions and their influence on invasion success}

Biotic interactions affect the fate of non-native populations only after these populations have passed a gauntlet of other threats and stressors. However, biotic interactions, such as predation, are, on their own or combined with abiotic stress and propagule pressure, an important determinant of whether introduced populations survive

or even thrive in a recipient region (Catford et al. 2009). Given the survival of a sufficient number of transported propagules, conditions within the recipient region will determine the survival and spread of a non-native species (Levine et al. 2004, Lockwood et al. 2005, Catford et al. 2009). If abiotic conditions at a site are outside the tolerance for a nonnative species then it cannot become established or persist without rapid evolutionary change (Weiher \& Keddy 1995, Werner \& Rothhaupt 2008, Firth et al. 2011). If an organism is able to tolerate abiotic conditions at the recipient location, then biotic interactions will affect the success or extent of a non-native species (Levine et al. 2004, Catford et al. 2009).

The influence of biotic interactions on invasion success is of particular import in aquatic systems, due to the relatively high risk of invasion (Lodge et al. 1998) and increased impact of biotic interactions on community structure (Bruno et al. 2005) compared with terrestrial systems. Human activities can result in the transport of both terrestrial and aquatic species far beyond natural rates and spatial scales through a variety of vectors (Lockwood et al. 2007). Vectors for pelagic and benthic aquatic species often have a greater potential to transport more individuals and species compared to terrestrial 
equivalents (Lodge et al. 1998). Ballast water (Carlton \& Geller 1993, Hutchings 1993, Hewitt \& Campbell 2007), vessels (Johnstone \& Coffey 1985, Hewitt \& Campbell 2007), and shipments of organisms for aquaculture or the pet trade (Padilla \& Williams 2004, Hewitt \& Campbell 2007) can transport nearly intact communities consisting of thousands of individuals (Lodge et al. 1998). Given the potential for biotic interactions to influence community structure, the composition of the recipient range community should play an important role in an aquatic habitats vulnerability to invasion.

The successful establishment and spread of an introduced species will thus in part be determined by the composition of the community in the recipient range. An incoming species may experience an increased chance of survival and potentially greater growth and reproductive output if the recipient range community lacks or has low abundance of potential predators, competitors, parasites, or diseases (enemy escape, release, or reduction hypotheses) (Keane \& Crawley 2002, Wolfe 2002, Mitchell \& Power 2003, Torchin et al. 2003, Torchin \& Mitchell 2004, Colautti et al. 2004). Additionally, an incoming species could benefit immediately from the ability to exploit unutilized resources in the recipient community because of the lack of competition (empty niche hypothesis) (Macarthur \& Levins 1967, Hierro et al. 2005, Catford et al. 2009). In contrast, populations with predators, parasites, or competitors that negatively impact introduced species may be more resistant to invasion, preventing the establishment of non-native species or limiting their abundance and distribution in the recipient region (biotic resistance hypothesis) (Case 1990, Hunt \& Yamada 2003, Harvey et al. 2004, 
Levine et al. 2004, de Rivera et al. 2005, Parker \& Hay 2005, Alpert 2006, Jensen et al. 2007, Dumont et al. 2011, Kimbro et al. 2013).

While any negative biotic interaction can limit the invasion potential of nonnative species, the impact should be strongest for lethal interactions. In a review of the relative importance of competition and predation in determining the characteristics of communities and populations, Sih et al. (1985) suggested that predation, an inherently lethal interaction, may more strongly influence community structure than does competition. Predation pressure from the recipient community (both native and previously established non-natives) can limit the abundance (Parker et al. 2006, Kimbro et al. 2009), habitat use (Hunt \& Yamada 2003, Harvey et al. 2004, Jensen et al. 2007, Dumont et al. 2011), and geographic range (de Rivera et al. 2005) of non-native species. Additionally, research by Bruno \& O’Connor (2005) and Shurin et al. (2002) suggests that the role of predation in determining species composition may be stronger in aquatic versus terrestrial communities.

Although predation is the first potentially lethal biotic interaction an invasive species will likely confront upon arriving in a new habitat, if the invader is known to or comes to cause ecological or economic harm it may become the target of removal efforts by humans (Simberloff 2014). Impacts of aquatic invaders can result in huge economic costs through damage to infrastructure (Galil \& Zenetos 2002, Leppäkoski et al. 2002, Davidson \& de Rivera 2012) and predation on fishery species (Glude 1955, Travis 1993, Jamieson et al. 1998, Grosholz et al. 2011). Biological invasions have also triggered shifts in community structure, size structure of native species, and in extreme cases local 
extinctions (Zaret \& Paine 1973, Goldschmidt et al. 1993, Grosholz et al. 2000, Grosholz 2002, Blackburn et al. 2004). Numerous laws, educational efforts, techniques and technologies have been developed to prevent the further distribution of propagules (Hewitt \& Campbell 2007, Tsolaki \& Diamadopoulos 2010, Cooper et al. 2012). If a potentially destructive non-native species becomes established and detected, they may become the targets of management efforts. While some management approaches utilize non-lethal means such as the introduction of sterile males or establishment of artificial barriers, many rely on lethal means (Halfyard 2010, Kolar et al. 2010) and have been successfully used to limit the geographic range, reduce the abundance, or completely eradicate populations of non-native species (Meronek et al. 1996, Mack et al. 2000, Halfyard 2010, Kolar et al. 2010).

While both predators and humans can limit the probability of establishment and spread of non-native species through lethal interactions, these interactions occur on very different scales and with different intent, which should affect effort at reduced population densities of the target species. Predators interact with their prey physically on a one-onone level. As highlighted by the components of predation described by Holling (1959, 1961, 1966, 1973; as sumarized by Rockwood 2006), a predator must search for and process every organism it consumes and typically moves elsewhere or switches prey once return on effort diminishes. An organism's vulnerability to predation will depend not only on the capabilities of the predator, but the ability of the organism to defend against the predator. As such, the ability of a non-native organism to avoid predation and survive in the recipient region will depend on its ability to effectively escape from or defend 
against individual predators. Anti-predator defenses can take many forms, including physically escaping from or avoiding the predator to physical and chemical defenses (Rockwood 2006). While many anti-predator defenses are permanent, constitutive defenses, other possess temporary or plastic inducible defenses (Tollrian \& Harvell 1998, Nunes et al. 2014).

Inducible defenses are a form of phenotypic plasticity whereby an organism undergoes a temporary morphological or behavior change that reduces susceptibility to predation (Trussell \& Nicklin 2002). In contrast to constitutive defenses, inducible defenses are energetically efficient and agile and potentially less energetically costly as resources are allocated to their development only if the risk of predation is high (Zangerl \& Rutledge 1996, Leonard et al. 1999, Trussell \& Nicklin 2002). When risk of predation is low, greater resources can be allocated to growth and reproduction (Tollrian \& Harvell 1998, Trussell \& Nicklin 2002). However, for inducible defenses to be effective the organism must be able to recognize cues that signal increased risk (Lively 1986, Harvell 1990, DeWitt et al. 1998, Tollrian \& Harvell 1998, Whitlow et al. 2003). Such cues, including tactile interactions with predators, chemical signals from predators (kairomones), or chemical signals from injured conspecifics (alarm cues), trigger the expression of inducible defenses (Harvell 1990, Trussell \& Nicklin 2002). However, given the lack of a shared evolutionary history between recipient range predators and introduced prey, it is possible that introduced prey will not identify predator cues and express inducible defenses in situations of increased risk (akin to the naïve prey hypothesis; Sih et al. 2010; Carthey and Banks 2014; Berthon 2015). 
Species capable of expressing inducible defenses should be more likely to successfully overcome biotic barriers to invasion than those that cannot, if they can identify and respond to cues from novel predators in the recipient range. Several studies have shown that non-native organisms will express inducible defenses in the presence of predators in the recipient range (Dzialowski et al. 2003, Flueck 2004, Grason \& Miner 2012, Naddafi \& Rudstam 2013, Cisterne et al. 2014, Castorani \& Hovel 2016) and thus appear to recognize these predators as threats. However, previous studies were performed using populations of non-native species that had coexisted with established predator species for generations. The expression of anti-predator behaviors in naïve prey can occur within a few generations (Thompson 1998, Yoshida et al. 2003, Freeman \& Byers 2006, Nunes et al. 2014, Berthon 2015), and thus it is highly possible the observed responses of non-native prey do not represent their responses during their initial introduction. It is likely that during this initial introduction, when the introduced population is small, is when biotic resistance from established predators has the greatest chance of preventing the establishment of the introduced species.

Hence, in Chapter 1, I conducted an experiment that specifically examined inducible defenses with the goal of determining if inducible defenses might have played an important role in the initial establishment and subsequent success of a non-native species. I collected specimens of the introduced bivalve, Nuttallia obscurata, from nonnative populations in the Northeast Pacific and from a native population in Japan. Specimens from Japan are naïve to cues from Northeast Pacific predators and thus should be similar to those from the species when it first invaded the recipient range. 
In contrast to impacts from predators, human-induced mortality of non-native species for eradication or control may operate on a larger scale, because an entire population of non-native species is targeted. Treatments can range from the application of biocides to trapping, netting and even explosives (Halfyard 2010, Kolar et al. 2010). The treatment selected is typically based on its effectiveness against the target species, impact on non-target organisms, and resource cost (Parkes \& Panetta 2009). For a removal effort to be effective, the removal rate (harvest, emigration \& natural deaths) must exceed the recruitment rate (births and immigration) of the target population. This is in part determined by the efficacy of the removal effort employed, but the magnitude of these variables (natural deaths, births, emigration, immigration) should be influenced by intraspecific interactions within the population (Best et al. 2007, Gotelli 2008, Turgeon \& Kramer 2016).

Basic population theory states that in a system with limited resources and inverse intraspecific density-dependence, birth rates will fall and death rates will rise with increased population abundance. Hence, as a population approaches the maximum number of individuals that can be supported (i.e., carrying capacity), its growth rate will steadily decrease due to a depletion of resources (Gotelli 2008). Cannibalism should also be higher in populations near their carrying capacity, further reducing the overall population growth rate (Fox 1975). In contrast, smaller populations with greater resource availability tend to grow faster due to greater per-capita reproductive output and lower mortality (Rockwood 2006, Gotelli 2008). However, despite high per-capita reproduction, overall population growth is hindered in small populations due to lower 
numbers of reproductive individuals. Additionally, some species have a minimum viable population size, below which they cannot maintain a self-sustaining population (i.e., Allee effect) (Rockwood 2006). In the classic logistic growth population model, the growth rate of a population is greatest at half of the carrying capacity $(\mathrm{K} / 2)$, where a balance in struck between availability of resources, intraspecific pressures (cannibalism, competition), and number of reproducing adults (Gotelli 2008). Actual populations are more variable and the relationship between abundance and growth will differ for populations with weaker stock-recruitment relationships, but even in such systems the strength of negative intraspecific pressures (competition, cannibalism, etc.) should be greatest as the population nears its carrying capacity (Fox 1975, Beeby \& Brennan 2008).

Populations with strong, negative intraspecific pressures that are targeted for removal may experience an increase in the recruitment and survival of young of the year or juveniles (i.e., recruitment rate), which can result in enough of an increase in population size to return to or even exceed the pre-removal size (Ricker 1954, Rose et al. 2001, De Roos et al. 2007). This phenomenon, which I will refer to here as compensation, occurs when the mortality from removal efforts (or other external forces) reduces intraspecific pressures to the point that ultimately result in an increase in the number of recruits added to the population relative to before the removal. Compensation can occur through a number of processes such as a reduction in cannibalism or competition, which, compared to the pre-removal, can result in increased per-capita reproductive output, increased survival of juveniles, faster maturation, increased immigration, or a combination of factors (Rose et al. 2001, Claessen et al. 2004, De Roos 
et al. 2007, Zipkin et al. 2008). The intensity of this response is variable; in some cases the increase in recruitment is not sufficient to overcome the increase in mortality, in others it can match the removal rate of harvest efforts and the population remains relatively stable (Rose et al. 2001). In the most extreme responses, the increased recruitment rate exceeds the removal rate, causing the population to increase in size (Ricker 1954, De Roos et al. 2007, Zipkin et al. 2008, Abrams 2009). This phenomenon of an increase in population size in response to removal of individuals, is known as overcompensation (Abrams 2009, Zipkin et al. 2009, Schröder et al. 2014).

The concept of compensation is integral to the sustainable harvest of fisheries species but has been less examined in the context of efforts to remove populations, such as with biological invasions (Rose et al. 2001, Seno 2008, Zipkin et al. 2008, 2009). In theory, compensatory (or overcompensatory) recruitment allows for the replacement of individuals that are harvested from the population, allowing the population to persist despite exploitation (Ricker 1954, 1975, Beverton \& Holt 1957, Sissenwine 1984, Goodyear 1993). Mortality can also be compensatory (hereafter referred to as compensatory reserve), with populations creating a 'surplus' of individuals whose harvest will reduce mortality of the remaining population while allowing the population to persist even under harvest conditions (Christensen \& Goodyear 1988, Boyce et al. 1999). However, if the goal of harvest is to reduce or eradicate the target population (as with non-native species) then harvest efforts will attempt to exceed a population's compensatory reserve and thus compensatory mortality should not strongly impact removal efforts. Compensatory or overcompensatory recruitment, in contrast, has a 
greater potential to hinder removal efforts. However, the potential for compensation to occur as a result of harvest is generally not taken into account ahead of removal.

Zipkin et al. (2009) developed a general population model to help determine the conditions under which removal efforts can result in overcompensation. They found overcompensation was more likely to occur for species with high fecundity and short maturation periods. Many invasive species, such as the European green crab, Carcinus maenas, fit this category but their overcompensatory potential has not been examined in the field. Marine organisms with pelagic larvae, such as $C$. maenas, can have weak stockrecruitment relationships, and thus may not respond to harvest in the same way as predicted by the model developed by Zipkin et al. (2009; see [Yamada 2001, Yamada \& Gillespie 2008]).

In Chapter 2, I developed and performed a series of field and lab assessments to determine the potential for overcompensation by a population of $C$. maenas in response to removal efforts. This was accomplished by testing whether the presence of adult crabs significantly reduced either juvenile survivorship or juvenile growth in Bodega Harbor. The accuracy of my determination was then assessed by using annual survey data from the removal site and comparing it to survey data from several reference bays.

In Chapter 3, I further explored the role of compensation and overcompensation in efforts to remove non-native populations through a literature review. I examined the details of efforts to remove populations of aquatic invasive species to examine the impact of compensation on the outcome of removal efforts and to determine if the compensatory potential of a population could be estimated using typically available information. 
The overall goal of my research was to examine how inter- and intraspecific biological responses of non-native species may overcome lethal biotic interactions and management strategies, which might otherwise prevent their establishment and persistence or limit their abundance. This work will expand our understanding of the response of naïve prey to novel predators, as well as our knowledge of the role inducible defenses and predator recognition play in the early stages of the invasion process. Finally, my examination of compensation and overcompensation in non-native populations may benefit managers by aiding the pre-removal assessment of a target populations compensatory potential. 


\section{Chapter 1: Examining inducible defenses to novel predators across native and introduced populations}

\section{Introduction}

A species invading a new location should be more likely to establish if it can successfully defend against novel predators in the recipient range, such as through the expression of inducible defenses. Inducible defenses are a form of phenotypic plasticity, which is the ability of a genotype to alter the expression of an organism's characteristics (e.g., morphology, behavior) in response to environmental cues (DeWitt et al. 1998, Dzialowski et al. 2003). Inducible defenses are triggered after exposure to risk cues, generally tactile interactions with predators, chemical signals from predators (kairomones) or chemical signals from injured conspecifics (alarm cues), and cause an organism to undergo morphological or behavioral changes that reduce susceptibility to predation (Trussell \& Nicklin 2002, Bourdeau 2010). While it might be expected that organisms would be unable to identify and defend against novel predators with which they do not have a shared evolutionary history (akin to the naïve prey hypothesis; Sih et al. 2010; Carthey and Banks 2014; Berthon 2015), several studies have shown that some non-native organisms express inducible defenses in the presence of predators in their new recipient range (Dzialowski et al. 2003, Flueck 2004, Grason \& Miner 2012, Naddafi \& Rudstam 2013, Cisterne et al. 2014, Castorani \& Hovel 2016), which could have aided in their establishment.

Although non-native organisms will have no previous interactions with novel predators in their new recipient range, they may still be able to identify and defend 
against these predators. The non-native organism may respond to a novel predator if it is taxonomically similar to a known predator species. For example, the freshwater snail, Physella virgata, will express an inducible defense (development of rotund shell), in the presence of a range of sunfish species, even species that are non-molluscivorous (Langerhans \& DeWitt 2002). Alternatively, the non-native organisms may use general cues that happen to include the novel predator, such as a presence of any large novel organism or object (Dill 1974 cited in Sih et al. 2010, Sih 1986).

Even when species do not immediately recognize and respond to novel predators, selective pressures from predators have resulted in the expression of anti-predator behaviors in prey with which they have coexisted for only a few generations (Thompson 1998, Yoshida et al. 2003, Nunes et al. 2014, Berthon 2015). For example, native blue mussels, Mytilus edulis, from habitats invaded by the Asian shore crab, Hemigrapsus sanguineus, approximately 15 years prior (7-15 generations of M. edulis prior) increased their shell thickness in response to the crab's presence whereas completely naïve mussels from other, uninvaded populations did not respond to its presence (Freeman \& Byers 2006, Zagata et al. 2008). Additionally, novel predators may not immediately recognize newly introduced non-native species as potential prey and there may be a delay in the initiation of predation (Sih et al. 2010). After non-native prey have coexisted with predators in the recipient range for multiple generations, examinations of inducible defenses in response to these predators may not be representative of what occurred during their initial introduction. Temporal separation between introduction and investigation complicates efforts to examine the relationship between inducible defenses and 
establishment success as the prey species used in inducible defense research involving non-native prey were introduced approximately 6 to 110 years before each of these studies took place (Table 1.1).

Examining whether the expression of inducible defenses by an introduced species may increase their success during the difficult early stages of invasion would require either studying the invasion as it occurs or bringing specimens from the native range in contact with recipient range predators. The lag time between introduction and detection of most unintentionally introduced species reduces the feasibility of the first approach (Crooks 2005). However, one could experimentally test for the potential immediate expression of inducible defenses given exposure to novel predators if naïve individuals were collected from the donor population. The expression of inducible defenses, or lack thereof, by specimens directly from their native range when exposed to risk cues should be similar to those from the species when it first invaded the recipient range. 
Table 1.1 Studies that found an inducible response by non-native species (Introduced Prey) to the presence of recipient range predators, including estimated minimum period of interaction (Min. Years of Overlap, from the Estimated Time of Introduction and Year Study Occurred) of the two species in the recipient range and the response of the non-native species. Numbers in parentheses indicate the footnoted reference

\begin{tabular}{|c|c|c|c|c|c|c|}
\hline $\begin{array}{c}\text { Introduced } \\
\text { Prey }\end{array}$ & $\begin{array}{c}\text { Recip. Range } \\
\text { Predators }\end{array}$ & $\begin{array}{c}\text { Est. Time } \\
\text { Introduction }\end{array}$ & $\begin{array}{c}\text { Year } \\
\text { Study } \\
\text { Occurred } \\
\end{array}$ & $\begin{array}{c}\text { Min. } \\
\text { Years of } \\
\text { Overlap } \\
\end{array}$ & $\begin{array}{c}\text { Age at } \\
\text { Maturity }\end{array}$ & $\begin{array}{l}\text { Inducible } \\
\text { Response }\end{array}$ \\
\hline $\begin{array}{l}\text { Cervus } \\
\text { elaphus }\end{array}$ & $\begin{array}{l}\text { Puma } \\
\text { concolor }\end{array}$ & 1920’s (1) & $\begin{array}{c}1996-1999 \\
(2)\end{array}$ & 67 & $\begin{array}{l}4 \text { years } \\
\text { (3) }\end{array}$ & $\begin{array}{c}\text { barked and } \\
\text { charged at } \\
\text { predator }\end{array}$ \\
\hline $\begin{array}{l}\text { Urosalpinx } \\
\text { cinerea }\end{array}$ & $\begin{array}{c}\text { Romaleon } \\
\text { antennarium }\end{array}$ & $\begin{array}{l}\text { early } 20^{\text {th }} \\
\text { century (4) }\end{array}$ & $\begin{array}{c}2005-2006 \\
\text { (4) }\end{array}$ & 85 & $\begin{array}{l}1-3 \text { years } \\
(5)\end{array}$ & $\begin{array}{l}\text { tested but no } \\
\text { response }\end{array}$ \\
\hline $\begin{array}{c}\text { Urosalpinx } \\
\text { cinerea }\end{array}$ & $\begin{array}{c}\text { Cancer } \\
\text { productus }\end{array}$ & $\begin{array}{c}\text { by the } \\
1920 \text { 's (6) }\end{array}$ & 2009 (7) & 89 & $\begin{array}{c}1-3 \text { years } \\
(5)\end{array}$ & $\begin{array}{l}\text { reduced } \\
\text { foraging }\end{array}$ \\
\hline $\begin{array}{l}\text { Hemidactylus } \\
\text { frenatu }\end{array}$ & $\begin{array}{c}\text { Acanthophis } \\
\text { antarcticus; } \\
\text { Antaresia } \\
\text { maculosa; } \\
\text { Boiga } \\
\text { irregularis; } \\
\text { Pseudechis } \\
\text { colletti }\end{array}$ & $1983(8)$ & $2013(9)$ & 30 & $\begin{array}{l}1 \text { year } \\
(10)\end{array}$ & $\begin{array}{c}\text { avoided } \\
\text { shelters } \\
\text { marked with } \\
\text { predator scent }\end{array}$ \\
\hline $\begin{array}{l}\text { Arcuatula } \\
\text { senhousia }\end{array}$ & $\begin{array}{c}\text { Urolophus } \\
\text { halleri; } \\
\text { Pteropurpura } \\
\text { festiva; } \\
\text { Panulirus } \\
\text { interruptus }\end{array}$ & 1960’s (11) & 2012 (12) & 43 & $\begin{array}{c}\text { } 1 \text { year } \\
\quad(13)\end{array}$ & $\begin{array}{l}\text { reduced } \\
\text { feeding; } \\
\text { increased } \\
\text { burrowing }\end{array}$ \\
\hline $\begin{array}{l}\text { Dreissena } \\
\text { polymorpha; } \\
\text { Dreissena } \\
\text { rostriformis } \\
\text { bugensis }\end{array}$ & $\begin{array}{c}\text { Neogobius } \\
\text { melanostomus; } \\
\text { Lepomis } \\
\text { gibbosus; } \\
\text { Orconectes } \\
\text { rusticus }\end{array}$ & $\begin{array}{l}\text { mid-1980’s } \\
\text { (14) }\end{array}$ & 2009 (15) & 24 & $\begin{array}{l}\leq 1 \text { year } \\
(16,17)\end{array}$ & $\begin{array}{l}\text { increased } \\
\text { attachment } \\
\text { strength and } \\
\text { aggregation }\end{array}$ \\
\hline $\begin{array}{l}\text { Daphnia } \\
\text { lumholtzi }\end{array}$ & $\begin{array}{c}\text { Chaoborus } \\
\text { punctipenni; } \\
\text { Lepomis } \\
\text { macrochirus }\end{array}$ & $\begin{array}{c}1990 / 1991 \\
(18,19)\end{array}$ & 1997 (20) & 6 & $\begin{array}{l}\text { 3-7 days } \\
\quad(21)\end{array}$ & $\begin{array}{c}\text { developed } \\
\text { long, rigid } \\
\text { spines at head } \\
\text { and tail } \\
\end{array}$ \\
\hline $\begin{array}{l}\text { Mustela } \\
\text { vison }\end{array}$ & $\begin{array}{c}\text { Haliaeetus } \\
\text { albicilla }\end{array}$ & 1920’s (22) & $\begin{array}{l}2004-2005 \\
\quad(23)\end{array}$ & 75 & $\begin{array}{l}1 \text { year } \\
(24)\end{array}$ & $\begin{array}{c}\text { reduced } \\
\text { swimming } \\
\text { distances }\end{array}$ \\
\hline $\begin{array}{c}\text { Rana } \\
\text { catesbeiana }\end{array}$ & $\begin{array}{c}\text { Richardsonius } \\
\text { balteatus; } \\
\text { Ptychocheilus } \\
\text { oregonensis } \\
\end{array}$ & $\begin{array}{l}\text { Early 1930’s } \\
\text { (25) }\end{array}$ & $\begin{array}{l}\text { Not noted } \\
\quad(26)\end{array}$ & $\begin{array}{l}<110 \\
(26)\end{array}$ & $\leq \underset{(27)}{1 \text { year }}$ & $\begin{array}{l}\text { increased } \\
\text { refuge use }\end{array}$ \\
\hline
\end{tabular}

Footnote: Table: 1.1 References: 1. Flueck \& Smith-Flueck 1993, 2. Flueck 2004, 3. Lincoln 1971, 4. Kimbro et al. 2009, 5. Carriker 1955, 6. Chapman \& Banner 1949, 7. Grason \& Miner 2012, 8. Markula \& Csurhes 2009, 9. Cisterne et al. 2014, 10. Markula and Csurhes 2009, 11. Macdonald 1969, 12. Castorani \& Hovel 2016, 13. Mistri et al. 2002, 14. Mills et al. 1996, 15. Naddafi \& Rudstam 2013, 16. Lucy 2006, 17. Delmott and Edds 2014, 18. Sorensen \& Sterner 1992, 19. Havel et al. 1995, 20. Dzialowski et al. 2003, 21. Dao et al. 2016, 22. Dunstone 1993, 23. Salo et al. 2008, 24. Nowak 1991, 25. Nussbaum et al. 1983, 26. Pearl et al. 2003, 27. Howard 1981 
I examined inducible defenses, including the potential for their expression by naïve individuals newly introduced to a region, in the bivalve Nuttallia obscurata (Reeve, 1857), the purple varnish clam. The class Bivalvia contains many species with expansive non-native ranges, and a large number of bivalves are known to express behavioral and morphological inducible defenses (summarized by Castorani and Hovel 2016). Larval $N$. obscurata are thought to have been transported via ballast water to the Northeast Pacific from their native range, which includes Japan, China, and Korea (Forsyth 1993, Coan et al. 2000). This non-native bivalve was discovered in British Columbia in 1991 (Forsyth 1993) and has since expanded its range south into Washington and Oregon (Byers 2002). Crabs common to the Northeast Pacific are known to readily consume N. obscurata and play a strong role in limiting their intertidal distribution (Byers 2002, Dudas et al. 2005). Therefore, I hypothesized that established populations would recognize and respond to cues from Pacific Northeast crab predators. Although there was no investigation into the expression of inducible defenses by $N$. obscurata prior to this study, a similarly thinshelled burrowing clam, Mya arenaria, increased its burrowing depth and consequently its survival in the presence of crab predators (Whitlow et al. 2003, Whitlow 2009). Given the similarities between $N$. obscurata and M. arenaria, I hypothesized that $N$. obscurata would also increase its burrowing depth and correspondingly their chances of survival in the presence of predatory crabs.

The goal of this research was to determine if the expression of inducible defenses, in the form of increasing burrowing depth, could have contributed to the initial survival of the first generation of $N$. obscurata in the Northeast Pacific. I tested this question using 
specimens from $N$. obscurata's native range as surrogates for the original colonizers of the Northeast Pacific. I examined N. obscurata's inducible defenses in four stages. First, I examined if they do indeed demonstrate inducible defenses by increasing their burrowing depth. Second, I examined which cues induce the defense. Third, I compared the responses of clams collected from their native range (Japan) and from two populations in the Northeast Pacific (USA and Canada). Finally, I examined whether deeper burrowing conferred a survival advantage.

By comparing the responses of clams from these native and introduced populations, I can determine if the expression of inducible defenses is reduced if $N$. obscurata is naïve to Northeast Pacific cues (USA vs. Japan) or varies across populations with previous exposure to the predators (USA vs. Canada). Given the many cases of bivalve inducible defense in multiple taxa and geographic regions (summarized by Castorani \& Hovel 2016), I predicted all populations would burrow deeper given alarm or tactile stimulus cues. I expected that clams that had co-existed with the predators for generations (USA and Canada) might also respond to predator kairomones. Deeper burrowing by $N$. obscurata naïve to the predators (Japan) would suggest that inducible defenses could have increased the initial survival of the first generation of the species in the Northeast Pacific while deeper burrowing by recipient range clams would suggest such defenses contribute to the long-term success in the Northeast Pacific. Failure of $N$. obscurata from Japan to burrow deeper when exposed to risk cues would suggest that while inducible defenses may contribute to the species' long-term success in the Northeast Pacific, they probably did not aid in their initial establishment. 


\section{Methods}

Collection and care of research specimens

Specimens of Nuttallia obscurata (25-50 $\mathrm{mm}$ in length) were collected by hand from three locations: Sand Lake estuary, Oregon, United States $\left(45^{\circ} 16 ' 26.7^{\prime \prime} \mathrm{N}\right.$ 1235'20.1" W) from August 2013 to April 2016; Departure Bay, British Columbia, Canada (49²' $\left.20.0^{\prime \prime} \mathrm{N} 123^{\circ} 58^{\prime} 05.7^{\prime \prime W}\right)$ in May 2015; and Hiroura Bay, Natori, Miyagi Prefecture, Japan (3809'58.1" N 14056'57.5" E) in May 2015. Collected specimens were placed in small plastic containers $(\sim 500 \mathrm{~mL})$ along with damp sediment collected on-site. They were transported on ice to Portland State University in Portland, Oregon, USA, where all organisms were housed and experiments were conducted. Handling of all clams was standardized to approximate the expected collection and transport of specimens from Japan. Burrowing depth and body length were recorded in the field for clams collected at Sand Lake in August 2013 to examine any potential length-depth relationship in the field.

Three species of crabs were collected to act as potential predators of $N$. obscurata in the experiments: Metacarcinus magister (Dana, 1852), Cancer productus (Randall, 1839) and Carcinus maenas (Linnaeus, 1758). Both M. magister and C. productus are native to the Northeast Pacific and their habitat overlaps that of N. obscurata (Dudas et al. 2005). Although C. maenas is native to Europe and Northern Africa, its introduced range in the Northeast Pacific occasionally overlaps with that of N. obscurata (Klassen \& Locke 2007). All three crab species consume N. obscurata in laboratory settings, and predation by $C$. productus was observed in the wild (Byers 2002, Dudas et al. 2005, Curtis et al. 
2012). Adult $M$. magister (95-125 mm carapace width [CW]; male and female) and adult C. productus (100-135 mm CW; male and female) were collected at Whiskey Creek in Netarts Bay, Oregon (45²4'50.6" N 12356'05.3" W), while adult C. maenas (74-81 CW; male) were collected at Bodega Harbor, California $\left(38^{\circ} 19^{\prime} 25.00^{\prime \prime}\right.$ N 12302'52.00" W).

All collected specimens were housed in tanks filled with artificial seawater brought to a salinity of 35 psu with Instant Ocean ${ }^{\circledR}$ and kept at $13^{\circ} \mathrm{C}$ on recirculating water tables. $N$. obscurata were separated by origin and housed in 20-gallon tanks containing $\sim 10 \mathrm{~cm}$ of fine to medium grain sand collected from Sand Lake, OR. Reed Mariculture Shellfish Diet ${ }^{\circledR} 1800$ (hereafter shellfish food) was added to the table weekly to provide food for N. obscurata. Crabs were housed on a separate, independent water table, divided into 20-gallon tanks by species. Crabs were fed squid 1-2 times a week and, as available, $N$. obscurata that had been used in experimental trials. For Experiments 1-3 below, crabs selected for use in an upcoming experimental trial were placed in a separate tank for and fed squid to excess 24 hours prior to being added to experimental enclosures. Water in each table was completely replaced between experiments.

\section{Experimental Enclosures}

All experiments were conducted in 10-gallon tanks filled to $20 \mathrm{~cm}$ depth with sediment collected from Sand Lake, a depth cited as the species' most commonly observed maximum burrowing depth (Byers 2002) and one I did not find surpassed in the field. I added aerated artificial saltwater with salinity at 35 psu to each tank, which was 
maintained at $10^{\circ} \mathrm{C}$ using a $120 \mathrm{GPH}$ (gallon per hr) Ponicspump ${ }^{\circledR}$ pump and a chiller (Sea Line Platinum Series Chiller Model SL-150A). Salinity, temperature and sediment composition reflected conditions where N. obscurata is found in the Northeast Pacific, specifically those at Sand Lake, the local collection site. Each tank was allowed to sit for 24 hrs prior to the addition of $N$. obscurata and was covered with a light diffuser grid with a plastic cage $(16 \mathrm{~cm} \mathrm{~L} * 12.5 \mathrm{~cm} \mathrm{~W} * 6 \mathrm{~cm} \mathrm{D})$ at its center.

Between trials, the sediment was collected from each tank, mixed, rinsed with fresh water, and then air-dried for a minimum of 24 hrs. Tanks, chillers and aerator stones were thoroughly rinsed with fresh water after each trial.

\section{Clam tethering}

For all experiments, $N$. obscurata were divided into similarly sized sets of six clams (one set per tank). Each clam was attached to a garden staple by gluing a $20 \mathrm{~cm}$ tether of $0.28 \mathrm{~mm}$ monofilament line to the clam's left valve, allowing it to burrow to its natural maximum depth. Clams were placed in a 10-gallon tank umbo up with their garden staple planted beside them. Burrowing depth of each clam was determined by removing the garden staple, pulling the line gently until it met resistance, and then measuring the length of the exposed line and subtracting it from the pre-determined 20 cm of line length (as in Griffiths and Richardson 2006; Flynn and Smee 2010). By gently pulling on the line until taught, which allowed it to cut through the sand if needed, I removed the slack and ensured I was measuring directly above the clam, as there was occasionally horizontal movement by clams. 
Experiment 1: Do N. obscurata collected in Oregon express inducible defenses?

From August-December 2013, I tested if N. obscurata from Sand Lake, Oregon, USA would burrow deeper in the presence of cues from local crab predators and damaged conspecifics. I used four treatments: a) Control (no risk cues); b) 1 C. productus plus 4 crushed $N$. obscurata; c) 1 M. magister plus 4 crushed $N$. obscurata; or d) 1 C. maenas plus 4 crushed $N$. obscurata. Shellfish food was also added to each enclosure, including the control, to provide food for N. obscurata during the experiment. The experiment was run over eight $72 \mathrm{hr}$ time blocks, with one replicate of each treatment per time. Prior to each time block, six tethered clams were placed in each tank and allowed 24 hrs to burrow and acclimatize. At the end of each time block all crabs and crushed $N$. obscurata were removed, water was drained to sand level, and the burrowing depth of clams was recorded to the nearest $\mathrm{mm}$.

Experiment 2: What risk cues trigger inducible defenses from Northeast Pacific $N$. obscurata?

From June-August 2014, I tested which of the cues from Experiment 1 caused $N$. obscurata from an introduced population at Sand Lake, Oregon, USA to burrow deeper than those in control treatments. I used the same general methods employed in Experiment 1, but using four different cue treatments: a) Control (no risk cues); b) Crushed conspecifics only (4 crushed N. obscurata); c) 1 Caged M. magister; or d) 1 Roaming M. magister. Tanks containing a Caged M. magister allowed N. obscurata to detect chemical signals from, but not physically interact with, the predator. In contrast, 
clams in tanks containing an uncaged Roaming crab could detect chemical signals and physically interact with the predator. Shellfish food (for clams) and $25 \mathrm{~mm}^{2}$ of squid meat (alternate food source for crabs) were added to each tank, including control tanks. The experiment was run over ten $72 \mathrm{hr}$ time blocks, with one replicate of each treatment per time block.

Experiment 3: Do individuals from the donor range burrow deeper in response to recipient-range predators?

From July-October 2015, I tested if naïve specimens of $N$. obscurata from their native range responded to the presence of local crab predators in a similar fashion to the established non-native populations of this species in the Northeast Pacific, and if the response of these non-native populations varied with geographic origin. I used the same methods employed in Experiments $1 \& 2$ with one major exception: cues were left in tanks for $48 \mathrm{hrs}$ rather than $72 \mathrm{hrs}$. The cue exposure time was reduced by $24 \mathrm{hrs}$ for this experiment after observations suggested there was no consistent difference in clam depth after 48 or 72 hrs of exposure. Nine treatments were used in this experiment, representing all possible combinations of cue treatments (Control, Caged M. magister and Roaming M. magister) and geographic origin of N. obscurata (USA, Canada and Japan). The experiment was run over ten time blocks, with one replicate of each treatment per time block. 


\section{Experiment 4: Do observed changes in burrowing depths prevent predation?}

From August-September 2015, I conducted an experiment to determine if the observed differences in burrowing depth increased survival of $N$. obscurata in the presence of a Northeast Pacific crab predator. Sets of six clams from Oregon were tethered and placed into separate tanks. To keep the clams at a pre-determined depth but able to re-orient, the tether length for $N$. obscurata was reduced to $2 \mathrm{~cm}$ and the garden staple was placed in the sediment to prevent clam movement.

Each tank was randomly assigned one of two sediment depths representing the mean burrowing depth found from Experiment 1's Control, $10 \mathrm{~cm}$ deep (hereafter Shallow), and from Experiment 1's M. magister treatment, $13 \mathrm{~cm}$ (hereafter Deep). Tanks either had a Predator, M. magister, or served as a predator-free Control treatment. The experiment was run across seven time blocks, with three, or once four, tanks per block. One tank per block was randomly assigned to be Predator-Deep and another to PredatorShallow sediment depth. The third, and once fourth, tank was randomly assigned to one of the treatments: Predator-Deep, Predator-Shallow, Control-Deep, or Control-Shallow. Across all time blocks a total of 18 Predator (9 Deep, 9 Shallow) and 4 Control (no predator; 2 Deep, 2 Shallow) treatments.

A base layer of sediment $(2 \mathrm{~cm})$ was added to each tank to prevent clams from being flush against the bottom of the tank. The six clams per tank were placed on the 2 $\mathrm{cm}$ of sediment with their garden staple laid down horizontally next to them. A wooden dowel was temporarily placed vertically next to the posterior of each clam to create a sand-free "pocket" allowing for the extension of the siphons to the surface. The creation 
of a sand-free "pocket" was implemented so the clams could access the surface after we added sand above them; else, their access to the surface would be much more limited by our sand addition than if they were allowed to burrow naturally. Finally, sediment was added to bury the clams to the target depth for each replicate, the dowels were removed, and the clams were allowed to acclimatize for $24 \mathrm{hrs}$.

Unlike the previous experiments, the $M$. magister used in this experiment were fed then starved for $24 \mathrm{hrs}$ prior to their addition to the Predator treatments to standardize hunger levels and to increase the likelihood that $M$. magister would actively forage for the buried clams.

After the clam acclimatization and crab starvation periods, the crab was added to the Predator treatment. Clam mortality was assessed $6 \mathrm{hr}$ and $24 \mathrm{hr}$ after crabs were added. At $6 \mathrm{hr}$, clams were recorded as consumed if the staple had been pulled up and a broken shell was visible. After $24 \mathrm{hr}$, crabs then clams were removed.

\section{Testing for other possible influences on experimental outcomes}

Multiple factors can influence the burrowing depth of marine bivalves. Some softsediment bivalves display a strong correlation between body size and burrowing depth (Zaklan \& Ydenberg 1997). Factors associated with location also could affect burrow depths. All tanks were in a single location within each experiment; however, due to varying space availability, I used different locations for the different experiments. For Experiments 1 and 3, tanks were located on shelves in the wet lab; tanks used during Experiment 2 were housed on, but not hydrologically linked to, operational water tables. 
From March-April 2016, I ran an experiment to determine if the location of tanks affected burrowing depth of $N$. obscurata collected in Oregon. I used the same general methods as the Controls of Experiments 1-3. Two tanks were housed at each location (shelf or water table) and clams were allowed 3-4 days to burrow after which time burrowing depth was measured. The experiment was run over nine time blocks for a total of 18 tanks at each location.

\section{Statistical analyses}

Using R statistical software version 3.1.0 (R Development Core Team 2014), I compared the burrowing depths of clams exposed to risk cue treatments to the depth of $N$. obscurata from the Control treatment for Experiments 1-3. After verifying that the data approximated the assumptions of a normal distribution and homoscedasticity of residuals, I created generalized linear mixed-effects models (GLMM) for each experiment using the package "Ime4" (Bates et al. 2015). I originally considered using analysis of variance (ANOVA) or analysis of covariance (ANCOVA) to analyze the experimental results but ultimately concluded a GLMM was more appropriate for my needs. For a breakdown of this rationale, see Appendix A Supplement A.1. A GLMM was used by Castorani and Hovel (2016) when they examined the response of the introduced Asian nest mussel, Arcuatula senhousia, in the presence of kairomones and alarm cues. When using categorical predictor variables with this approach, each group within a category is compared against a selected reference group. For Experiments $1 \& 2$, the reference group was the Control treatment. For Experiment 3, the reference group for all 1-way 
comparisons was the Control treatment for USA N. obscurata; the USA Control was also part of the comparison for the interaction term (Table 1.4). The interaction term for Experiment 3 tests for differences between treatments across geographic origin. For example, the model will test if the differences in $N$. obscurata burrowing depth for Control versus Roaming $M$. magister changes when using USA $N$. obscurata compared to those from Japan (Table 1.4). R code and complete model outputs for all GLMM's can be found in Appendix A.

For Experiments $1 \& 2$, final clam burrowing depth was the response variable and cue treatment was the independent variable. Time block (1-8 \& 1-10, for Experiment $1 \&$ 2 respectively), Tank (1-4), and clam position (1-6; nested within tank) were included as random factors. For Experiment 3, final burrowing depth was the response variable while cue treatment (Control, Caged M. magister or Roaming M. magister), geographic origin (USA, Canada or Japan) and the cue treatment*geographic origin interaction term were fixed effects. Time block (1-10), Tank (1-9) and clam position (1-6; nested within tank) were included as random factors.

Clam body size was originally a covariate in the models for Experiments 1-3 to determine if clam size influenced depth. However, there never was a significant or strong relationship between clam body size and burrowing depth in any of the models, and scatterplots of depth versus size for each experiment (1-3) using data collected from Control treatments did not indicate strong trends (Appendix A Figure A.1A-C). The covariate was removed for the final models to improve statistical power, and the results of the models did not change qualitatively as a result of this removal. 
While I considered the inclusion of a barrier to separate Nuttallia from crabs in the Roaming crab treatment, I ultimately decided that the treatment would most closely mimic potential real-world interactions between predators and prey than would be possible using a barrier to separate them. However, this design came at the cost of rendering the clams vulnerable to predation. While alternate food sources were included to reduce predation on the clams, predation on tethered $N$. obscurata occasionally occurred. To eliminate the possibility of predation on any shallow clams making the data on remaining clam depths appear as if clams were burrowing deeper in predator treatments, I excluded from the analysis of Experiments 1-3 any replicate in which more than one clam was consumed in a given tank. No more than 2 tanks were excluded per treatment per experiment (Appendix A Table A.1). Additionally, any clams that failed to burrow within a given tank were excluded from analysis.

For Experiment 4, I compared mortality of N. obscurata 6 and 24 hrs after burial at the two experimental depths, Shallow and Deep. The data from Control tanks were also compared with the two experimental depths but were used to document the extent of clam mortality independent of crab predation.

Although the statistical analyses found no significant relationship between burrowing depth and size for N. obscurata, I also tested whether burrowing depth (mm) was correlated with size (nearest $5.0 \mathrm{~mm}$ ) of clams in situ at Sand Lake, Oregon, USA using Pearson's correlation (R function 'cor.test'). I included all clams 25-50 mm in length as this was the size range used in the experiments (Appendix A Figure A.1D). 
To determine if the location of tanks during Experiments 1-3 influenced clam burrowing depth, a GLMM similar to those in Experiments 1 \& 2 was constructed. Final clam burrowing depth was the response variable, and location in the lab (shelf vs. water table) was the independent variable. Time block (1-9), Tank (1-4), and Clam position (16; nested within tank) were included as random factors.

\section{Results}

Experiment 1: Do N. obscurata collected in Oregon express inducible defenses?

Nuttallia obscurata collected from Sand Lake, OR burrowed significantly deeper in the presence of Metacarcinus magister + crushed N. obscurata (Table 1.2; Figure 1.1) and Carcinus maenas + crushed N. obscurata compared to Control treatments. There was no significant difference between burrowing depth of $N$. obscurata in Control treatments and those exposed to C. productus + crushed N. obscurata.

Table 1.2 Mean \pm SE burrowing depth of Nuttallia obscurata and generalized linear mixed effect model estimated model coefficients \pm SE, test statistic and probability for risk cue treatments relative to control treatments in Experiments 1. All specimens of N. obscurata were collected at Sand Lake, Oregon, USA. Bold and italicized $p$-values are significant, while italicized alone are marginally significant.

\begin{tabular}{lccccc}
\hline \multicolumn{1}{c}{ Variable } & N & Mean \pm SE $(\mathbf{c m})$ & Coefficient \pm SE & $t$ & $p$ \\
\hline Control (no cues) & 41 & $10.6 \pm 0.8$ & - & - \\
C. productus + crushed N. obscurata & 32 & $11.6 \pm 0.7$ & $-0.06 \pm 0.90$ & -0.07 & 0.95 \\
C. maenas + crushed N. obscurata & $\mathbf{2 6}$ & $\mathbf{1 2 . 9} \pm \mathbf{0 . 9}$ & $\mathbf{2 . 2 3} \pm \mathbf{0 . 9 9}$ & $\mathbf{2 . 2 6}$ & $\mathbf{0 . 0 3}$ \\
M. magister + crushed N. obscurata & $\mathbf{3 2}$ & $\mathbf{1 2 . 7} \pm \mathbf{0 . 8}$ & $\mathbf{2 . 0 6} \pm \mathbf{0 . 9 2}$ & $\mathbf{2 . 2 5}$ & $\mathbf{0 . 0 3}$ \\
\hline
\end{tabular}




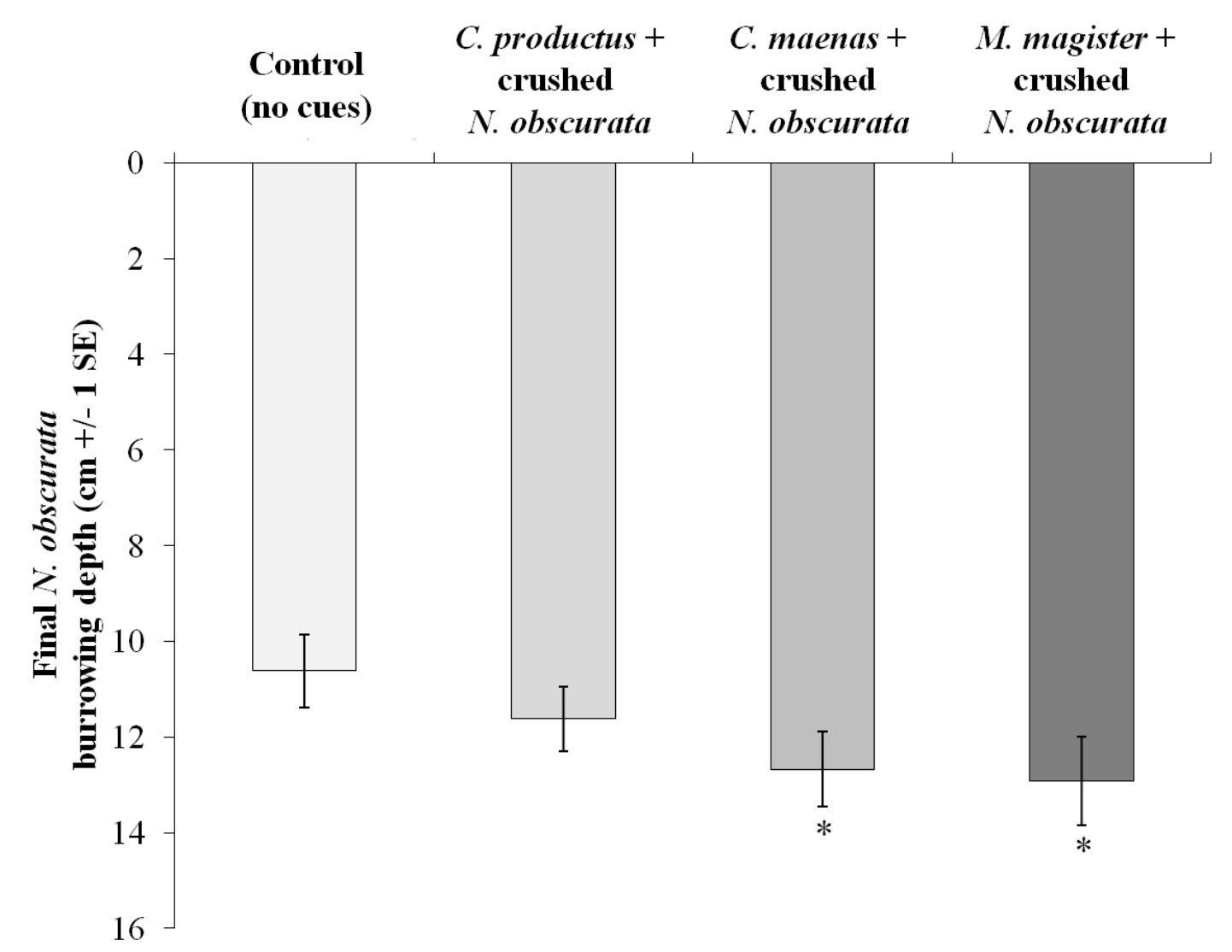

Figure 1.1 Average burrowing depth (mean $\pm 1 \mathrm{SE}$ ) of Nuttallia obscurata collected in Oregon exposed to combinations of risk cues in Experiment 1. Maximum possible burrowing depth is $20 \mathrm{~cm}$. An asterisk (*) designates that the burrowing depth of clams in a treatment was significantly different from those in the Control treatment $(p \leq 0.05)$. Clams burrowed significantly deeper in the presence of a free roaming Metacarcinus magister + crushed $N$. obscurata $(p=0.03)$ and a free roaming Carcinus maenas + crushed $N$. obscurata $(p=0.03)$ compared to Control tanks. There was no difference in burrowing depth of clams in Control treatment vs. clams in the presence of a free roaming Cancer productus + crushed $N$. obscurata $(p=0.95)$.

Experiment 2: What risk cues trigger inducible defenses from Northeast Pacific $N$.

obscurata?

N. obscurata from Oregon burrowed deeper in the presence of a Roaming $M$.

magister than in Control treatments, but not in the presence of Crushed conspecifics or a Caged M. magister (Table 1.3; Figure. 1.2). Burrowing depths of N. obscurata in the presence of a Caged M. magister or crushed conspecifics were not significantly deeper than those in the Control treatment. 
Table 1.3 Mean \pm SE burrowing depth of Nuttallia obscurata and generalized linear mixed effect model estimated model coefficients \pm SE, test statistic and probability for risk cue treatments relative to control treatments in Experiment 2. All specimens of N. obscurata were collected at Sand Lake, Oregon, USA. Bold and italicized $p$-values are significant, while italicized alone are marginally significant.

\begin{tabular}{lccccc}
\multicolumn{1}{c}{ Variable } & $\mathbf{N}$ & Mean $\pm \mathbf{S E}(\mathbf{c m})$ & Coefficient $\pm \mathbf{S E}$ & $\boldsymbol{t}$ & $\boldsymbol{p}$ \\
\hline Control (no cues) & 46 & $8.8 \pm 0.8$ & - & - & - \\
Crushed N. obscurata & 50 & $9.4 \pm 0.9$ & $0.52 \pm 1.00$ & 0.52 & 0.61 \\
Caged M. magister & 57 & $10.1 \pm 0.6$ & $1.31 \pm 0.97$ & 1.35 & 0.18 \\
Roaming M. magister & $\mathbf{3 7}$ & $\mathbf{1 0 . 9} \pm \mathbf{0 . 7}$ & $\mathbf{2 . 1 8} \pm \mathbf{1 . 1 1}$ & $\mathbf{1 . 9 7}$ & $\mathbf{0 . 0 5}$ \\
\hline
\end{tabular}

Experiment 3: Do individuals from the donor range burrow deeper in response to recipient-range predators?

N. obscurata from Oregon, USA and from British Columbia, Canada exposed to Roaming M. magister burrowed deeper than clams in their Control treatments, but clams from Miyagi Prefecture, Japan did not (Table 1.4; Figure 1.3). Specimens of N. obscurata collected in Canada in the presence of a Roaming M. magister reacted similarly to clams from the USA, burrowing deeper than clams in the Canadian Control treatment. In contrast, $N$. obscurata collected in their native range from Japan did not appear to respond to the presence of a Roaming $M$. magister, burrowing slightly shallower compared to clams in their Control treatment. It should be noted, however, that Japanese N. obscurata burrowed significantly deeper than their USA counterparts in control treatments (Table 1.4). 


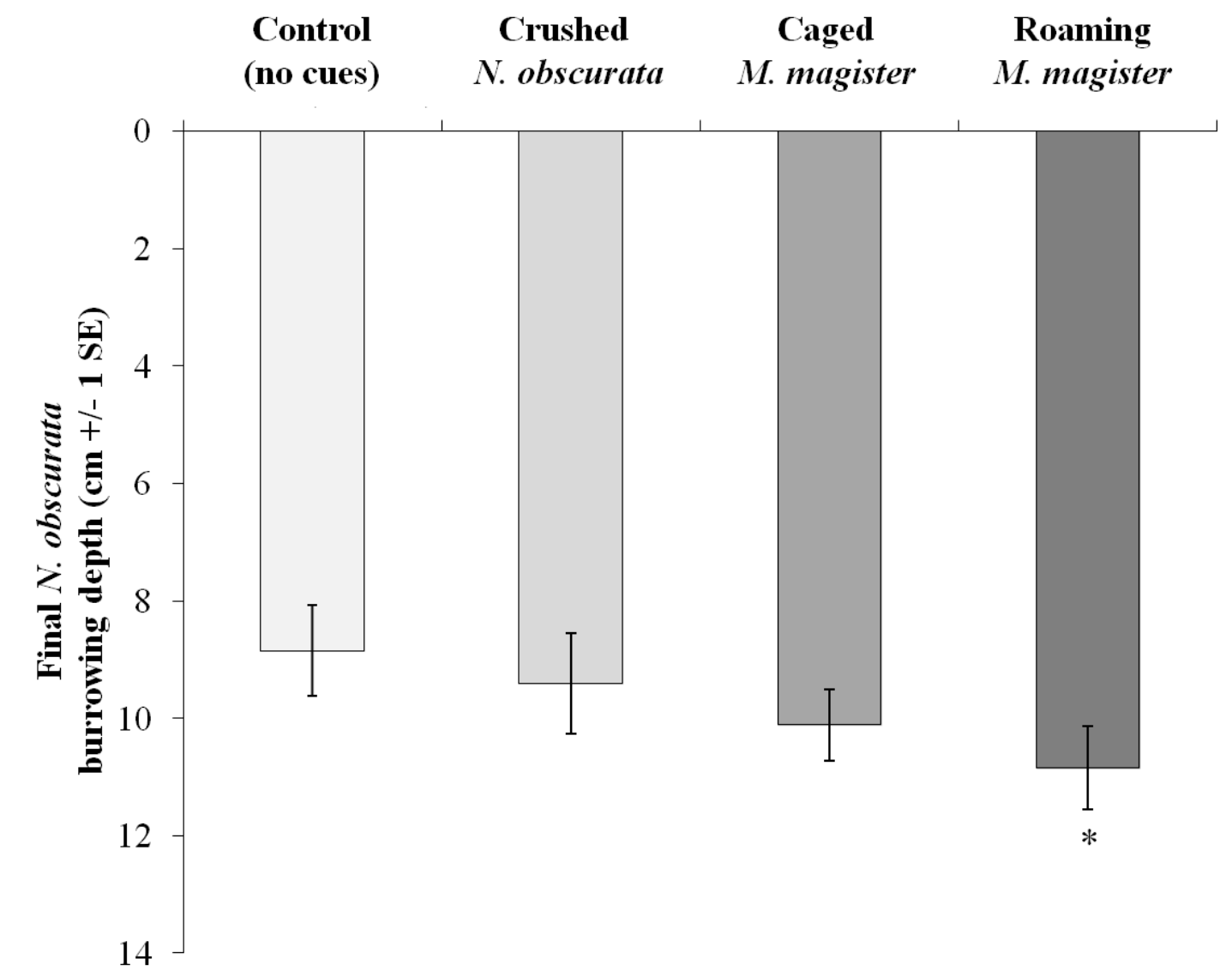

Figure 1.2 Average burrowing depth (mean $\pm 1 \mathrm{SE}$ ) of Nuttallia obscurata collected in Oregon exposed to individual risk cues in Experiment 2. Maximum possible burrowing depth is $20 \mathrm{~cm}$. An asterisk (*) designates that the burrowing depth of clams in a treatment is significantly different from those in the Control treatment $(p \leq 0.05)$. Clams burrowed significantly deeper in the presence of a free Roaming Metacarcinus magister $(p=0.05)$ compared to Control tanks. There was no difference in burrowing depth of clams in Control treatment vs. clams in the presence of a Caged M. magister $(p=0.18)$ or Crushed $N$. obscurata $(p=0.61)$.

Similar to Experiment 2, none of the clams, regardless of source population, demonstrated significant increases in burrowing depth when M. magister was caged and clams were only exposed to effluent, suggesting chemical cues on their own did not induce significantly deeper burrowing in this experiment (Table 1.4).

No significant differences were found in the interactions between geographic origin and cue treatment when comparing the Caged M. magister treatment with their 
Control (Table 1.4). Similarly, there was no significant difference when comparing the interaction of the Roaming M. magister treatment with their Control for N. obscurata from Canada versus USA clams. However, the difference in burrowing depth between Control and Roaming M. magister treatments was significantly greater for USA $N$. obscurata compared to their Japanese counterparts. 
Table 1.4 Mean \pm SE burrowing depth of Nuttallia obscurata, generalized linear mixed effect model estimated model coefficients \pm SE and statistical output for risk cue treatments relative to the USA $N$. obscurata, Control treatment in Experiment 3. Bold and italicized $p$-values are significant, while italicized alone are marginally significant.

\begin{tabular}{|c|c|c|c|c|c|c|}
\hline Variable & $\mathbf{N}$ & $\begin{array}{l}\text { Mean } \pm \mathrm{SE} \\
\quad(\mathrm{cm})\end{array}$ & $\begin{array}{c}\text { Comparison in } \\
\text { LMM }\end{array}$ & $\begin{array}{l}\text { Coefficient } \\
\quad \pm \mathrm{SE}\end{array}$ & $t$ & $p$ \\
\hline $\begin{array}{l}\text { USA N. obscurata, } \\
\text { Control }\end{array}$ & 55 & $10.5 \pm 0.8$ & - & - & - & - \\
\hline $\begin{array}{l}\text { USA } N \text {. obscurata, } \\
\text { Caged M. magister }\end{array}$ & 53 & $10.1 \pm 0.8$ & $\begin{array}{l}\text { USA N. obscurata, } \\
\text { Control }\end{array}$ & $-0.24 \pm 0.94$ & -0.26 & 0.80 \\
\hline $\begin{array}{l}\text { USA } N . \text { obscurata, } \\
\text { Roaming M. magister }\end{array}$ & 41 & $12.1 \pm 0.7$ & $\begin{array}{l}\text { USA N. obscurata, } \\
\text { Control }\end{array}$ & $1.92 \pm 1.01$ & 1.90 & 0.06 \\
\hline $\begin{array}{c}\text { Canadian N. obscurata } \\
\text { Control }\end{array}$ & 53 & $10.5 \pm 0.7$ & $\begin{array}{l}\text { USA N. obscurata, } \\
\text { Control }\end{array}$ & $0.29 \pm 0.93$ & 0.31 & 0.76 \\
\hline $\begin{array}{l}\text { Canadian N. obscurata, } \\
\text { Caged M. magister }\end{array}$ & 53 & $11.3 \pm 0.7$ & - & - & - & - \\
\hline $\begin{array}{l}\text { Canadian N. obscurata, } \\
\text { Roaming M. magister }\end{array}$ & 49 & $12.0 \pm 0.7$ & - & - & - & - \\
\hline $\begin{array}{c}\text { Japanese } N \text {. obscurata, } \\
\text { Control }\end{array}$ & 54 & $12.5 \pm 0.7$ & $\begin{array}{l}\text { USA } N . \text { obscurata, } \\
\text { Control }\end{array}$ & $2.16 \pm 0.93$ & 2.33 & 0.02 \\
\hline $\begin{array}{l}\text { Japanese } N \text {. obscurata, } \\
\text { Caged M. magister }\end{array}$ & 49 & $11.9 \pm 0.7$ & - & - & - & - \\
\hline $\begin{array}{l}\text { Japanese } N . \text { obscurata, } \\
\text { Roaming M. magister }\end{array}$ & 48 & $11.2 \pm 0.6$ & - & - & - & - \\
\hline $\begin{array}{l}\text { Interaction term (Canadian } \\
\text { N. obscurata, Control vs. } \\
\text { Caged M. magister) }\end{array}$ & - & - & $\begin{array}{l}\text { USA N. obscurata, } \\
\text { Control vs. Caged } \\
\text { M. magister }\end{array}$ & $0.98 \pm 1.33$ & 0.74 & 0.46 \\
\hline $\begin{array}{l}\text { Interaction term (Canadian } \\
\text { N. obscurata, Control vs. } \\
\text { Roaming M. magister) }\end{array}$ & - & - & $\begin{array}{l}\text { USA N. obscurata, } \\
\text { Control vs. Roaming } \\
\text { M. magister }\end{array}$ & $-0.52 \pm 1.39$ & -0.37 & 0.71 \\
\hline $\begin{array}{l}\text { Interaction term (Japanese } \\
\text { N. obscurata, Control vs. } \\
\text { Caged M. magister) }\end{array}$ & - & - & $\begin{array}{l}\text { USA N. obscurata, } \\
\text { Control vs. Caged } \\
\text { M. magister }\end{array}$ & $-0.22 \pm 1.34$ & -0.16 & 0.87 \\
\hline $\begin{array}{l}\text { Interaction term (Japanese } \\
N . \text { obscurata, Control vs. } \\
\text { Roaming M. magister) }\end{array}$ & - & - & $\begin{array}{c}\text { USA } N \text {. obscurata, } \\
\text { Control vs. } \\
\text { Roaming } \\
\text { M. magister } \\
\end{array}$ & $-3.46 \pm 1.39$ & -2.48 & 0.01 \\
\hline
\end{tabular}




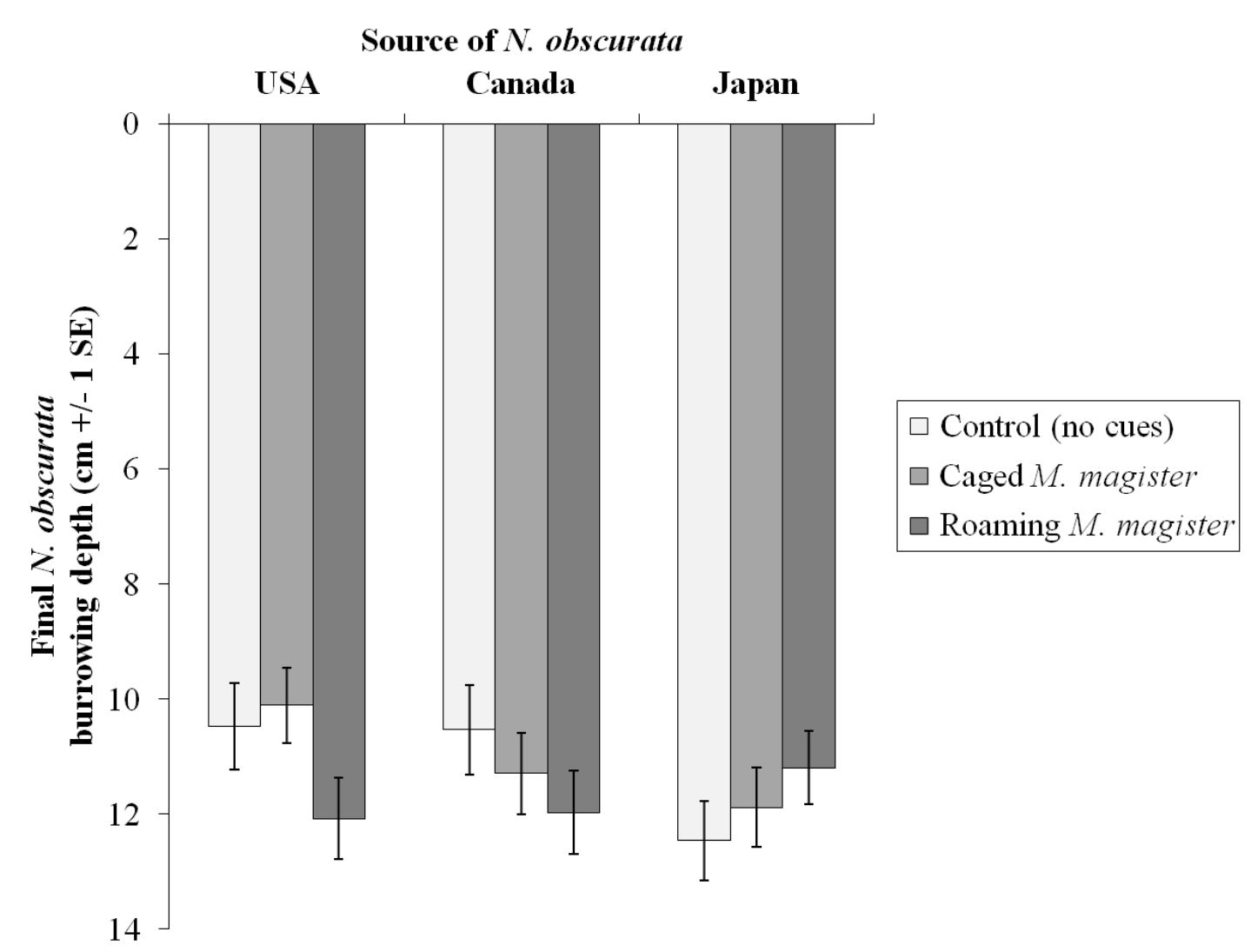

Figure 1.3 Average burrowing depth (mean $\pm 1 \mathrm{SE}$ ) of Nuttallia obscurata from two regions it has invaded (USA and Canada) and one to which it is native (Japan) exposed to individual risk cues in Experiment 3. Maximum possible burrowing depth is $20 \mathrm{~cm}$. There was no significant difference in burrowing depth for clams in Control tanks from Canada $(p=0.76)$ relative to those collected in the USA, though Japanese clams burrowed significantly deeper $(p=0.02)$. USA clams burrowed marginally deeper in the presence of a Roaming Metacarcinus magister $(p=0.06)$ than those in Control treatments but not in the presence of a Caged crab $(p=0.80)$. No significant differences were found in the interaction between geographic origin and cue treatment when comparing the Caged $M$. magister treatment with the Control (USA vs. Canada, $p$ $=0.46$; USA vs. Japan, $p=0.71$ ) There was also no significant interaction for $N$. obscurata from the USA and Canada when comparing the Roaming M. magister treatment with the Control $(p=0.87)$. However, the difference in burrowing depth between Roaming M. magister treatments and the Control was significantly greater for USA $N$. obscurata compared to their Japanese counterparts $(p=0.01)$.

Experiment 4: Do observed changes in burrowing depths reduce predation?

The experiment testing if $N$. obscurata's response to the presence of M. magister increased survival revealed that no N. obscurata buried at the Deep depth $(13 \mathrm{~cm})$ were consumed after 6 or $24 \mathrm{hrs.} \mathrm{In} \mathrm{contrast,} \mathrm{an} \mathrm{average} \mathrm{of} 0.7 \pm 0.4$ (mean \pm SE) N. obscurata 
(11\%) were consumed by M. magister per tank after 6 hrs, while $1.7 \pm 0.7 \mathrm{~N}$. obscurata (28\%) were consumed after $24 \mathrm{hrs}$ when buried at the Shallow depth $(10 \mathrm{~cm})$. No mortality occurred in the Control treatments.

Testing for other possible influences on experimental outcomes

There was no significant positive relationship between body size and burrowing depth for N. obscurata collected at Sand Lake, Oregon for clams with body sizes consistent with those used in experiments $(25-50 \mathrm{~cm} ; \mathrm{N}=49, \mathrm{r}=0.09, t=0.64, p=0.26$; Appendix A Figure A.1D).

$N$. obscurata burrowed deeper when tanks were placed on the wet lab shelves, as was done during Experiments $1 \& 3$, compared with tanks placed on the water tables, as was done during Experiment 2 (Figure 1.4). However, the GLMM results showed this difference was not statistically significant. 


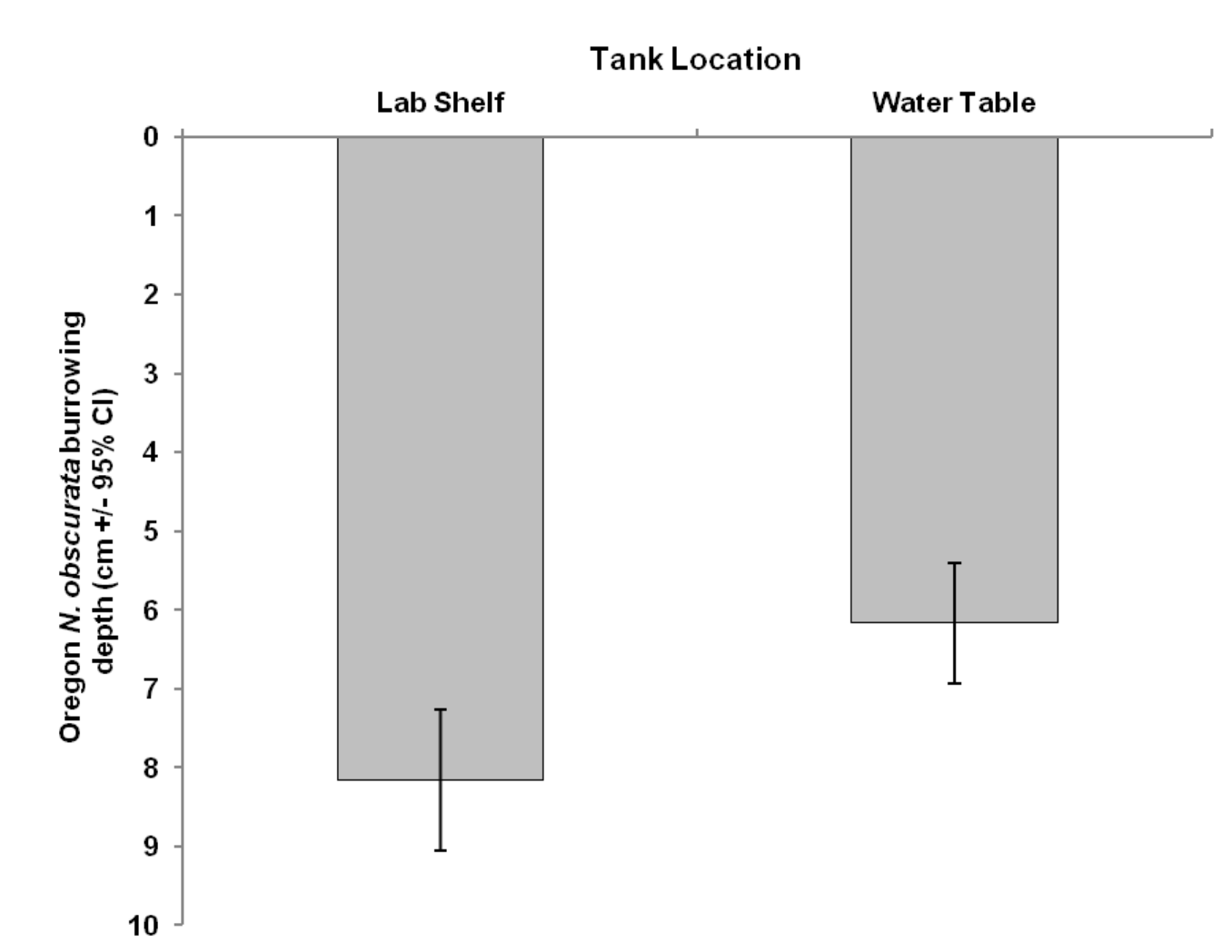

Figure 1.4 Average burrowing depth (mean $\pm 95 \%$ CI) of Oregon Nuttallia obscurata in tanks at two different locations in the Marine Ecology Research Lab at Portland State University: shelves lining the laboratory walls and water tables located in the middle of the lab. The $\sim 2 \mathrm{~cm}$ difference in burrowing depth between the locations was similar to the $\sim 2 \mathrm{~cm}$ difference observed for control treatments in Experiments 1 \& 3 (housed on shelves) and Experiment 2 (housed on water tables). Although location appears to affect clam burrowing depth, the difference was not statistically significant (linear mixed-effects model: $\mathrm{N}=9$ tanks in each group, $t=2.13, p=0.17$ ).

\section{Discussion}

Nuttallia obscurata from Oregon increased their burrowing depth in the presence of Metacarcinus magister, consistent with the use of inducible defenses in the presence of known predators. However, not all populations responded to this recipient-range predator similarly and not all potential risk cues used in these experiments elicited this defensive response. Clams collected from introduced populations in the USA and Canada both responded by burrowing deeper in the physical presence of $M$. magister. Specimens from Japan, however, did not burrow deeper as a response to chemical cues or the physical 
presence of M. magister. This suggests that while inducible defenses may play a role in the perpetuation and spread of $N$. obscurata in its introduced range, it is unlikely to have contributed to the clam's initial establishment.

Differences in the response of $N$. obscurata to cues from M. magister across populations appear to be directly linked to a difference in exposure to M. magister. Clams from the USA and Canada have been preyed upon by M. magister in the Northeast Pacific for $>20$ years, providing an opportunity for these populations to recognize and respond to M. magister as a threat. In contrast, clams from Japan have had no previous exposure to M. magister and their lack of response may be due to prey naiveté (akin to the naïve prey hypothesis; Sih et al. 2010; Berthon 2015).

Contrary to my initial predictions Japanese clams showed no evidence of inducible defenses, even when exposed to tactile stimulus from a free roaming crab. A previous study by Flynn and Smee (2010) found that tactile cues in the absence of predator kairomones caused the soft shell clam, Mya arenaria, to increase its burrowing depth. Hence, tactile cues from any predator, familiar or novel, could elicit a response from prey. However, the stimulus applied by Flynn and Smee to M. arenaria (directly prodded each clam's siphon once daily) likely was more intense than that experienced by clams in this study.

The response of $N$. obscurata from USA and Canadian populations to the presence of M. magister appears to confer increased protection from predation. All specimens buried at $13 \mathrm{~cm}$ (Deep treatment) survived the predation trials, while some clams were consumed by M. magister when buried at $10 \mathrm{~cm}$ (Shallow treatment). While 
the differences in burrowing depth resulting from the presence of M. magister may seem insufficient to provide increased protection for $N$. obscurata, it not only increased survival in our lab experiment but is in line with the findings of similar studies. Flynn \& Smee (2010) observed that a $1.5 \mathrm{~cm}(15 \%)$ increase in burrowing depth by M. arenaria exposed to the crab Carcinus maenas resulted in a $38 \%$ increase in clam survival. Additionally, Byers (2002) found a significant reduction in of $N$. obscurata with a $\sim 3 \mathrm{~cm}$ increase in burrowing depth, though these were for clams at shallower depths than in my study or what I observed in the field. Given that M. magister has been observed digging as deep as $30 \mathrm{~cm}$ to collect bivalve prey, even deep burrowing $N$. obscurata should still be vulnerable to some predation, albeit to a lesser degree (Auster \& Crockett 1984).

Although Japanese clams did not burrow deeper in the presence of M. magister, they did burrow significantly deeper in Controls than clams from the USA or Canada. One possible explanation for the relatively consistent, deep burrowing of Japanese specimens is that they may have been subject to higher predator encounter rates in Japan compared to clams from the Northeast Pacific. Habitats where predator encounter rates are high and consistent are thought to promote the development of ever-present constitutive defenses (Tollrian \& Harvell 1998) and habitats with variable encounter rates promote plastic inducible defenses (Lively 1986, Harvell 1990), though this is not always the case (Bourdeau 2011). Either plastic or general constitutive defenses (e.g., depth refuge) may aid invasion into areas with generalist predators such as $M$. magister because both defense strategies should reduce susceptibility to predation (Blundon \& Kennedy 1982, Stevens et al. 1982, Zwarts \& Wanink 1989, Jensen \& Asplen 1998). Alternatively, 
it may be that $N$. obscurata are not commonly consumed by crabs in the sampled Japanese population, and thus do not burrow deeper after exposure to physical or chemical cues from crabs. However, if predation risk is low one would expect clams to burrow more shallowly, as growth and feeding rates are higher at shallower burrowing depths (Zaklan \& Ydenberg 1997, De Goeij \& Luttikhuizen 1998, Edelaar et al. 2003). While information on predation pressure of $N$. obscurata in Japan would aid in the interpretation of my observed responses, I was unable to locate any records of predation on N. obscurata by Japanese crab species. Whatever the cause, if the observed burrowing depth of Japanese clams is reflective of the first clams to be introduced to the Northeastern Pacific then they may have experienced reduced susceptibility to predation without expressing an inducible response.

The intensity and nature of an organisms inducible defenses can vary with predator identity (Kishida \& Nishimura 2005, Bourdeau 2009, Kishida et al. 2009, Freeman et al. 2009, Garner \& Litvaitis 2013, Naddafi \& Rudstam 2013, Castorani \& Hovel 2016). Non-native species may respond to novel predators if the response of a nonnative species is a generalized response to a broad class of predators (e.g., predatory crustaceans) that includes the novel predator or if the novel predator is evolutionarily similar to predators present in the home range of the non-natives species. In this study, clams responded to M. magister (Family: Cancridae) and C. maenas (Family: Portunidae) but not Cancer productus (Family: Cancridae), which suggests that $N$. obscurata is responding to cues that vary among species rather than solely to cues common to all Brachyuran (Infraorder) or Cancrid crabs. A similar trend was observed for introduced 
populations of the Atlantic oyster drill, Urosalpinx cinerea, along the Northeast Pacific coast when work by Grason \& Miner (2012) found $U$. cinerea reduced their feeding rates in the presence of $C$. productus, while Kimbro et al. (2009) did not observe a similar response to the closely related Romaleon antennarium (formerly Cancer antennarius). However, C. maenas is in the same Family (Portunidae) as a potential (though unconfirmed) crab predator of N. obscurata. The ishigani, Charybdis japonica, is a predator of bivalves and other benthic organisms and has been found near Hiroura Bay, though generally in lower tidal zones than N. obscurata is found (Jiang et al. 1997, Urabe et al. 2013). It is possible that $N$. obscurata from Oregon responded to C. maenas primarily because of its similarity to $C$. japonica, although this idea is somewhat contradicted by the fact the clams also responded to the more distantly related $C$. magister. In addition, Carcinus sp. has invaded parts of Japan and could have interacted with ancestors of the N. obscurata that arrived in Oregon (Geller et al. 1997).

It is also possible that differences in N. obscurata's response across predators may have less to do with their phylogenetic similarity to the predators in the clam's native range, but rather the result of predator foraging behavior. C. productus has powerful claws and has been observed to select shallower-burrowing but thicker-shelled clams even when thinner-shelled but deeper-burrowing clams were available (Yamada \& Boulding 1998, Dudas et al. 2005). In contrast, M. magister and C. maenas have weaker claws and will preferentially choose thinner-shelled clams, even when this requires more active foraging (Hunt \& Yamada 2003, Dudas et al. 2005, Curtis et al. 2012). The more 
active foraging of M. magister and C. maenas may result in greater physical disturbance of siphons of $N$. obscurata, causing the clams to burrow deeper in response.

Specimens of $N$. obscurata collected in the USA and Canada increased their burrowing depth when M. magister was free to roam throughout the tank. In contrast, clams exposed solely to kairomones from caged M. magister or alarm cues from crushed conspecifics appeared to have no measured effect. Alarm cues are considered a general risk cue because they would be present regardless of the predator species involved and therefore response to alarm cues should be more likely to facilitate invasion than cues from specific predator species (Payne et al. 2004, Sih et al. 2010). Previous studies have observed that alarm cues alone can trigger inducible defenses for non-native prey, although they are generally weaker responses than those triggered by predator kairomones (Grason \& Miner 2012, Garner \& Litvaitis 2013, Castorani \& Hovel 2016). My data presented here suggest that alarm cues alone did not contribute to the inducible burrowing behavior I observed for N. obscurata.

Another factor that could have influenced the burrowing depth of clams from Japan is differences in sediment characteristics. Byers (2002) found that the burrowing depth of $N$. obscurata increased in looser, sandier sediment compared with more densely packed, muddier sediment. The sediment used in all of my experiments was collected from the same location within Sand Lake and was handled in the same way to reduce variation in sediment type or compaction. In contrast, conditions between $N$. obscurata collection sites were not identical. Specimens were collected from small areas $\left(<100 \mathrm{~m}^{2}\right)$ at the same tidal height at each embayment (Sand Lake, Departure Bay, Hiroura Bay) to 
minimize the impact of habitat variation on the behavior of our specimens. Sediment type was similar but not identical across embayments, with sediment being somewhat finer and denser at Hiroura Bay compared with Sand Lake (Appendix A Figure A.2-3). However, the burrowing depths of clams during collection were similar between embayments.

Some species of soft-sediment bivalves display a strong correlation between body size and burrowing depth, which could influence the expression of a behavioral inducible defense like those displayed by N. obscurata (Zaklan \& Ydenberg 1997). However, this size-depth pattern does not hold for all species. For example, Mercenaria mercenaria did not display this size-depth relationship (Roberts et al. 1989). There did not appear to be a clear relationship between body size and burrowing depth for $N$. obscurata, described as having a "shotgun distribution" (Gillespie et al. 1999). Data from the control treatments in my experiments and from the Sand Lake, Oregon field site found no significant relationship between body size and burrowing depth for the size range used in the four experiments.

Other factors aside from sediment characteristics and predator presence have been observed to influence the burrowing depth of soft-sediment bivalves. Environmental stresses will influence burrowing depth, with hypoxia driving bivalves closer to the surface while extreme temperatures and risk of being washed away will drive them deeper (Stanley 1970 cited by Edelaar et al. 2003, Ratcliffe et al. 1981 cited by Edelaar et al. 2003, Sutherland 1982, Tallqvist 2001). Burrowing depths will also vary with the tide; with clams generally burrowing shallowest at high tide and deepest at low tide (Roberts 
et al. 1989). For species like $N$. obscurata that are both suspension and deposit feeders, the feeding method employed should also influence burrowing depth (Zwarts \& Wanink 1989). However, given that every effort was taken to ensure conditions (e.g., sediment type, food availability, temperature, salinity) were identical across specimen storage tanks and experimental tanks, these factors likely did not cause any of the observed differences in burrowing depth of $N$. obscurata in my experiments.

Location within the laboratory setting did not statistically significantly influence burrowing depth, though there was a weak but consistent pattern based on location. Specimens of $N$. obscurata from Oregon burrowed an average of $2.2 \mathrm{~cm}$ and $1.1 \mathrm{~cm}$ deeper in Experiments $1 \& 3$ respectively than clams in Experiment 2, which were housed on water tables. The follow-up experiment similarly found clams housed on shelves burrowed an average of $2 \mathrm{~cm}$ deeper than those housed on water tables. This potential location-based variation in burrowing depth across experiments may be due to lighting differences. An inverse relationship between day length and burrowing depth was found for the clam Macoma balthica (Reading and McGrorty 1978). Though all the experiments had the same day-night durations, the lighting is brighter at the water table than at the shelves. Each experiment took place in only one location (shelf or table) so lighting or other location-specific factors should not have influenced findings of each given experiment. Moreover, patterns in the response of $N$. obscurata to risk cues were consistent across all experiments. Therefore, I remain confident that the response of clams to risk cues strongly influenced burrowing depth within each experiment. 
Although clams used in these experiments had between 72 and 96 hrs (acclimatization period and experiment duration together) to reach their equilibrium depth it is possible that the clams did not have sufficient time to burrow. However, burrowing depths achieved under these experimental durations are within ranges I observed in the field and those observed by other researchers (Gillespie et al. 1999, Byers 2002).

For species brought to a new area with suitable abiotic conditions, overcoming biotic resistance from local predators and competitors will facilitate establishment and spread. While I did not find evidence that first generation invaders expressed an inducible defense, as mimicked by exposing individuals just arrived from the native range to the recipient predators in tanks, this mechanism may still be important for the initial establishment of some species and for delayed success in other species once they learn the cues of local predators. Many non-native species experience a lag time between introduction and population growth resulting from small population sizes (i.e., Allee effect), and effectively responding to local predators may increase non-native survival and decrease the duration of this lag. Expanding the scope of research to include additional non-native species and offspring of previously naïve prey would allow for a clearer picture of the role of inducible defenses in the invasion process. 


\section{Chapter 2: Assessing population increase as a possible outcome to management of invasive species}

\section{Introduction}

Removal of individuals from a population can reduce intraspecific pressure (e.g., cannibalism, competition) enough that it results in an increase in the population's growth rate and size relative to its pre-removal rate and size, producing a growth response known as overcompensation (De Roos et al. 2007, Abrams 2009). Not only a predicted outcome of numerous population models (Ricker 1954, De Roos et al. 2007, Abrams 2009), this phenomenon has been observed in some plants (Buckley et al. 2001, Pardini et al. 2009), insects (Nicholson 1954, Postma et al. 1994, Moe et al. 2002) and fish (Smith et al. 1996, Meyer et al. 2006, Weidel et al. 2007, Ohlberger et al. 2011, Thuesen et al. 2011). Thwarting management goals, efforts to reduce or eradicate invasive populations have, in some cases, paradoxically led to population increases as the result of overcompensation (Zipkin et al. 2009). For example, a seven year electrofishing effort to remove an invasive population of small mouth bass (Micropterus dolomieu) from Little Moose Lake, New York, resulted in a massive increase in juvenile abundance, causing a large increase in overall bass abundance (Weidel et al. 2007, Zipkin et al. 2008). Similar efforts to remove other invasive freshwater fish populations also coincided with increased juvenile abundance, causing an overall increase in population size (Smith et al. 1996, Meyer et al. 2006). Thus, a population's response to management strategies will depend on its potential for overcompensation, along with demographic parameters. While 
populations that overcompensate can successfully be eradicated or reduced, they require a more intensive, often more expensive, removal regime (Zipkin et al. 2009).

To evaluate and advance efficient management options for invasions, it would be a tremendous benefit to know if a population is likely to overcompensate in response to removal efforts. Overcompensation is considered more likely to occur in populations with high fecundity and short maturation periods (Zipkin et al. 2009). Because overcompensation only occurs if a density-dependent process has been released from density-related suppression (De Roos et al. 2007), it follows that overcompensation would be more likely to occur if a population demonstrated stronger intraspecific interactions in general. It should be possible to use recorded life history data and field experiments that test for strong density-dependence in intraspecific interactions to determine a population's potential for overcompensation in response to management.

In this study, we apply an experimental approach to evaluate density-dependent processes and the likelihood of overcompensation for the European green crab, Carcinus maenas (Linnaeus, 1758; hereafter Carcinus). This crab species is a widespread marine invader, with established populations on both coasts of North America, the southern coast of Australia, Argentina, South Africa and possibly Japan (Carlton \& Cohen 2003). Invasions by Carcinus have resulted in ecological and economic consequences, such as a decline in soft-shell clam fisheries in New England, and are a major concern of commercial, environmental, and government organizations (Glude 1955, Jamieson et al. 1998, Yamada 2001). As a result, Carcinus has been a target for removal and control efforts on the east and west coasts of North America (DFO 2011). The early age of 
maturation and high per-capita fecundity of Carcinus are similar to those of invasive freshwater species that appear to have overcompensated in response to removal (Table 2.1). To our knowledge, the potential for overcompensation in removal efforts has not been evaluated for Carcinus or any other invasive marine species.

Table 2.1 Maturation and fecundity data for Carcinus maenas and for fish species that showed signs of overcompensation in response to removal efforts. Carcinus maturation time and fecundity is comparable to the fish species, indicating it has the potential to overcompensate. The numbers in parentheses indicate the appropriate reference

\begin{tabular}{llll}
\hline \multirow{2}{*}{ Species } & $\begin{array}{l}\text { Female } \\
\text { Maturation }\end{array}$ & $\begin{array}{l}\text { Per Capita } \\
\text { Fecundity }\end{array}$ & $\begin{array}{l}\text { Potential } \\
\text { Overcompensation }\end{array}$ \\
\hline Carcinus maenas & $\leq 2$ years $(1)$ & $180,000(2)$ & NA \\
Micropterus dolomieu & $4-7$ years $(3)$ & $\leq 2000(4)$ & Weidel et al. 2007 (5) \\
Oreochromis mossambicus & $\sim 1-2$ years $(6)$ & $50-1,780(7)$ & Thuesen et al. 2011(8) \\
Salvelinus fontinalis & $1-4$ years $(9)$ & $18-17,000(9)$ & Meyer et al. 2006 (10) \\
Stizostedion lucioperca & $\geq 2$ years $(11)$ & $13.1 .1 * 10^{5}-2 * 10^{6}(12)$ & Smith et al. 1996 (13) \\
\hline
\end{tabular}

Footnote: Reference numbers from Table 2.1: 1. Broekhuysen 1936, 2. Yamada 2001, 3. Dunlop et al. 2005, 4. Smith 1979, 5. Weidel et al. 2007, 6. Caskey et al. 2007, 7. Trewavas 1983, 8. Thuesen et al. 2011, 9. Carlander 1969, 10. Meyer et al. 2006, 11. Lappalainen et al. 2003, 12. Kosior and Wandzel 2001, 13. Smith et al. 1996

Three potential causes of overcompensation in response to harvest are increases in adult reproduction rates, juvenile survival rates, and juvenile maturation rates (Govindarajulu et al. 2005, De Roos et al. 2007). An increase in adult reproduction can result if harvest efforts reduce adult competition or otherwise increase resource availability. Under most circumstances, it would be essential to examine how harvest will impact the reproductive potential of adults in the targeted population. However, this is not necessarily the case for those marine species with pelagic larval development; a wide variety of species which includes Carcinus. Because the pelagic larvae of Carcinus can recruit from other regional populations and larval recruitment is highly variable across years, changes in adult reproductive output do not necessarily affect the size or recruitment potential of the local population (Yamada 2001, Yamada \& Gillespie 2008). 
For this reason, and because removal efforts of crabs typically focus on adults, it is the response of juvenile Carcinus to harvest of adults that determines if overcompensation will occur. This is also likely true for other species with pelagic larvae, provided removal efforts target adults.

Overcompensation can also result from increases in juvenile survival, triggered by increased mortality of their predators. Given that harvest efforts to manage invasive species focus on the target species, reductions in juvenile predation pressure as a response to removal efforts will only occur in populations that exhibit cannibalism. Cannibalism was the main driver of overcompensation in laboratory cultures of the flour beetle Tribolium (Dennis et al. 1997) and is a potential driver of overcompensation in bullfrog populations (Govindarajulu et al. 2005). Given that cannibalism has been observed among juvenile Carcinus and is common for brachyuran crabs, the infra-order to which Carcinus belongs, adult impacts on juvenile mortality may set the stage for overcompensation (Hines \& Ruiz 1995, Moksnes et al. 1997, Moksnes 2004).

The third potential cause of overcompensation, an increase in juvenile maturation rates, occurs when harvest results in increased food intake. Increased feeding rates occur when juvenile or adult harvest reduces competition for shared resources (De Roos et al. 2007, Abrams 2009). Juvenile food intake may also increase if harvest occurs in populations with high rates of cannibalism. Many organisms, including crabs, will reduce their foraging in the presence of a predator, resulting in reduced growth (Yamada et al. 1998, Grabowski \& Kimbro 2005, Preisser et al. 2005). If juveniles perceive either adults or larger juveniles as predators, the removal of conspecifics may cause the remaining 
juveniles to increase time spent foraging. Given that adults are far easier to detect and capture, they are the primary targets of most removal efforts. If adults are harvested, adult impacts on juvenile growth could increase the likelihood of overcompensation.

Overcompensation is not a subtle phenomenon. At Little Moose Lake the average spring catch per unit effort (CPUE) of Micropterus dolomieu, more than doubled after removal, with juvenile CPUE tripling and adult CPUE reduced to $1 / 5^{\text {th }}$ of its pre-removal levels (Zipkin et al. 2008). One year after a pathogen outbreak decimated adult populations of Perca fluviatili in Windermere, UK, the juvenile percentage of total population biomass shifted from $\sim 20 \%$ to $\sim 80 \%$, both because there were fewer adults and because of a strong increase in juveniles (Ohlberger et al. 2011). Exposure of foodlimited populations of Chironomus riparius to cadmium $(\mathrm{Cd})$, despite its toxicity, doubled the population growth rate at $2.0 \mu \mathrm{g} \mathrm{Cd} / \mathrm{L}$ and tripled the population growth rate at exposure to $5.6 \mu \mathrm{g} \mathrm{Cd} / \mathrm{L}$ (Postma et al. 1994). If overcompensation were to occur in our study population of Carcinus, we would expect to see obvious, dramatic changes in population structure. Smaller changes may still impact population growth rates, but would not be symptomatic of overcompensation.

The goal of this research was to develop and evaluate straight-forward lab experiments that can help determine the potential for overcompensation. These experiments were designed to test whether the impacts of adult crabs on either juvenile survivorship or juvenile growth in Bodega Harbor are indicative of overcompensation. Further, we evaluated whether our experiments were effective in predicting overcompensation using a two-part process. First, we made predictions based on the 
outcomes of our experiments about whether adult removal would increase juvenile growth or survival. Second, we analyzed data from pre- and post-removal surveys in Bodega Harbor and two reference bays, looking for evidence of overcompensation occurring in Bodega Harbor once removal had started. The results of the analysis were examined in the context of our predictions to determine if our experiments accurately predicted if overcompensation would occur.

\section{Methods}

Study sites

The majority of our work was undertaken at Bodega Harbor, California, USA $\left(38^{\circ} 19^{\prime} 25.00^{\prime \prime} \mathrm{N} 123^{\circ} 02^{\prime} 52.00^{\prime \prime} \mathrm{W}\right)$. From mid-July 2006 through August 2009, Bodega Harbor was the site of an intensive effort to reduce the population of Carcinus in their introduced range. A self-sustaining population of Carcinus was discovered in Bodega Harbor in 1993, since which time it has altered community composition and significantly reduced the abundance of some native infauna and epifauna (Grosholz et al. 2000). The other locations related to this study are Tomales Bay $\left(38^{\circ} 10^{\prime} 16.60^{\prime \prime} \mathrm{N} 122^{\circ} 54^{\prime} 45.98^{\prime \prime} \mathrm{W}\right)$ and Elkhorn Slough (36 $49^{\prime} 00.61^{\prime \prime}$ N 121 $\left.44^{\prime} 49.21^{\prime \prime} \mathrm{W}\right)$. While Carcinus are present at these locations, no effort has been made to remove or reduce these populations.

\section{Collection and care of crabs}

Two species of crabs were collected for use in this study: Carcinus and Hemigrapsus oregonensis (Dana 1851; hereafter Hemigrapsus). Hemigrapsus is a species 
of shore crab native to the Pacific Coast of North America. Adults are similar in size to juvenile Carcinus and are commonly preyed upon by Carcinus (Grosholz et al. 2000, de Rivera et al. 2011). All specimens were collected from Bodega Harbor and were housed with similarly sized conspecifics in holding tanks at the University of California Davis, Bodega Marine Laboratory. Each tank was supplied with a continuous flow of filtered seawater. Crabs (Carcinus and Hemigrapsus) were fed frozen anchovies in excess every other day while in captivity. Uneaten fish was removed after a minimum of $2 \mathrm{hrs}$ or, if feeding was observed, when the crabs stopped feeding. All activities undertaken in this study met permit requirements for collection and followed guidelines for experimental use of and humane euthanasia and disposal of animals.

For experiments with adults, unless otherwise stated, we used male Carcinus with a carapace width $(\mathrm{CW})$ between $55-65 \mathrm{~mm}$. This size range was the most common for adult males captured in Bodega Harbor and thus reflects the size of adults that juvenile green crabs were most likely to encounter in the field. In addition, based on field observations of behavioral interactions, we expected adult males to be more likely than females to cannibalize or otherwise impact juveniles. Only males were used to reduce variability across replicates and treatments if any sexual bias existed.

\section{Experiment 1: Adult consumption of juvenile conspecifics}

Two procedures were conducted in June-July 2010 to examine if adult Carcinus have a significant impact on juvenile survival in Bodega Harbor. First we experimentally determined if adult Carcinus would consume juvenile conspecifics in the absence or, 
separately, in the presence of alternate prey. Sets of six enclosures were placed $25 \mathrm{~m}$ apart on the intertidal mudflat at Gaffney Point in Bodega Harbor. These enclosures were $\sim 38 \mathrm{~L}$ plastic tubs $(\sim 0.6 \mathrm{~m} * 0.4 \mathrm{~m} * 0.2 \mathrm{~m})$ modified with screen-covered portholes to allow water to flow freely but prevent any organisms $>1 \mathrm{~mm}$ in diameter from entering or exiting the enclosure. The bottom of each enclosure was lined with approximately four inches of sediment. All sediment was collected from the mudflat and sifted through a 1 $\mathrm{mm}$ sieve prior to use.

To examine cannibalism by adults in the absence of alternate prey, ten juvenile Carcinus (15-25 mm CW, male or female), serving as potential prey, were added to each enclosure in sets of six enclosures blocked by time. For a given block, four randomly selected enclosures were assigned to our predator treatment, while the remaining two enclosures were assigned to our control treatment. One adult Carcinus was added to predator treatments, while no adult was added to control treatments. Adult crabs were fed then held without food for $48 \mathrm{hrs}$ prior to being placed in enclosures to standardize hunger levels. All organisms were left in their designated enclosures for $24 \mathrm{hrs,} \mathrm{after}$ which time the adults were removed and the final status of each prey crab (alive or eaten) was recorded $(n=8)$. The same basic procedure was used to examine cannibalism in the presence of alternate prey, only instead of ten juvenile Carcinus as potential prey, five juvenile Carcinus (15-25 mm CW, male or female) and five adult Hemigrapsus (15-20 $\mathrm{mm} \mathrm{CW}$, male or female) were added to each enclosure $(\mathrm{n}=12)$. Alternate prey were added to better mimic field conditions. 
Using R statistical software (R Development Core Team 2012), we created general linear models (GLMs) to compare the average number of prey consumed by an adult Carcinus for three scenarios: a) the average number of juvenile Carcinus versus Hemigrapsus consumed, b) the average number of prey crabs consumed given one versus two species of prey, and c) the average number of juvenile Carcinus consumed in the presence versus absence of alternate prey. An additional GLM was created to compare the average mortality of juvenile Carcinus in control versus predator treatments when only juvenile Carcinus were present. We originally included 'enclosure position' and 'time block' as predictor variables for each GLM, but we removed both due to nonsignificance in all models. The number of crabs consumed was the response variable for all models. Since crabs could only be classified as eaten or alive, the response variable for all of the models had a binomial distribution.

For GLMs with binomial data, the data can be a vector or, as in our study, a twocolumn matrix (Rodríguez 2007). For our two-column matrices, the first column was the number of prey crabs (juvenile Carcinus or Hemigrapsus) consumed per enclosure. The second column was the number of surviving prey crabs per enclosure. This process allows for an accurate assessment when the overall number of events is not consistent across all replicates. For example, the comparison of predation on juvenile Carcinus in the presence versus absence of alternate prey involves a difference in the number of juveniles that could have potentially been eaten ( 5 versus 10 respectively). The GLM with a two-column matrix corrects for these differences in number of potential prey. 


\section{Experiment 2: Juveniles survivorship across adult densities}

The second procedure examining the impact of adult Carcinus on juvenile survival was designed to determine if the short-term survivorship of juvenile Carcinus is related to adult density. Tethering can serve as a proxy for predation pressure rather than an absolute measure of it, and can help determine relative rates of risk among sites with similar habitat structure (Heck \& Thoman 1981, Wilson et al. 1987, Everett \& Ruiz 1993, Hines \& Ruiz 1995, de Rivera et al. 2005). Our study sites consisted of four locations in Bodega Harbor and four locations in Tomales Bay, California. These sites were used because they encompassed the main areas with Carcinus and provided a range from low to high Carcinus abundance (de Rivera et al. unpublished data). At each site, we deployed ten juvenile Carcinus (15-30 mm CW, male or female) tethered to bricks with $0.5 \mathrm{~m}$ of lightweight wire leader. The leader was then hooked to a harness of $20 \mathrm{lb}$ test fishing line. At each site, the tethered crabs were deployed $25 \mathrm{~m}$ apart in areas without or cleared of algae and submerged aquatic vegetation and along a transect placed parallel to the shore at -0.5 ' mean lower low water. The tethered crabs were retrieved after $24 \mathrm{hrs,}$ and the final status of each crab was recorded as alive, obviously eaten, or missing. Only missing tether specimens that had remaining evidence of predation by another crab (part of carapace remained glued to tether) were categorized as eaten, while other tethers lacking crabs were classified as missing since the ultimate fate of the crab (eaten or escaped) could not be determined. However, tethered crabs never escaped when they were held in lab in this or other tethering surveys. Other indications of aggressive interactions (limb loss) were not analyzed but did not appear to vary across locations. 
Upon tether retrieval, each crab was replaced with traps baited with anchovies, with trap type alternating between larger box traps (Fukui multi-species marine traps model FT-100) and smaller, modified minnow traps (increased one opening from $2.5 \mathrm{~cm}$ to $7.5 \mathrm{~cm}$ to increase ease of entry). This combination of trap types was deployed to allow capture of a wide range of crab sizes as larger Carcinus can be aggressive and result in trap avoidance by smaller individuals. Minnow traps possess smaller openings and mesh size than box traps, even with our modifications, excluding larger individuals while retaining smaller ones. The traps were recovered after $24 \mathrm{hrs}$ and their contents recorded. The number of adult Carcinus (> $45 \mathrm{~mm} \mathrm{CW}$, male or female) trapped acted as a proxy for local adult abundance. We selected $45 \mathrm{~mm}$ as the minimum $\mathrm{CW}$ for classifying crabs as adults because mature females, those with abdomens characteristic of the adult morphology, collected in Bodega Harbor were this size or larger. These survey procedures (deployment of tethered juveniles with subsequent trapping) occurred twice, separated in time by one month, at each of our eight sites $(n=16)$.

After testing for normality and homoscedasticity, we used linear regression to test the relationship between the abundance of adult Carcinus and number of tethered juveniles consumed. We used two classification schemes to analyze predation data of the tethered crabs with these regressions. In one we counted crabs that were verified to have been eaten (where some carapace remained attached to the tether) and missing crabs towards predation, while for the other we only counted as predation the crabs verified to have been eaten. 


\section{Experiment 3: Juvenile foraging in the presence of an adult}

This experiment, conducted in June-July 2010, was designed to determine if the presence of an adult conspecific affects the foraging rate of juvenile Carcinus.

Reductions in foraging rate may be indicative of negative responses to the presence of adult conspecifics which, if they lead to a slower maturation rate via decreased growth or delays in molting, would contribute to the overcompensatory potential of a population. Two of the $38 \mathrm{~L}$ enclosures used in Experiment 1 were placed in two separate flowthrough tanks ( 190 L) at the Bodega Marine Laboratory and filled to approximately 10 $\mathrm{cm}$ deep with sieved sediment collected from Bodega Harbor. Clams (Nutricola tantilla; Gould, 1853; hereafter Nutricola) to be used as food for the crabs were collected $24 \mathrm{hrs}$ prior to use and kept in separate holding tanks. Nutricola are small $(<6 \mathrm{~mm}$ width) softsediment bivalves native to western North America and are a common prey item for all sizes of Carcinus (Grosholz et al. 2000). Fifty Nutricola with shell length 2-3 mm were added to each enclosure. In addition to the clams, one of a matching pair of juvenile Carcinus (20-30 mm CW, male or female) was added to each enclosure. For this experiment, a matching pair refers to two juveniles of the same sex and size (CW to the nearest $\mathrm{mm}$ ) that had been fed then held without food for $48 \mathrm{hrs}$ to standardize hunger levels. The enclosures were then assigned to one of two treatments: adult presence or control. For the adult presence treatment, an adult Carcinus with banded claws was added to the enclosure $(\mathrm{n}=8)$. No additional crabs were added to our control treatment $(\mathrm{n}=8)$. Adult claws were banded using duct tape and zip ties to prevent adults from consuming clams or the juvenile crab. The juveniles were then left to forage for $24 \mathrm{hrs}$, after which 
time the number of clams consumed was recorded. After the data were log-transformed to meet assumptions of normality, we compared differences in the number of clams consumed in the presence versus absence of an adult conspecific by performing a Welch's t-test.

\section{Experiment 4: Juvenile growth in the presence of an adult}

This experiment, conducted in June-July 2011, was designed to determine if the presence of an adult conspecific affected the growth rate (mass and CW increases) of juvenile Carcinus. Twenty sediment-lined $19 \mathrm{~L}$ hydroponic pots were placed on water tables at the Bodega Marine Laboratory. Each pot contained one piece of PVC piping ( $7.5 \mathrm{~cm}$ long x $5 \mathrm{~cm}$ diameter) to serve as a refuge. Of our twenty pots, five were randomly assigned to each of four treatments: a) a single juvenile Carcinus, b) a juvenile housed with a second, larger juvenile ( $<10 \mathrm{~mm} \mathrm{CW}$ wider $), \mathrm{c})$ a juvenile exposed to the effluent (seawater mixed with excrement and any chemical signals) of a banded adult conspecific, and d) a juvenile housed with a banded adult. The focal juveniles ranged from $0.07-0.84 \mathrm{~g}$ in mass and 7-17 $\mathrm{mm} \mathrm{CW}$. The different sizes were equally represented across the treatments. Crab effluent was added to the seawater for the effluent treatments by having it first flow through a separate $4 \mathrm{~L}$ hydroponic pot housing a banded conspecific adult. All adults were banded to prevent cannibalism and in the case of the effluent treatment, to ensure consistency across treatments. Adults were replaced every 10 days because it is unlikely juveniles would be continuously exposed to the presence of any one adult in the field, and co-habiting individuals might shift interactive behaviors 
over time. All crabs, including adults, were fed anchovy flesh daily for the duration of the experiment, with excess removed after $3 \mathrm{hrs}$. Anchovy flesh was used in lieu of Nutricola because the banded adults could feed on the anchovy flesh despite their banded claws by pushing the flesh to their mandibles, which was important over the long duration of the experiment. The juveniles were allowed to grow for $30(n=3$ replicates $)$ or $21(n=2)$ days. The replicates and treatments ran concurrently with two replicates starting one week later due to low numbers of Carcinus juveniles in Bodega Harbor. Mass and CW were recorded for each juvenile prior to and at the completion of the experiment. After testing for normality and homoscedasticity it was determined that it was appropriate to perform Analysis of Variance (ANOVA) tests to examine differences in percent mass and $\mathrm{CW}$ increase across treatments. A Student's t-test was performed to determine if trial duration influenced juvenile growth.

During the course of this experiment, we conducted four $2 \mathrm{hr}$ periods of behavioral observations of all enclosures using instantaneous scan sampling to examine crab behavior across treatment. The numbers of observations were identical across all replicates regardless of time in captivity. Status of each juvenile crab was noted every 5 minutes and recorded. Status options consisted of active (feeding, moving, and interacting with other crabs) or inactive (burrowed in sediment, hiding in refuge, and immobile on surface of sediment). Differences in activity across treatments were compared using a Fisher's exact test. 


\section{Assessing overcompensation}

To evaluate the applicability of the experiments to assessing the likelihood of overcompensation in Bodega Harbor, we predicted the likelihood of overcompensation from removal based on our experimental results. The accuracy of our prediction was then evaluated using data collected from annual Carcinus surveys. Our survey data consisted of annual Carcinus catch from survey events in Bodega Harbor, Tomales Bay, and Elkhorn Slough that occurred in 2004-2009. During each year of the surveys, we simultaneously deployed a row of traps at three sites located throughout each bay $(>800$ m apart). Surveys in 2006-2009 were performed using standardized protocols, with 10 traps deployed at each site and each survey being three days in duration. Surveys in 20042005 occurred prior to the development of these protocols, and as a result trap numbers vary from 5 to 10 at each site and surveys were only one day in duration. Traps were the same as those used in Experiment 2 (alternating box and minnow traps) across all years. Each day of the survey the number, size, and sex of Carcinus in each trap were recorded.

Because the overall abundance of Carcinus varied greatly across bays, we chose to examine the number of juveniles captured relative to adult green crabs captured during annual surveys rather than juvenile counts. Crabs caught with $\mathrm{CW}<45 \mathrm{~mm}$ were classified as juveniles while larger crabs were classified as adults, giving crab size class a binary outcome. If overcompensation occurred, the number of juveniles caught relative to adults caught should be significantly higher post removal in Bodega Harbor compared to the other bays. 
We tested the annual survey data for evidence of overcompensation using a modified BACI (Before/After/Control/Impact) design. Removal efforts began after our 2006 surveys, so data from 2004-2006 acted as our Before removal period. Removal efforts continued through 2009, so data from 2007-2009 acted as our After removal period. Bodega Harbor was the only bay where removal efforts occurred and acted as our Impact bay (hereafter referred to as Removal). Tomales Bay and Elkhorn Slough, where no removal efforts occurred, acted as our Control bays (hereafter referred to as Reference). While there are substantial hydrologic and geomorphic differences between Bodega Harbor and our reference bays, Tomales Bay and Elkhorn Slough provide the best comparisons to Bodega Harbor for two reasons. First, both have had established populations of C. maenas for a prolonged period of time (pre-2004 to present). Second, both are near Bodega Harbor, and Tomales Bay is hydrologically connected with it. The Elkhorn Slough habitat and Carcinus population are more similar to Bodega in terms of size and gradient of marine influence than other area bays.

A generalized linear mixed effect model (GLMM) was used to test if relative juvenile abundance at our Removal bay (Bodega Harbor) changed significantly after removal compared to our Reference bays (Tomales Bay and Elkhorn Slough). The GLMM is similar in nature to the GLMs constructed for our predation trials (Experiment 1), with a binomial response variable made of a two-column matrix. For this model, the first column consisted of the number of juvenile Carcinus $(\mathrm{CW}<45 \mathrm{~mm})$ caught at a site in a given bay during a given annual sampling event, while the second column was the number of adult Carcinus caught. Unlike GLMs, the GLMM allows the inclusion of 
random effects in addition to the fixed-effects of our linear predictor. Bay Treatment (Removal or Reference), Period (Before or After), and Bay Treatment*Period interaction were fixed-effect parameters within the model. Bay ID (Bodega Harbor, Tomales Bay and Elkhorn Slough), Year (2004-2009), Site (within each bay), and the Bay ID* Year interaction were included in the model as random effects. To compensate for variation in trapping effort (number of traps, duration of survey) prior to 2006, trapping effort was added to the model as a weight function. The weight function was created by scaling the counts from each year/site combination to the maximum trapping effort. For example, crab counts for a Bodega Harbor site in 2006 which consisted of 30 trap days (10 traps over 3 days) would remain unchanged. In contrast, crab counts for some Bodega sites in 2004 consisted of 6 trap days ( 6 traps over 1 day) so they were multiplied by 5 and rounded to the nearest whole number. If overcompensation occurred at our Removal bay as a result of our removal efforts, the Bay Treatment*Period interaction should have a significant relationship with changes in juvenile abundance relative to adult abundance (our predictor).

We determined the sensitivity of our GLMM for detecting impacts of removal by performing a simulation-based analysis of the relationship between statistical power of our original GLMM and effect size (increase in juvenile percentage of Carcinus in Bodega Harbor post-removal vs. pre-removal relative to reference bays). Simulated datasets were constructed consisting of two parameters: catch total (total number of crabs caught) and juvenile percentage (percentage of total catch consisting of juvenile crabs). Parameter estimates were constructed by fitting observed values for each bay-year 
combination to a given distribution and then randomly pulling values from those distributions. Our observed data for total catch, being over-dispersed count data, were fit to a negative binomial distribution, while data for percent juvenile were fit to a beta distribution. To evaluate the impact that increasing effect size would have on the analysis, the expected mean juvenile percentage was systematically increased by a fixed amount (0-80\%, at intervals of 5\%) for each year for Bodega Harbor. For example, if the fixed juvenile percentage increase was $20 \%$ and the randomly selected value for the distribution was $40 \%$, then the juvenile percentage in Bodega Harbor for our simulated dataset was $60 \%$. The estimated variance of spread of the data remained the same, based on each year. For each fixed increase in juvenile percentage we generated 1,000 data sets (16,000 in total). We then re-ran our GLMM with the simulated datasets and the percent of runs resulting in significant results were calculated as our measure of power for two scenarios: $\alpha=0.05$ and $\alpha=0.10$. It should be noted that the data are highly variable and as many as $5 \%$ of the runs could not converge on a good solution, most likely due to random simulations that included a high proportion of zero totals.

\section{Results}

\section{Experiment 1: Adult consumption of juvenile conspecifics}

Adult Carcinus rarely cannibalized juveniles. Adults consumed juveniles in 3 of 8 replicates when only Carcinus were present, and in 2 of 12 when alternate prey was present. Adults housed only with conspecific juveniles consumed few juveniles (mean \pm $1 \mathrm{SE}: 0.5 \pm 0.27)$. In fact, when only Carcinus was present, cannibalism rates were so 
low that there was no significant difference in juvenile mortality between predator and control treatments $(z=0.003, \mathrm{df}=11, p>0.99)$. Presence of heterospecific prey did not significantly affect the number of juvenile conspecifics consumed by adult Carcinus $(0.25 \pm 0.18, z=0.00, \mathrm{df}=19, p>0.99)$. When alternate prey was present, adult Carcinus consumed significantly more Hemigrapsus $(1.92 \pm 0.29)$ than conspecific juveniles $(z=3.8, \mathrm{df}=23.00, p<0.001)$. Ignoring prey species identity, adults consumed approximately four times as many prey crabs when alternate prey were present than when only Carcinus were present $(z=2.97, \mathrm{df}=19, p=0.003)$, suggesting adults in Carcinus only treatments were likely not sated.

\section{Experiment 2: Juveniles survivorship across adult densities}

Contrary to what would be expected with overcompensation, there was a nonsignificant, negative relationship between mortality and density, with fewer tethered Carcinus eaten when and where Carcinus density was higher. This was the case when verifiably eaten or missing tethered crabs were included (Figure 2.1, juveniles consumed $=3.28-0.07 *$ (\# of adults trapped $), r^{2}=0.09, \mathrm{df}=14, p=0.27$, power $\left.=0.36\right)$ or when only tethers verified as eaten were included (juveniles consumed $=2.3-0.03 *$ (\# of adults trapped), $r^{2}=0.04, \mathrm{df}=14, p=0.46$, power $\left.=0.49\right)$. Carcinus ranging in size from 20 $\mathrm{mm}-76 \mathrm{~mm} \mathrm{CW}$ were collected during post-tether trapping efforts, suggesting habitat overlap between adults and juveniles at our study sites. Although no statistical analysis was performed, there appeared to be an extremely weak, negative relationship between juvenile Carcinus density and mortality of tethered crabs. 


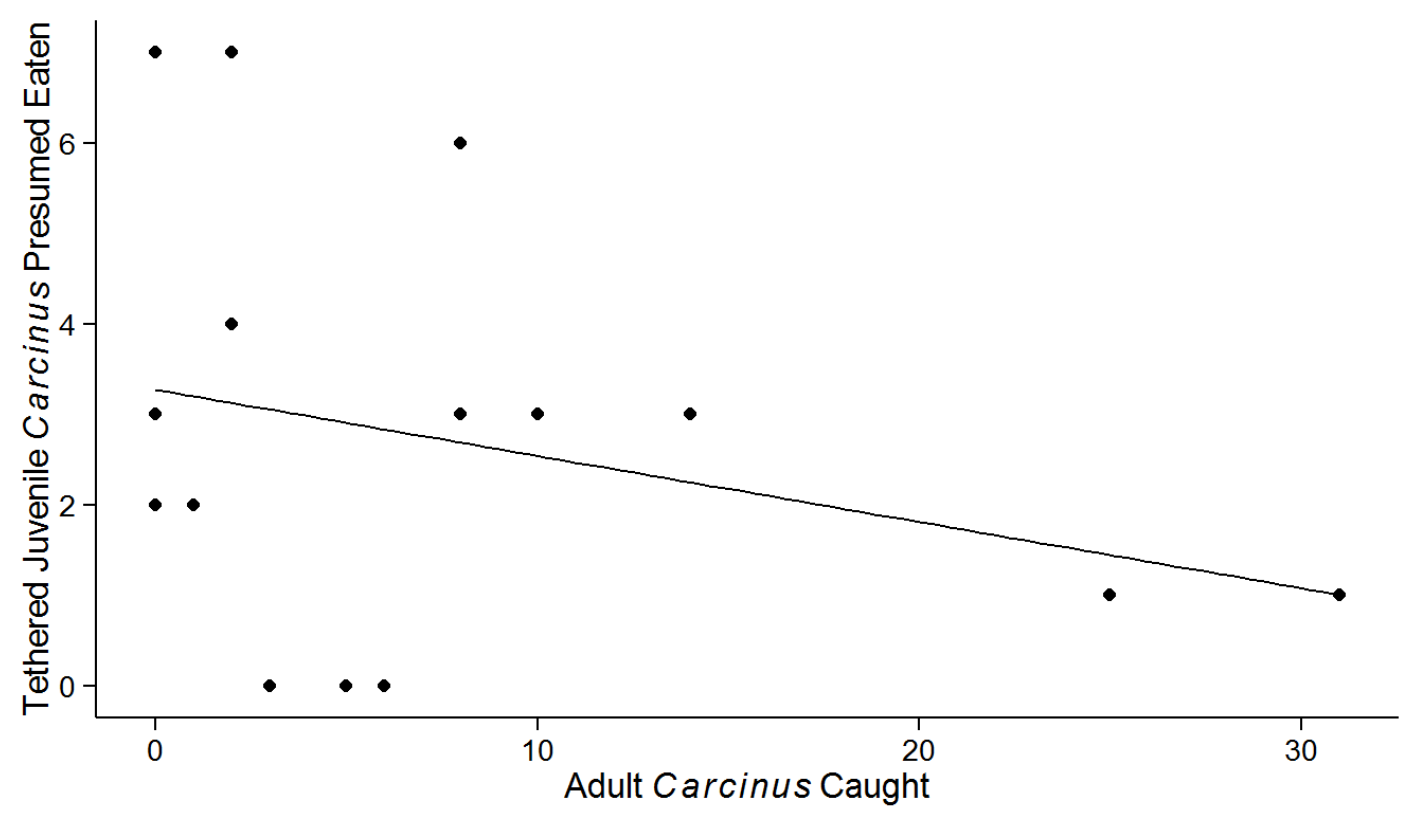

Figure 2.1 Number of tethered juvenile (<30 mm width) Carcinus that were presumed eaten (confirmed eaten or missing) across adult Carcinus densities. No significant relationship was found between adult density and consumption of juvenile Carcinus (juveniles consumed $=3.28-0.07 *$ (\# of adults trapped), $r^{2}=0.09, \mathrm{df}=14, p=0.27$, power $=0.36$ ).

\section{Experiment 3: Juvenile foraging in the presence of an adult}

When in the presence of adult Carcinus, juvenile conspecifics in enclosures consumed few Nutricola (mean \pm 1 SE: $3.4 \pm 1.08$ ). When adults were absent, consumption of Nutricola by juveniles was significantly higher and tenfold greater ( 34.2 $\pm 7.65, t=-4.45, \mathrm{df}=4, p=0.002)$ than when adults were present.

\section{Experiment 4: Juvenile growth in the presence of an adult}

The juvenile growth over 21 to 30 days differed across treatments. There was a marginally significant difference in percent mass increase $(F=2.85, \mathrm{df}=3, p=0.07$, power $=0.68)$ and a significant difference in $\mathrm{CW}$ increase $(F=3.99, \mathrm{df}=3, p=0.03$, power $=0.83$ ) across treatments (Figure 2.2). However, the trend of the results was in the 
opposite direction than would be expected if there were adult suppression of juvenile growth. Juveniles in the treatment with effluent had the largest average mass $(132.0 \% \pm$ $7.9 \%)$ and $\mathrm{CW}(36 \% \pm 0.06 \%)$ increase while those in the two-juvenile treatment had the smallest average increase for mass $(51 \% \pm 67.6 \%)$ and $\mathrm{CW}(11.6 \% \pm 16.0 \%)$. There was no significant difference in juvenile growth between in trials lasting 30 days versus 21 days $(t=-1.16, \mathrm{df}=15.16, p=0.27)$.

The lower average growth of specimens in the two-juvenile treatment was driven by the fact that three of the specimens, including two from the 30 day replicates, did not molt while in captivity. Only one other specimen, one from the single-juvenile treatment, failed to molt. The size of individuals that failed to molt ranged from 8-15 mm CW; other individuals within this size range successfully molted. All other specimens molted once.

Behavioral observations revealed the crabs in all treatments spent the majority of their time inactive, typically buried or in a refuge. Time observed active varied significantly across treatment (Fisher's test $p<0.001$ ). Juveniles in the two-juvenile and the juvenile-with-adult treatments were active during more observations (15/750 and 20/750 observations respectively) than individual juveniles or those exposed to effluent (2/750 for both). Antagonistic interactions were only observed in the two-juvenile treatment; however, these interactions were observed outside of the instantaneous scan sampling. Adults did not visibly respond to or behave aggressively towards juveniles even when in physical contact. 


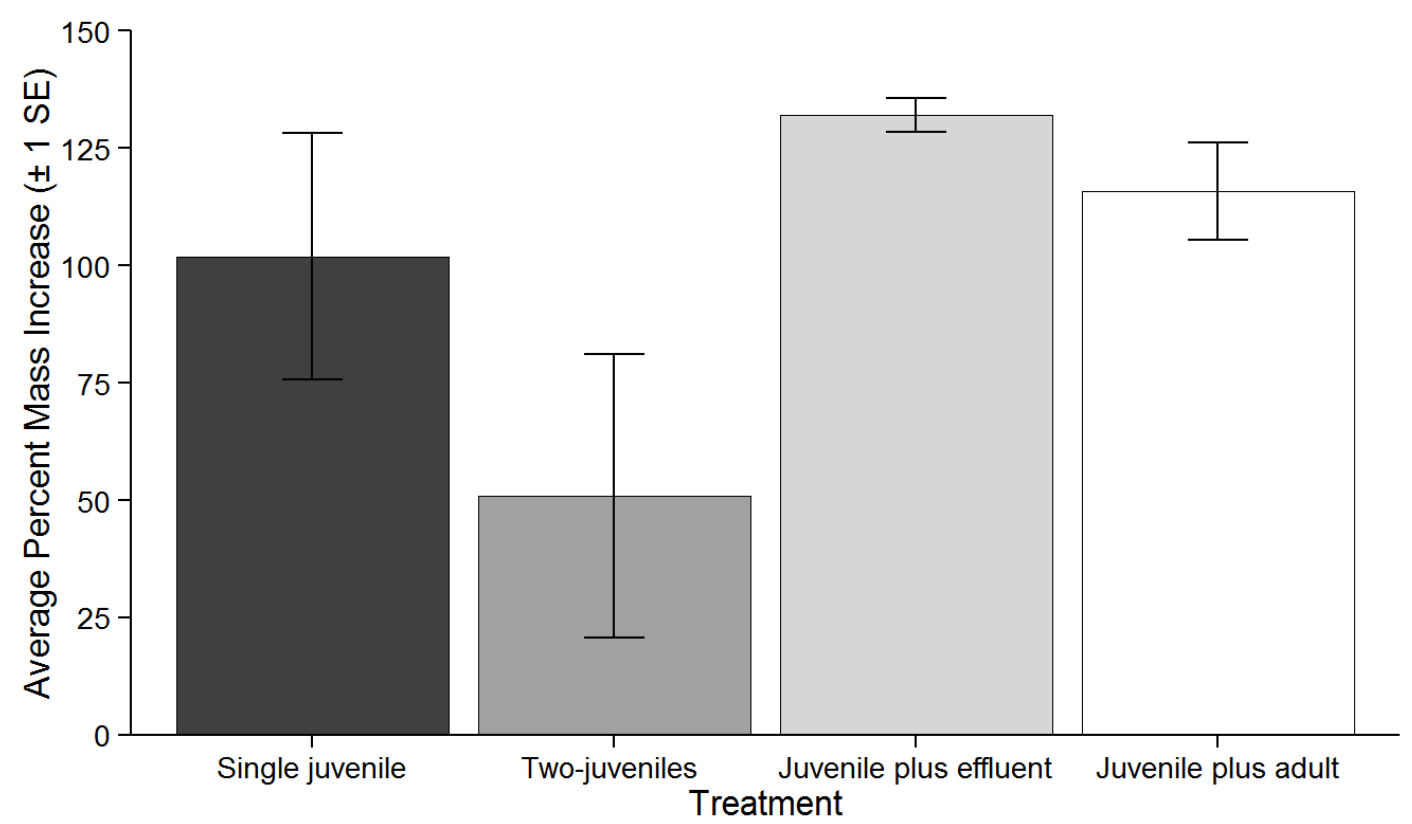

Figure 2.2 Average (mean $\pm 1 \mathrm{SE}$ ) percent mass increases of juvenile Carcinus for each treatment. There was a marginally significant difference in percent mass increase between the juvenile plus effluent treatment (mean \pm SE: $132.0 \% \pm 7.9 \%)$ compared to the two-juveniles treatment $(51 \% \pm 67.6 \%, F=2.85$, $\mathrm{df}=3, p=0.07$, power $=0.68$ ). These patterns were similar for CW increases across treatments, with a significant difference between the adult plus effluent $(36 \% \pm 0.06 \%)$ and the two-juvenile treatments ( $11.6 \% \pm 16.0 \%, F=3.99, \mathrm{df}=3, p=0.03$, power $=0.83$ ).

\section{Assessing overcompensation}

Our analysis of yearly survey data detected no evidence of overcompensation occurring in Bodega Harbor (Figure 2.3). The results of our GLMM showed no significant interaction between Bay Treatment (Removal and Reference) and Period (Before and After removal occurred) ( $\mathrm{z}$-value $=-0.23, \mathrm{p}=0.82)$, suggesting that the Carcinus population in Bodega Harbor did not overcompensate in response to the removal of adult crabs. Looking at the individual effects of our predictors, there was no significant difference in the abundance of juveniles relative to adults across the Bay Treatment (Removal or Reference $(\mathrm{z}=-1.18, \mathrm{p}=0.24)$, but there was a difference across Periods (Before or After removal) $(\mathrm{z}=2.78, \mathrm{p}=0.005)$. Crabs trapped during our survey 
events ranged from juveniles $<10 \mathrm{~mm} \mathrm{CW}$ to adults $92 \mathrm{~mm} \mathrm{CW}$. As such, we are

confident that our survey methods captured the full size range of crabs present at our sampling locations. Overall abundances of Carcinus in Bodega Harbor (daily per site CPUE of all age classes) failed to increase post-removal (pre-removal mean \pm SE: $2.6 \pm$ 1.01 crabs versus post-removal $1.1 \pm 0.2$ crabs).

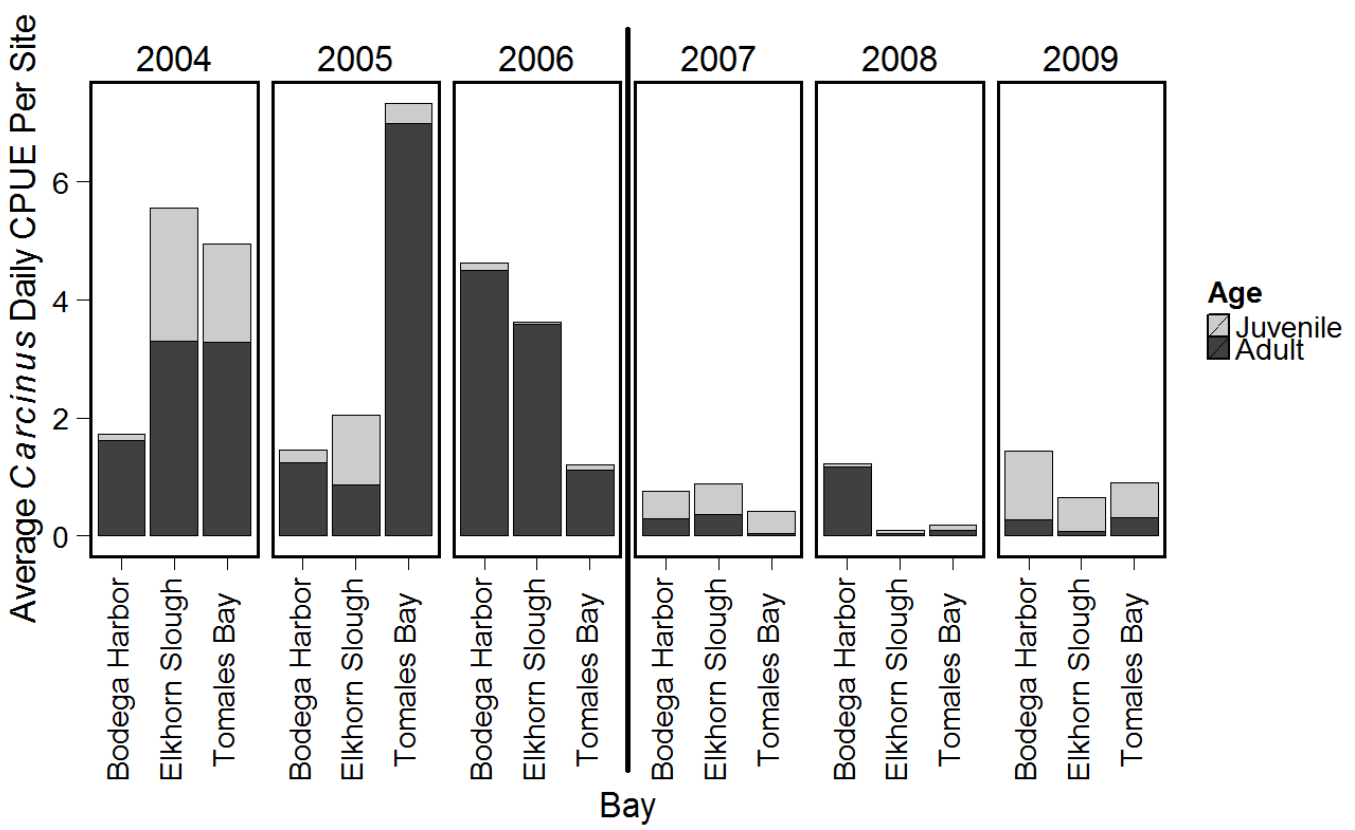

Figure 2.3 Average Carcinus daily catch per unit effort (CPUE) per site during annual systematic survey events at Removal (Bodega Harbor) and Reference (Elkhorn Slough, Tomales Bay) bays. The vertical line denotes the start of removal efforts, which began after the 2006 sampling. Carcinus catch is divided by age class to examine changes in juvenile abundance (light gray portion of bars) relative to adult abundance (dark gray portion of bars) across period (Before or After removal) and across bays (Removal or Reference) and interactions between period and bay. Relative abundances of juveniles and adults varied significantly across period $(\mathrm{z}=2.78, \mathrm{p}=0.005)$ but not across bay $(\mathrm{z}=-1.18, \mathrm{p}=0.24)$. If overcompensation occurred in Bodega Harbor as the result of removal efforts, I would expect to see significant interactive effects between period and bay. Because this was not the case $(z=-0.23, p=0.82)$, there was no evidence that overcompensation occurred.

The results of our simulation-based power analysis suggest that, given the high natural variability of the data, in order for us to have detected a significant increase of juveniles in Bodega Harbor post-removal compared to our reference bays, the juvenile 
percentage of our catch would need to be $>70 \%(\alpha=0.05)$ or $>65 \%(\alpha=0.1)$ higher than what we observed in our survey data. To detect changes in juvenile abundance (with $\alpha=0.05$ ), our post removal populations would have needed to be $\sim 73-100 \%$ juveniles (See Appendix B Figure B.1).

\section{Discussion}

Our results indicate that adult Carcinus have only weak intraspecific impacts on juvenile conspecifics. Adults cannibalized very few juveniles and, when it was available, consumed alternative prey in far greater numbers. Additionally, adult density did not have a negative relationship with the survival of tethered juveniles. Adult presence reduced the foraging rate of juveniles in $24 \mathrm{hr}$ trials, which if unchanged over time could lead to a reduction in juvenile growth. However, when exposed to adults over a longer period of time (30 or 21 days) juveniles grew larger than ones housed with other juveniles. Based on these experimental findings, we concluded that the removal of Carcinus from Bodega Harbor would not be likely to result in overcompensation. This conclusion was further supported by analysis of annual survey data, finding no evidence of large increases in juvenile Carcinus abundance relative to adult abundance in Bodega Harbor post-removal compared to our Reference bays.

Cannibalism on juveniles did not appear to be sufficiently high for a decrease in adult abundance to greatly increase juvenile survival. Adult cannibalism of juveniles was so infrequent that, when only juvenile Carcinus were available as prey, there was no significant difference in juvenile mortality between our control and predator treatments. 
Additionally, there was no difference in cannibalism rates between treatments with and without alternate prey. However, when alternate prey was present adult predation rates increased dramatically due to consumption of Hemigrapsus. Previous work by Grosholz et al. (2000) found similar trends with adult Carcinus housed with a single prey crab consuming Hemigrapsus at a much higher frequency than juvenile conspecifics. Whether observed differences in predation rates are due to predator preference or differences in ease of capture between species, cannibalism rates of adult Carcinus on juveniles were very low in the presence or absence of similar alternate prey.

Consistent with our findings of low cannibalism rates by adult Carcinus, increases in adult abundance did not have a strong negative impact on the survival of tethered juveniles. In fact, predation on juveniles was highest at locations where adult abundance was low. While our statistical power was low, if adults' impacts on juvenile Carcinus were sufficient to trigger overcompensation, we would expect adults to have a large, easily detectable negative effect on juvenile survival. Given that predation rates on enclosed or tethered animals can be much higher than rates on unrestrained animals in nature, our observations of cannibalism and mortality of tethered crabs are likely overestimates (Peterson \& Black 1994, Zimmer-Faust et al. 1994). Consequently, intraspecific pressures by adults are probably even lower in the wild than in this study. However, it should be noted that even our highest adult Carcinus density (31 adults caught) was relatively low. As such, survival of tethered juveniles may be lower at very high adult densities. Nonetheless, based on these results, we conclude that the relatively 
low predation pressure on juvenile Carcinus by adult conspecifics is not indicative of likely overcompensation in Bodega Harbor.

Adult presence had strong short-term impacts on juvenile Carcinus by reducing foraging rates, a common response of organisms in the presence of a known predator (Trussell et al. 2003). This reduction in foraging rates suggests juvenile Carcinus may perceive adult conspecifics as potential predators, which was not expected given our observations of minimal cannibalism. The reduction in foraging by juveniles could, however, be a universal response to the presence of a larger crab, regardless of species. Whether a response to adult conspecifics specifically or larger crabs in general, to contribute to the overcompensatory potential of the population reduction in juvenile foraging would require frequent encounters with adults in the field or low prey density (typically not the case in Bodega Harbor) that result in the reduction of juvenile maturation rates via long-term reductions in growth or delays in molting.

Contrary to our short-term foraging experiments, juveniles exposed to adults for longer periods showed no evidence of severe reductions in growth or delays in molting. While juveniles did not experience reduced mass increases or fewer molts when housed with adults or exposed to their effluent, the majority of juveniles in our two-juvenile treatment failed to molt. Work by Moksnes et al. $(1998,2004)$ found larger juveniles frequently cannibalize smaller conspecifics. Additionally, the only antagonistic interactions we witnessed during our behavioral observations were between crabs in the two-juvenile treatment. These antagonistic interactions may indicate higher levels of 
competition among juveniles than between juveniles and adults, which in turn could explain our observations of delayed molting.

There are several possible explanations for the contradictory responses of juveniles to adult presence observed in our experiments. Our 21 to 30 day timeframe provided only a short growth period for organisms like crabs with episodic growth, so it may be our observational period was too brief to detect impacts of adult presence. However, this concern is somewhat mitigated by the fact that juvenile activity was not reduced in the presence of an adult conspecific. Alternatively, after 3-4 weeks of exposure the juveniles habituated to the presence of adult Carcinus. The replacement of adult specimens every 10 days reduces this possibility, but the juveniles may have become habituated to the presence of adults in the absence of cues from damaged conspecifics. Chemical cues from damaged conspecifics can reduce feeding and growth of marine organisms and elicit avoidance behaviors among crabs (McKillup \& McKillup 1992, Yamada et al. 1998, Ferner et al. 2005, Moir \& Weissburg 2009, Freeman et al. 2009). Continued exposure to adults without these chemical cues may cause juveniles to prioritize foraging over safety. The contradictory responses of juveniles to adult presence could also result from reduced effects from artificially low growth due to experimental conditions. All specimens, however, were fed to excess and housed in flow-through seawater pumped from Bodega Bay (hydrologically connected to the area where the Carcinus were collected), so it is unlikely food or water quality (salinity, temperature) adversely affected their growth. Additionally, while the intermolt period for Carcinus varies with size and water temperature, the observed molting frequency of crabs in this 
experiment is similar to that observed in other populations (Yamada 2001). Therefore it appears unlikely that holding conditions themselves resulted in reduced growth of juveniles in our experiment. Finally, juveniles may simply not identify adult conspecifics as a significant threat, resuming foraging after a brief reduction in activity.

The contrast of adult presence reducing short-term foraging but not reducing long-term growth makes it difficult to determine the impacts of adult presence on juvenile growth in Bodega Harbor. Clearly, however, the response to adults is not dramatic over time as no strong impacts were detected when juveniles were exposed to adults but were detected when exposed to other juveniles. Based on these results, we conclude the effects of adult Carcinus presence on juvenile growth are not indicative of possible overcompensation in Bodega Harbor

Contrary to our findings, Bückman and Adelung (1964) found that juvenile Carcinus housed with larger conspecifics delayed molting by $1 / 3^{\text {rd }}$ compared to the normal molt interval. Bückman and Adelung used a juvenile size range similar to our own (4-16 mm CW and 7-17 mm CW respectively) but provided few details about the study. A possible explanation for the divergent results is that the larger conspecifics used by Bückman and Adelung were larger juveniles rather than adults. This would be in keeping with our observations that the majority ( 3 of 5 ) of the juveniles housed with larger juveniles failed to molt within the timeframe of the experiment whereas juveniles alone or in the presence of an adult or its effluent increased in mass and CW.

Our analysis of Carcinus caught during our annual surveys found no evidence that overcompensation occurred in Bodega Harbor. The similarity in relative juvenile 
abundance across location, even as these abundances change over time, suggests removal efforts in Bodega Harbor did not affect local juvenile recruitment. The high inter-annual variability coupled with the similar relative abundances of juveniles across bays support the hypothesis that juvenile Carcinus recruitment in this region is driven not by biotic conditions unique to location, such as intraspecific pressures, but rather by regional abiotic conditions (Shanks \& Roegner 2007, Yamada \& Kosro 2009). This is in line with observations by Yamada \& Kosro (2009), who found that recruitment of juvenile Carcinus in Oregon and Washington were correlated with a number of regional abiotic conditions including winter water temperatures in bays surveyed, timing of the spring transition (i.e., shift in wind direction along the north-eastern Pacific resulting in shift from downwelling to upwelling) and weak southward shelf currents. It may be that for non-native species with pelagic larvae, such as Carcinus, overcompensation can only occur in years where abiotic conditions are favorable to juvenile recruitment. If the system were recruitment limited, overcompensation may fail to occur because of inadequate supply of juveniles. However, because there was fairly high recruitment in the removal and reference bays after removal began (2007 and 2009) it seems unlikely that the lack of overcompensation in Bodega Harbor was due to low recruitment.

The sensitivity to detect changes in juvenile abundance in Bodega Harbor was reduced by regional increases in juvenile abundance and high inter-annual variability in catch across locations. With less spatio-temporal variability, statistical differences could be found with a smaller effect size in the removal bay. However, even a statistical increase in juvenile abundance in our removal bay compared to our reference bays after 
removal would not necessarily indicate that overcompensation had occurred.

Overcompensation occurs when population size increases as a result of the increase in the number of juveniles (Smith et al. 1996, Meyer et al. 2006, Weidel et al. 2007, Thuesen et al. 2011). As overall abundances of Carcinus in Bodega Harbor not only failed to increase but in fact declined post-removal, our data do not support the conclusion that overcompensation occurred in Bodega Harbor.

The results of our simulation-based analysis suggest that the juvenile percentage of the Bodega Harbor post-removal populations would have to be substantially higher than our observed values, comprising $\sim 68-100 \%$ of the total population (when $\alpha=0.05$ ), in order for our model to detect change. However, other removal efforts suggest this scenario is not unreasonable as the result of an overcompensatory removal effort. Two years into the removal of tilapia (Oreochromis mossambicus), individuals $<1$ year old increased by $366 \%$ and made up $95 \%$ of all catch, up from $24 \%$ (Thuesen et al. 2011). Similarly, removal of brook trout, Salvelinus fontinalis, resulted in a $789 \%$ increase in individuals $<1$ year old, comprising an estimated $74 \%$ of the population, up from $16 \%$ at the beginning of electrofishing efforts (Meyer et al. 2006). If overcompensation occurred in Bodega Harbor with similar impacts, our model would be capable of detecting the ensuing demographic shift.

While there was no evidence that overcompensation occurred in Bodega Harbor, variations in population and habitat structure that affect conspecific interactions may allow overcompensation to result from other removal efforts. Bodega Harbor had a large Carcinus population (estimated at $\sim 14,000$ in 2006) there are other populations of 
Carcinus with higher densities on the Pacific Coast (de Rivera et al. 2010, Duncombe 2014). These high-density populations could experience comparatively higher encounter rates and reduced food availability, which in turn could result in higher rates of cannibalism and competition (Fox 1975). Harvest could, through removal of intraspecific competitors and predators, have a greater potential impact on higher density populations. High density populations may also be indicative of high recruitment potential, which would result in rapid responses to any release in pressure on juvenile survival or growth.

The goal of this research was to develop an experimental framework that could be used to assess the overcompensatory potential of invasive populations prior to removal efforts. Using multiple approaches, our results indicated that cannibalism, a potentially powerful driver of overcompensation, was not of sufficient intensity to likely result in overcompensation in this population. Our experiments examining adult impacts on growth were less informative because they were contradictory. We suggest long-term growth studies should be implemented initially, with the life history of the organism taken into account to determine the appropriate trial duration. If adult presence is found to impact growth, then an examination of the mechanistic drivers (i.e., reductions in foraging) should be implemented. Finally, while potential impacts of adult removal on adult reproductive output were not examined for Carcinus, we recommend future assessments examine how adult competition may limit per capita reproduction.

This project was the first attempt we know of to use field experiments to determine if an invasive population would overcompensate as a result of removal efforts. Although the life history traits of Carcinus suggested overcompensation was possible, 
our experiments suggest that the intraspecific pressures of adults on juvenile Carcinus in the Bodega Harbor population did not significantly affect juvenile survival and growth. While our approach has potential broad application to other populations and species, our results can only be confidently applied to the Bodega Harbor removal efforts. Variations in crab density, resource availability, and habitat structure will vary across populations, altering intraspecific interactions and thus the population's response to harvest. Examining the overcompensatory potential of a population prior to removal will allow for more informed planning, increasing the chances of successful mitigation efforts or avoiding resource expenditure on unfeasible efforts.

This chapter is a reprint of Turner et al. (2016) of which I am the original lead author and it is included in this dissertation with the permission of Springer. 


\section{Chapter 3: Outcomes of aquatic invasive species management efforts help determine the cause of compensatory population growth}

\section{Introduction}

Understanding density-dependent recruitment and mortality is fundamental to predicting population response to changes in abundance. For populations where negative density-dependent processes (e.g., cannibalism, competition) increase with abundance, an increase in mortality can result in an increase in a population's recruitment rate (Abrams 2009, Zipkin et al. 2009, Schröder et al. 2014). This increase in the number of individuals recruiting into a population, also known as compensation, can result from natural increases in mortality (e.g., disease, predation) or through anthropogenic harvest (Boyce et al. 1999, Ohlberger et al. 2011). This compensatory response to harvest is a double edged-sword for natural resource managers. Stage-specific harvest efforts have been used to facilitate the recovery of an at-risk predator population by increasing prey abundance via harvest (Persson et al. 2007) and stimulate individual growth rates in stunted populations (Donald \& Alger 1989). Additionally, compensation is a critical component for in the determination of sustainable harvest limits for fisheries (summarized in Rose et al. 2001, Myers 2002). In contrast, efforts to remove nuisance species can be derailed when compensatory recruitment matches or exceeds harvest rates (Zipkin et al. 2008, 2009). While rarer, compensatory recruitment can result in the population exceeding its pre-removal abundance in a phenomenon called overcompensation (Abrams 2009, Zipkin et al. 2009, Schröder et al. 2014). Given the potential for compensation to adversely 
affect removal efforts, improving our understanding of the circumstances under which compensation could occur would be of great benefit to managers.

In order for a removal effort to cause compensatory recruitment in a population, a density-dependent process must be released from density-related suppression (Rose et al. 2001, De Roos et al. 2007). Any number of changes to density-dependent processes could facilitate this process including increased adult reproductive output or juvenile maturation rates resulting from a reduction in competition, increased survival of juveniles through maturity due to reductions in cannibalism, or a combination of processes (Rose et al. 2001, Zipkin et al. 2008). However, the outcome of removal efforts can vary even among populations of the same species.

For example, brook trout, Salvelinus fontinalis (Mitchill, 1814), are known to have density-dependent recruitment (Donald \& Alger 1989). Efforts to manage populations of S. fontinalis have resulted in successful eradications (Gresswell 1991, Knapp et al. 2007) and reductions (Thompson \& Rahel 1996, Koenig et al. 2015). By contrast, abundance remained relatively constant (Earle \& Lajeunesse 2007) or increased (Paul et al. 2003, Meyer et al. 2006) during efforts to remove other populations. While researchers reported signs of compensation for some unsuccessful removal efforts (Paul et al. 2003, Meyer et al. 2006) this was not the case for all unsuccessful efforts (Koenig et al. 2015). Thus, in order to accurately predict the response of a given population to harvest, knowledge of the potential for density-dependent interactions must be supplemented with details specific to the population or location. 
A population's response to changes in abundance can be site-specific, even among populations of the same species, suggesting that characteristics of a removal site influence the likelihood of a compensatory response resulting from removal efforts (Rose \& Cowan 2000). Size of the removal area will influence the effort required to find and remove individuals from a given location (Rejmánek \& Pitcairn 2002). Habitat heterogeneity, and thus spatial variation in resource availability, varies with habitat size (Gotelli 2008) and therefore habitat size should affect density-dependent processes (Persson et al. 2000, Forrester \& Steele 2004). Connectivity of a removal site may also influence the compensatory potential of a population by altering emigration and immigration into the population, as well as altering larval and/or juvenile retention (Cowen et al. 2000, Turgeon \& Kramer 2016).

The removal techniques employed by managers could also influence the response of populations targeted for removal. Removal efforts that employ physical methods, such as electrofishing and gillnetting, require a substantial investment of time and effort and can be size-selective (Sutherland 2006, Halfyard 2010). Chemical treatments, such as the application of rotenone, are fast acting and target all age classes of a target species, although generally at the cost of high mortality among non-target species as well (Sigler \& Sigler 1990, Halfyard 2010). Biocontrol efforts, such as stocking predators in the target site, continue beyond the initial application but typically aim for population reduction rather than eradication (Simberloff 2014).

Predicting the compensatory potential of a given population can be difficult. Understanding the natural variance of the abundance and demographic characteristics of 
a given population requires years, if not decades, of monitoring data (Rose et al. 2001). Models and experimental manipulations of populations can provide insight on specific locations and populations, but are problematic to expand their conclusions to a broader scale (Rose et al. 2001, Myers 2008). However, the compensatory potential of a specific population can be quantified and understood given sufficient time, data, and knowledge of biological interactions (Rose et al. 2001).

While long-term examinations of a population's compensatory potential may be possible for populations where the goal is to maintain or increase abundance (e.g., fisheries) this is not the case for populations of invasive species for which the goal is eradication or reduction. Best management practices for invasive species management promote rapid removal after detection to reduce impacts and increase the likelihood of eradication (Hobbs \& Humphriest 1995, Myers et al. 2000, Rejmánek \& Pitcairn 2002). As a result, long-term studies or analysis of these populations are generally counter to the goal of eradication. Efforts have been made to develop procedures to assess a populations compensatory potential (Turner et al. 2016), but may not be feasible, particularly if multiple populations must be examined within a short time frame. However, typically available characteristics of a removal effort (characteristics of the removal site, methodology of the removal effort, etc.) could allow for a more rapid assessment of compensatory risk. To examine the broad-scale patterns of compensation and its impact on removal efforts, I conducted a synthesis of efforts to remove invasive aquatic animals. While other studies have summarized efforts to eradicate or remove invasive aquatic animals (Meronek et al. 1996, Rayner \& Creese 2006, Locke et al. 2009, Freeman et al. 
2010, Halfyard 2010, Kolar et al. 2010, Britton et al. 2011, Gherardi et al. 2011, Nico \& Walsh 2011), mine is the first to examine removal efforts through the lens of compensation. I aimed to examine the relationship between compensation and removal success across a diverse assortment of locations and removal strategies.

The primary objectives of this review were twofold. First, I aimed to examine the relationship between compensation and removal efforts in aquatic systems in terms of the frequency with which compensation occurs. Removal efforts showing evidence of compensation were then examined for any potential impact of compensation on removal effort outcome. Second, I assessed the relationship between compensation resulting from removal efforts and information typically available to managers about the target area and removal methodology. This assessment could aid managers in determining a high risk of compensation prior to the start of removal.

\section{Methods}

\section{Literature search}

To examine the role of compensation in efforts to remove unwanted aquatic species, I reviewed primary literature and government reports that provided case studies detailing removal efforts. This literature search was performed using the following key words: aquatic, pest, management, removal, eradication, species. Citations in topical review papers and books were also examined (Meronek et al. 1996, Veitch \& Clout 2002, Halfyard 2010, Kolar et al. 2010, Britton et al. 2011, Loppnow et al. 2013, Ojaveer et al. 2015). I also performed a secondary literature search to look for evidence of density- 
dependent recruitment for each species that was a target of removal in the case studies. This literature search was performed using the target species scientific name and the following topics: recruitment, density-dependent, compensation. For all searches, I used the databases Web of Science - All Databases and Science.gov from 1986 to 2016. In all searches, word roots were used to get the largest return for each search. Due to linguistic limitations only publications in English were included. For this review, 'article' refers to the document describing efforts to remove aquatic species (e.g., journal article, government report, etc.), while 'case study' refers to the actions taken to remove a specific target species from a specific location. As a result, there could be multiple 'case studies' within a given 'article'. For example, many articles covered multiple distinct geographic locations (e.g., multiple lakes in a region, separate river reaches), targeted multiple species, or both. In a meta-analysis, a larger study can be divided into separate studies provided that it consists of multiple, independent subgroups (Borenstein et al. 2009). Therefore, I subdivided these articles, treating each independent location and/or target species as a separate case study.

Articles were included in this review if they met a set of pre-determined criteria. First, a primary goal of the project had to be the reduction or eradication of a specific population of an aquatic animal species. This condition excluded studies solely assessing the efficacy of chemical or mechanical removal techniques (Mallison et al. 1995, Boogaard et al. 1996, Shroyer 2007, de León et al. 2013) and efforts limited to small patches of a larger population (Watanuki et al. 2010). Second, the article had to contain details on the removal methodology including equipment, duration, and intensity. Third, 
the target species had to be specified. This excluded studies where the target of removal was listed in general terms such as "non-native cyprids" (Trammel et al. 2004). Fourth, sufficient information about changes in target species abundance had to be included. Whereas population estimates before and after removal provide the best information and were used when provided for each case study $(n=2)$, changes in population estimates after removal began $(n=12)$, catch per unit effort $($ CPUE; $n=39)$, and catch data from surveys $(n=46)$ were also used. These measures of abundance were considered sufficient to include in this review if they were ongoing throughout the removal effort, continued for at least one year after removal efforts concluded or were performed for a minimum of 3 consecutive years during removal.

\section{Analysis of removal efforts}

The following data were collected for each case study meeting the aforementioned criteria: 1) general removal method, 2) primary removal technique, 3) connectivity of removal area to other water bodies and 4) size of removal area (ha). The general removal methods used in these articles fell into one of four categories: chemical (application of biocides to the system), physical (physically removing organisms through techniques such as electrofishing and netting), biocontrol (manipulation of the abundance of another species to suppress the target species), or combination (multiple categories used in combination). The primary removal technique was the process that was used to remove the majority of specimens from the target area. Examples include electrofishing, gillnetting, rotenone, chlorine, or stocking of predators. 
When only one technique was employed, it was considered the primary technique. If multiple techniques were used in equal measure or if I was unable to determine the relative importance of each technique I classified the primary technique as 'multiple'. Primary techniques among physical removal efforts that were used in $\leq 5$ removal efforts (hand collection $[n=3]$, suffocation with plastic wrap $[n=1]$, spearfishing $[n=1]$, angling $[n=1]$, dredging $[n=1]$, deployment of traps $[n=3]$, dredging $[n=1]$, and seining $[\mathrm{n}=1])$ were grouped together as 'rare'. Connectivity of each removal site was classified as open (target species likely to freely emigrate or immigrate), closed (target species unlikely to freely emigrate or immigrate), variable (connectivity varied with water level, seasonality or could be altered mechanically, such as lock gates). The mobility of the target species (sessile vs. mobile) was taken into account when determining connectivity. Many of the case studies included the installation of barriers designed to prevent the immigration and emigration of the target species. If the installed barriers were to be permanent, then the site was considered closed.

Size of the removal area was taken directly from each article or, when not directly stated in the document, was estimated whenever possible using dimensions or maps provided in the document. However, 8 of the 98 case studies I examined contained only enough information for a broad assessment of area (e.g., $\leq 1$ ha $<$ ) but not enough to accurately determine the exact size of the area treated. Additionally, the data for sites where area could be more precisely determined were highly skewed. As a result, I chose to classify the area for each case study as being $>1$ ha $(n=60)$ or $\leq 1$ ha $(n=38)$. 
Abundance data from each article was examined to determine the outcome of each case study. Removal effort outcome was classified as 'successful', or 'unsuccessful' based on the conclusions presented by the authors and my own evaluation. A removal effort was classified as 'successful' if the target population was eradicated or there was a significant reduction in abundance (controlled for effort) compared to pre-removal levels. If there was no significant reduction in target species then the removal effort was classified as unsuccessful. Changes in target species abundance were determined, whenever possible, by analyses performed by the paper's authors. Otherwise changes were determined using provided measures of variance (e.g., a decrease in population size greater than $1 \mathrm{SE}$ or $\mathrm{SD}$, or lower than the lower bound of $95 \% \mathrm{CI}$ ).

Finally, I determined whether or not compensation likely occurred for each removal effort based on the conclusions presented by the authors and my own evaluation of the information provided (as described below). Case studies showing evidence of compensation and overcompensation were grouped together due to the rarity of potentially overcompensatory removal efforts in our analysis. For a case study to be classified as showing evidence of compensation there had to be an increase in young of the year (YOY) and/or juvenile abundance of the target species compared to pre-removal data or to data collected during the first year of the removal. This increase in YOY and/or juvenile recruitment had to coincide with evidence that this increased recruitment was, at least temporarily, compensating for the increased mortality resulting from removal efforts (e.g., total abundance remained constant or increased for at least one year into the removal effort). For one removal effort where compensation seemed likely but there was 
insufficient data to draw a confident conclusion (Coggins Jr. et al. 2011), the lead author was contacted to clarify certain details and provide further insight.

\section{Statistical analysis}

Using R statistical software (R Development Core Team 2014), I performed a number of analyses examining the relationship between removal efforts and compensation. First, I performed a Fisher's exact test, in conjunction with a visual assessment of count data, to determine if the frequency with which I found evidence of compensation (yes, no) varied across removal effort outcome (successful, unsuccessful). Although the chi-square test or G-test of independence can also be used for this type of analysis, the Fisher's exact test is more accurate when the expected numbers are small (total sample size $<1000$ or one or more of the expected values are $<5$; $[\mathrm{McDonald}$ 2014]). While not definitive, this combination of statistical testing and visual assessment provides insight into the potential impact of compensation on removal effort success. This same approach was taken to examine if the number of removal efforts with or without evidence of compensation varied with removal method employed (physical, chemical, biocontrol, combination). R scripts and additional model outputs for all statistical analyses can be found in Appendix C.

Next, I created a binomial logistic regression model to examine the relationship between a) removal efforts showing evidence of compensation and b) details of the removal effort (technique, site characteristics) for those removals that employed physical methods only. To generate these models, I used the R function "glm()" with binomial 
error distribution (family $=$ binomial) and a logit link function. Evidence of compensation (categorical: yes, no) was the dependent variable while removal area (categorical: >1 ha; $\leq 1$ ha), connectivity (categorical: open, closed, variable), and removal technique (categorical: electrofishing, gillnetting, multiple, or rare) served as the predictor variables. Additionally, I used the R function "glht()" from the package multcomp to perform a post hoc multiple comparison analysis for predictor variables with more than two levels (connectivity, technique).

In addition to the full dataset analysis outlined above, I also conducted an analysis of the case studies that described removal efforts targeting fish populations. This was done for several reasons. First, fish are a very common target of invasive species removal efforts, a fact highlighted by the fact the vast majority of the case studies I found focused on fish populations. Second, while fecundity, maturation rates, tendency to cannibalism, and other characteristics that can influence the population's response to harvest vary across fish species, these characteristics should be more similar among fish species than between fish and other aquatic organisms. In particular, we might expect fish, which can swim in their environment as adults and juveniles, to respond more similarly to differences in connectivity compared to organisms that are generally sessile (e.g. ascidians, mussels, clams) or benthic (e.g. crabs, crayfish) as adults. Using data only from removal efforts targeting fish, I repeated the processes outlined in the previous paragraphs, created a binomial logistic regression model and performed post hoc multiple comparison analyses identical to those performed on the full dataset. 


\section{Results}

In total, 56 articles detailing 98 separate case studies were examined (Table 3.1, Appendix C Table C.1). Of the case studies examined, 16 showed evidence of compensatory recruitment (Table 3.1). Of case studies showing signs of compensation, the increase in juvenile and overall abundance was sufficient in five cases to suggest overcompensation may have occurred (Smith et al. 1996, Meyer et al. 2006, Weidel et al. 2007, Thuesen et al. 2011, Shepard et al. 2014). The majority of unsuccessful removal efforts showed evidence of compensation (Fisher's exact $p<0.001$; Table 3.2), though compensation appeared to have occurred in a few efforts that resulted in the successful reduction or eradication of the target species.

Table 3.1 Case studies included in the literature review with site description, species targeted for removal, and outcome of the examination for evidence of compensation.

\begin{tabular}{|c|c|c|c|c|c|}
\hline $\begin{array}{c}\text { Case } \\
\text { Study ID }\end{array}$ & Article & $\begin{array}{c}\text { Evidence of } \\
\text { Compensation }\end{array}$ & $\begin{array}{l}\text { Species } \\
\text { Targeted }\end{array}$ & $\begin{array}{c}\text { Fish } \\
\text { Species }\end{array}$ & $\begin{array}{c}\text { Site } \\
\text { Description }\end{array}$ \\
\hline 1 & Pinto et al. 2005 & Yes & Cyprinus carpio & Yes & Botany Wetlands \\
\hline 2 & $\begin{array}{c}\text { Finney \& } \\
\text { Haines } 2008\end{array}$ & Yes & Esox lucius & Yes & $\begin{array}{c}\text { Yampa River: } \\
\text { Elkhead Creek \& } \\
\text { Elkhead Reservoir }\end{array}$ \\
\hline 3 & Hines 2014 & Yes & Ictalurus punctatus & Yes & San Juan River \\
\hline 4 & $\begin{array}{l}\text { Hawkins et al. } \\
2009\end{array}$ & Yes & $\begin{array}{c}\text { Micropterus } \\
\text { dolomieu }\end{array}$ & Yes & $\begin{array}{c}\text { Yampa Canyon: } \\
\text { Little Yampa Canyon } \\
\text { \& Lily Park }\end{array}$ \\
\hline 5 & $\begin{array}{l}\text { Weidel et al. } \\
2007\end{array}$ & Yes & $\begin{array}{c}\text { Micropterus } \\
\text { dolomieu }\end{array}$ & Yes & Little Moose Lake \\
\hline 6 & $\begin{array}{c}\text { Thuesen et al. } \\
2011\end{array}$ & Yes & $\begin{array}{l}\text { Oreochromis } \\
\text { mossambicus }\end{array}$ & Yes & The Herberton Weirs \\
\hline 7 & $\begin{array}{l}\text { Ludgate \& } \\
\text { Closs } 2003\end{array}$ & Yes & Perca fluviatilis & Yes & $\begin{array}{c}\text { Waihola/Waipori } \\
\text { Wetland Complex: } \\
\text { Large Pond }\end{array}$ \\
\hline 8 & $\begin{array}{l}\text { Saunders et al. } \\
2015\end{array}$ & Yes & Salmo trutta & Yes & Logan River \\
\hline
\end{tabular}




\begin{tabular}{|c|c|c|c|c|c|}
\hline 9 & $\begin{array}{l}\text { Saunders et al. } \\
2015\end{array}$ & Yes & Salmo trutta & Yes & Right Hand Fork \\
\hline 10 & $\begin{array}{l}\text { Carmona-Catot } \\
\text { et al. } 2010\end{array}$ & Yes & $\begin{array}{l}\text { Salvelinus } \\
\text { fontinalis }\end{array}$ & Yes & Bogard Spring Creek \\
\hline 11 & $\begin{array}{c}\text { Earle \& } \\
\text { Lajeunesse } 2007\end{array}$ & Yes & $\begin{array}{l}\text { Salvelinus } \\
\text { fontinalis }\end{array}$ & Yes & Canmore Creek \\
\hline 12 & $\begin{array}{l}\text { Meyer et al. } \\
2006\end{array}$ & Yes & $\begin{array}{l}\text { Salvelinus } \\
\text { fontinalis }\end{array}$ & Yes & Pike's Fork \\
\hline 13 & Paul et al. 2003 & Yes & $\begin{array}{l}\text { Salvelinus } \\
\text { fontinalis }\end{array}$ & Yes & Quirk Creek \\
\hline 14 & $\begin{array}{c}\text { Shepard et al. } \\
2014\end{array}$ & Yes & $\begin{array}{l}\text { Salvelinus } \\
\text { fontinalis }\end{array}$ & Yes & Whites Creek \\
\hline 15 & Syslo et al. 2011 & Yes & $\begin{array}{l}\text { Salvelinus } \\
\text { namaycush }\end{array}$ & Yes & Yellowstone Lake \\
\hline 16 & $\begin{array}{l}\text { Smith et al. } \\
1996\end{array}$ & Yes & $\begin{array}{c}\text { Stizostedion } \\
\text { lucioperca }\end{array}$ & Yes & North Oxford Canal \\
\hline 17 & Brastrup 2001 & No & Cyprinus carpio & Yes & Knife Lake \& River \\
\hline 18 & $\begin{array}{l}\text { Diggle et al. } \\
2004\end{array}$ & No & Cyprinus carpio & Yes & Crescent Lake \\
\hline 19 & $\begin{array}{l}\text { Diggle et al. } \\
\quad 2004\end{array}$ & No & Cyprinus carpio & Yes & Sorell Lake \\
\hline 20 & $\begin{array}{l}\text { Donkers et al. } \\
2012\end{array}$ & No & Cyprinus carpio & Yes & Lake Crescent \\
\hline 21 & $\begin{array}{c}\text { Scarnecchia } \\
1988\end{array}$ & No & Cyprinus carpio & Yes & McHose Pond \\
\hline 22 & Lee 2001 & No & Esox lucius & Yes & Lake Davis \\
\hline 23 & $\begin{array}{l}\text { Schaufler } \\
\text { et al. } 2015\end{array}$ & No & Esox lucius & Yes & Lake Grundlsee \\
\hline 24 & $\begin{array}{l}\text { Ruiz-Navarro } \\
\text { et al. } 2013\end{array}$ & No & $\begin{array}{l}\text { Gambusia } \\
\text { holbrooki }\end{array}$ & Yes & Chicamo Stream \\
\hline 25 & Eilers et al. 2011 & No & Gila bicolor & Yes & Diamond Lake \\
\hline 26 & $\begin{array}{l}\text { de Lourdes } \\
\text { Lozano-Vilano } \\
\text { et al. } 2006\end{array}$ & No & $\begin{array}{c}\text { Hemichromis } \\
\text { guttatus }\end{array}$ & Yes & $\begin{array}{c}\text { Poza San Jose' del } \\
\text { Anteojo }\end{array}$ \\
\hline
\end{tabular}




\begin{tabular}{|c|c|c|c|c|c|}
\hline 27 & $\begin{array}{l}\text { Scarnecchia } \\
1988\end{array}$ & No & Ictalurus melas & Yes & McHose Pond \\
\hline 28 & Fuller 2009 & No & Ictalurus punctatus & Yes & $\begin{array}{c}\text { Yampa Canyon: } \\
\text { Lower Yampa River }\end{array}$ \\
\hline 29 & $\begin{array}{l}\text { Scarnecchia } \\
1988\end{array}$ & No & Ictalurus punctatus & Yes & McHose Pond \\
\hline 30 & $\begin{array}{l}\text { Scarnecchia } \\
\quad 1988\end{array}$ & No & Ictiobus cyprinellus & Yes & McHose Pond \\
\hline 31 & Fuller 2009 & No & $\begin{array}{l}\text { Micropterus } \\
\text { dolomieu }\end{array}$ & Yes & $\begin{array}{c}\text { Yampa Cayon: } \\
\text { Lower Yampa River }\end{array}$ \\
\hline 32 & $\begin{array}{l}\text { Coggins Jr. } \\
\text { et al. } 2011\end{array}$ & No & $\begin{array}{c}\text { Oncorhynchus } \\
\text { mykiss }\end{array}$ & Yes & Little Colorado River \\
\hline 33 & $\begin{array}{c}\text { Kelso \& } \\
\text { Shuter } 1989\end{array}$ & No & $\begin{array}{c}\text { Oncorhynchus } \\
\text { mykiss }\end{array}$ & Yes & Batchawana Lake \\
\hline 34 & $\begin{array}{c}\text { Knapp \& } \\
\text { Matthews } 1998\end{array}$ & No & $\begin{array}{c}\text { Oncorhynchus } \\
\text { mykiss }\end{array}$ & Yes & Maul Lake \\
\hline 35 & $\begin{array}{c}\text { Kulp \& } \\
\text { Moore } 2000\end{array}$ & No & $\begin{array}{c}\text { Oncorhynchus } \\
\text { mykiss }\end{array}$ & Yes & Mannis Branch \\
\hline 36 & $\begin{array}{c}\text { Lintermans \& } \\
\text { Raadik } 2001\end{array}$ & No & $\begin{array}{c}\text { Oncorhynchus } \\
\text { mykiss }\end{array}$ & Yes & Lees Creek \\
\hline 37 & $\begin{array}{c}\text { Lintermans \& } \\
\text { Raadik } 2001\end{array}$ & No & $\begin{array}{c}\text { Oncorhynchus } \\
\text { mykiss }\end{array}$ & Yes & $\begin{array}{l}\text { Goulburn River } \\
\text { catchment }\end{array}$ \\
\hline 38 & $\begin{array}{l}\text { Moore et al. } \\
\quad 2005\end{array}$ & No & $\begin{array}{l}\text { Oncorhynchus } \\
\text { mykiss }\end{array}$ & Yes & Sam's Creek \\
\hline 39 & $\begin{array}{l}\text { Knapp et al. } \\
2007\end{array}$ & No & $\begin{array}{l}\text { Oncorhynchus } \\
\text { mykiss hybrids }\end{array}$ & Yes & $\begin{array}{l}\text { Humphreys Basin: } \\
\text { Marmot Lake }\end{array}$ \\
\hline 40 & $\begin{array}{l}\text { Knapp et al. } \\
2007\end{array}$ & No & $\begin{array}{l}\text { Oncorhynchus } \\
\text { mykiss hybrids }\end{array}$ & Yes & $\begin{array}{l}\text { LeConte Basin: } \\
\text { Black Giant Lake }\end{array}$ \\
\hline 41 & $\begin{array}{l}\text { Knapp et al. } \\
2007\end{array}$ & No & $\begin{array}{l}\text { Oncorhynchus } \\
\text { mykiss hybrids }\end{array}$ & Yes & $\begin{array}{l}\text { LeConte Basin: } \\
\text { Upper \& Lower } \\
\text { LeConte Lake }\end{array}$ \\
\hline 42 & $\begin{array}{l}\text { Ludgate \& } \\
\text { Closs } 2003\end{array}$ & No & Perca fluviatilis & Yes & $\begin{array}{c}\text { Waihola/Waipori } \\
\text { Wetland Complex: } \\
\text { Small Pond }\end{array}$ \\
\hline 43 & $\begin{array}{l}\text { Ludgate \& } \\
\text { Closs } 2003\end{array}$ & No & Perca fluviatilis & Yes & $\begin{array}{c}\text { Waihola/Waipori } \\
\text { Wetland Complex: } \\
\text { Medium Pond }\end{array}$ \\
\hline 44 & $\begin{array}{c}\text { Rayner \& } \\
\text { Creese } 2006\end{array}$ & No & $\begin{array}{c}\text { Phalloceros } \\
\text { caudimaculatus }\end{array}$ & Yes & $\begin{array}{l}\text { Long Reef Golf } \\
\text { Course }\end{array}$ \\
\hline
\end{tabular}




\begin{tabular}{|c|c|c|c|c|c|}
\hline 45 & $\begin{array}{l}\text { Scarnecchia } \\
1988\end{array}$ & No & Pomoxis spp. & Yes & McHose Pond \\
\hline 46 & $\begin{array}{l}\text { Britton \& } \\
\text { Brazier } 2006\end{array}$ & No & $\begin{array}{l}\text { Pseudorasbora } \\
\text { parva }\end{array}$ & Yes & A lake \\
\hline 47 & $\begin{array}{l}\text { Britton et al. } \\
\quad 2008\end{array}$ & No & $\begin{array}{c}\text { Pseudorasbora } \\
\text { parva }\end{array}$ & Yes & $\begin{array}{l}\text { Two small adjacent } \\
\text { fishing lakes }\end{array}$ \\
\hline 48 & $\begin{array}{l}\text { Britton et al. } \\
\quad 2008\end{array}$ & No & $\begin{array}{c}\text { Pseudorasbora } \\
\text { parva }\end{array}$ & Yes & $\begin{array}{l}\text { Six hydrologically } \\
\text { linked ponds }\end{array}$ \\
\hline 49 & $\begin{array}{l}\text { Britton et al. } \\
\quad 2010\end{array}$ & No & $\begin{array}{c}\text { Pseudorasbora } \\
\text { parva }\end{array}$ & Yes & Pond in the Wirral \\
\hline 50 & $\begin{array}{c}\text { Hill \& } \\
\text { Sowards } 2015\end{array}$ & No & $\begin{array}{l}\text { Pterygoplichthys } \\
\text { disjunctivus }\end{array}$ & Yes & Rainbow River \\
\hline 51 & $\begin{array}{c}\text { Caudron \& } \\
\text { Champigneulle } \\
2011\end{array}$ & No & Salmo trutta & Yes & Chevenne Creek \\
\hline 52 & $\begin{array}{c}\text { Lintermans \& } \\
\text { Raadik } 2001\end{array}$ & No & Salmo trutta & Yes & $\begin{array}{l}\text { Goulburn River } \\
\text { catchment }\end{array}$ \\
\hline 53 & Pham et al. 2013 & No & Salmo trutta & Yes & $\begin{array}{c}\text { Kaiwharawhara } \\
\text { catchment: River } 1\end{array}$ \\
\hline 54 & Pham et al. 2013 & No & Salmo trutta & Yes & $\begin{array}{l}\text { Kaiwharawhara } \\
\text { catchment: River } 2\end{array}$ \\
\hline 55 & $\begin{array}{l}\text { Buktenica et al. } \\
2013\end{array}$ & No & $\begin{array}{l}\text { Salvelinus } \\
\text { fontinalis }\end{array}$ & Yes & Sun Creek \\
\hline 56 & Gresswell 1991 & No & $\begin{array}{l}\text { Salvelinus } \\
\text { fontinalis }\end{array}$ & Yes & $\begin{array}{c}\text { Arnica Lagoon, Creek } \\
\text { \& Drainage }\end{array}$ \\
\hline 57 & $\begin{array}{c}\text { Kelso \& } \\
\text { Shuter } 1989\end{array}$ & No & $\begin{array}{l}\text { Salvelinus } \\
\text { fontinalis }\end{array}$ & Yes & Batchawana Lake \\
\hline 58 & $\begin{array}{l}\text { Knapp et al. } \\
2007\end{array}$ & No & $\begin{array}{l}\text { Salvelinus } \\
\text { fontinalis }\end{array}$ & Yes & $\begin{array}{l}\text { Humphreys Basin: } \\
\text { Cony Lake }\end{array}$ \\
\hline 59 & $\begin{array}{l}\text { Knapp et al. } \\
2007\end{array}$ & No & $\begin{array}{l}\text { Salvelinus } \\
\text { fontinalis }\end{array}$ & Yes & $\begin{array}{l}\text { Humphreys Basin: } \\
\text { No Good Lake }\end{array}$ \\
\hline 60 & $\begin{array}{c}\text { Knapp \& } \\
\text { Matthews } 1998\end{array}$ & No & $\begin{array}{l}\text { Salvelinus } \\
\text { fontinalis }\end{array}$ & Yes & Maul Lake \\
\hline 61 & $\begin{array}{l}\text { Koenig et al. } \\
\quad 2015\end{array}$ & No & $\begin{array}{l}\text { Salvelinus } \\
\text { fontinalis }\end{array}$ & Yes & Corral Lakes \\
\hline 62 & $\begin{array}{l}\text { Koenig et al. } \\
\quad 2015\end{array}$ & No & $\begin{array}{l}\text { Salvelinus } \\
\text { fontinalis }\end{array}$ & Yes & Black Lake \\
\hline
\end{tabular}




\begin{tabular}{|c|c|c|c|c|c|}
\hline 63 & $\begin{array}{c}\text { Koenig et al. } \\
2015\end{array}$ & No & $\begin{array}{l}\text { Salvelinus } \\
\text { fontinalis }\end{array}$ & Yes & Fly Lake \\
\hline 64 & $\begin{array}{c}\text { Koenig et al. } \\
2015\end{array}$ & No & $\begin{array}{l}\text { Salvelinus } \\
\text { fontinalis }\end{array}$ & Yes & Platinum Lake \\
\hline 65 & $\begin{array}{c}\text { Koenig et al. } \\
2015\end{array}$ & No & $\begin{array}{l}\text { Salvelinus } \\
\text { fontinalis }\end{array}$ & Yes & Heather Lake \\
\hline 66 & $\begin{array}{c}\text { Koenig et al. } \\
2015\end{array}$ & No & $\begin{array}{l}\text { Salvelinus } \\
\text { fontinalis }\end{array}$ & Yes & Shirts Lake \\
\hline 67 & $\begin{array}{l}\text { Koenig et al. } \\
2015\end{array}$ & No & $\begin{array}{l}\text { Salvelinus } \\
\text { fontinalis }\end{array}$ & Yes & Grass Mountain 1 \\
\hline 68 & $\begin{array}{l}\text { Koenig et al. } \\
2015\end{array}$ & No & $\begin{array}{l}\text { Salvelinus } \\
\text { fontinalis }\end{array}$ & Yes & Grass Mountain 2 \\
\hline 69 & $\begin{array}{c}\text { Koenig et al. } \\
2015\end{array}$ & No & $\begin{array}{l}\text { Salvelinus } \\
\text { fontinalis }\end{array}$ & Yes & Running Lake \\
\hline 70 & $\begin{array}{c}\text { Koenig et al. } \\
2015\end{array}$ & No & $\begin{array}{l}\text { Salvelinus } \\
\text { fontinalis }\end{array}$ & Yes & Spruce Gulch \\
\hline 71 & $\begin{array}{c}\text { Koenig et al. } \\
2015\end{array}$ & No & $\begin{array}{l}\text { Salvelinus } \\
\text { fontinalis }\end{array}$ & Yes & Upper Hazard \\
\hline 72 & $\begin{array}{l}\text { Koenig et al. } \\
2015\end{array}$ & No & $\begin{array}{l}\text { Salvelinus } \\
\text { fontinalis }\end{array}$ & Yes & Granite Twin Lake \\
\hline 73 & $\begin{array}{c}\text { Koenig et al. } \\
2015\end{array}$ & No & $\begin{array}{l}\text { Salvelinus } \\
\text { fontinalis }\end{array}$ & Yes & Merriam Lake \\
\hline 74 & $\begin{array}{c}\text { Pacas \& } \\
\text { Taylor } 2015\end{array}$ & No & $\begin{array}{l}\text { Salvelinus } \\
\text { fontinalis }\end{array}$ & Yes & Clearwater River \\
\hline 75 & $\begin{array}{c}\text { Pacas \& } \\
\text { Taylor } 2015\end{array}$ & No & $\begin{array}{l}\text { Salvelinus } \\
\text { fontinalis }\end{array}$ & Yes & $\begin{array}{l}\text { Middle \& Lower } \\
\text { Devon Lakes }\end{array}$ \\
\hline 76 & $\begin{array}{c}\text { Parker et al. } \\
2001\end{array}$ & No & $\begin{array}{l}\text { Salvelinus } \\
\text { fontinalis }\end{array}$ & Yes & Bighorn Lake \\
\hline 77 & $\begin{array}{c}\text { Shepard et al. } \\
2014\end{array}$ & No & $\begin{array}{l}\text { Salvelinus } \\
\text { fontinalis }\end{array}$ & Yes & Staubach Creek \\
\hline 78 & $\begin{array}{c}\text { Shepard et al. } \\
2014\end{array}$ & No & $\begin{array}{l}\text { Salvelinus } \\
\text { fontinalis }\end{array}$ & Yes & Muskrat Creek \\
\hline 79 & $\begin{array}{c}\text { Shepard et al. } \\
2014\end{array}$ & No & $\begin{array}{l}\text { Salvelinus } \\
\text { fontinalis }\end{array}$ & Yes & Cottonwood Creek \\
\hline 80 & $\begin{array}{c}\text { Thompson \& } \\
\text { Rahel } 1996\end{array}$ & No & $\begin{array}{l}\text { Salvelinus } \\
\text { fontinalis }\end{array}$ & Yes & Nylander Creek \\
\hline
\end{tabular}




\begin{tabular}{|c|c|c|c|c|c|}
\hline 81 & $\begin{array}{l}\text { Thompson \& } \\
\text { Rahel } 1996\end{array}$ & No & $\begin{array}{l}\text { Salvelinus } \\
\text { fontinalis }\end{array}$ & Yes & Nameless Creek \\
\hline 82 & $\begin{array}{l}\text { Thompson \& } \\
\text { Rahel } 1996\end{array}$ & No & $\begin{array}{l}\text { Salvelinus } \\
\text { fontinalis }\end{array}$ & Yes & Irene Creek \\
\hline 83 & $\begin{array}{l}\text { Vredenburg } \\
2004\end{array}$ & No & $\begin{array}{l}\text { Salvelinus } \\
\text { fontinalis }\end{array}$ & Yes & $\begin{array}{l}\text { Sixty Lake Basin: } \\
\text { Lake } 1\end{array}$ \\
\hline 84 & $\begin{array}{l}\text { Vredenburg } \\
\quad 2004\end{array}$ & No & $\begin{array}{l}\text { Salvelinus } \\
\text { fontinalis }\end{array}$ & Yes & $\begin{array}{l}\text { Sixty Lake Basin: } \\
\text { Lake } 2\end{array}$ \\
\hline 85 & $\begin{array}{l}\text { Vredenburg } \\
\quad 2004\end{array}$ & No & $\begin{array}{l}\text { Salvelinus } \\
\text { fontinalis }\end{array}$ & Yes & $\begin{array}{l}\text { Sixty Lake Basin: } \\
\text { Lake } 3\end{array}$ \\
\hline 86 & $\begin{array}{l}\text { Vredenburg } \\
\quad 2004\end{array}$ & No & $\begin{array}{l}\text { Salvelinus } \\
\text { fontinalis }\end{array}$ & Yes & $\begin{array}{l}\text { Sixty Lake Basin: } \\
\text { Lake } 4\end{array}$ \\
\hline 87 & $\begin{array}{l}\text { Vredenburg } \\
\quad 2004\end{array}$ & No & $\begin{array}{l}\text { Salvelinus } \\
\text { fontinalis }\end{array}$ & Yes & $\begin{array}{l}\text { Sixty Lake Basin: } \\
\text { Lake } 5\end{array}$ \\
\hline 88 & $\begin{array}{c}\text { Kelso \& } \\
\text { Shuter } 1989\end{array}$ & No & $\begin{array}{l}\text { Salvelinus } \\
\text { namaycush }\end{array}$ & Yes & Batchawana Lake \\
\hline 89 & $\begin{array}{l}\text { Turner et al. } \\
\quad 2016\end{array}$ & No & Carcinus maenas & No & Bodega Harbor \\
\hline 90 & $\begin{array}{c}\text { Coutts \& } \\
\text { Forrest } 2007\end{array}$ & No & $\begin{array}{l}\text { Didemnum } \\
\text { vexillum }\end{array}$ & No & Shakespeare Bay \\
\hline 91 & $\begin{array}{c}\text { Holt \& } \\
\text { Cordingley } 2011\end{array}$ & No & $\begin{array}{l}\text { Didemnum } \\
\text { vexillum }\end{array}$ & No & Holyhead Harbour \\
\hline 92 & $\begin{array}{l}\text { Wimbush } \\
\text { et al. } 2009\end{array}$ & No & $\begin{array}{l}\text { Dreissena } \\
\text { polymorpha }\end{array}$ & No & Lake George marina \\
\hline 93 & Bax et al. 2000 & No & Mytilopsis sp. & No & Cullen Bay Marina \\
\hline 94 & Hein et al. 2006 & No & $\begin{array}{l}\text { Orconectes } \\
\text { rusticus }\end{array}$ & No & Sparkling Lake \\
\hline 95 & Dana et al. 2010 & No & $\begin{array}{l}\text { Pacifastacus } \\
\text { leniusculus }\end{array}$ & No & Riofrío River \\
\hline 96 & $\begin{array}{c}\text { Hopkins et al. } \\
2011\end{array}$ & No & Perna perna & No & Tasman Bay \\
\hline 97 & $\begin{array}{c}\text { Bernatis \& } \\
\text { Warren } 2014\end{array}$ & No & $\begin{array}{l}\text { Pomacea } \\
\text { canaliculata }\end{array}$ & No & $\begin{array}{c}\text { Jacksonville retention } \\
\text { pond }\end{array}$ \\
\hline 98 & $\begin{array}{l}\text { Culver \& } \\
\text { Kuris } 2000\end{array}$ & No & $\begin{array}{l}\text { Terebrasabella } \\
\text { heterouncinata }\end{array}$ & No & $\begin{array}{c}\text { Intertidal habitat below } \\
\text { water discharge } \\
\text { outflow }\end{array}$ \\
\hline
\end{tabular}


Table 3.2 Cases with or without evidence that compensation occurred for each of two possible outcomes from removal efforts. The majority of removal efforts were successful (eradication or reduction) and these rarely showed evidence for compensation; efforts were unsuccessful significantly more often when they had evidence of compensation (Fisher's exact test; $p<0.001$ ).

Evidence of Compensation

\begin{tabular}{cccccc|c}
\hline $\begin{array}{c}\text { Outcome of } \\
\text { Removal Effort }\end{array}$ & Yes & Yes (\%) & No & No (\%) & Total & \% of Total \\
\hline Successful & 3 & $4 \%$ & 77 & $96 \%$ & 80 & $82 \%$ \\
Unsuccessful & 13 & $72 \%$ & 5 & $28 \%$ & 18 & $18 \%$ \\
\hline Total & 16 & & 82 & & 98 & $100 \%$
\end{tabular}

Physical methods were more commonly employed for removal than chemical, biocontrol, or a combination of methods (Table 3.3). Evidence of compensation was exclusively found in removal efforts that utilized physical removal methods (Fisher's exact $p=0.02)$.

Table 3.3 Cases with or without evidence that compensation occurred for each of four possible removal methods. The majority of removal efforts utilized physical removal methods and only physical removal efforts showed evidence of compensation (Fisher's exact test; $p=0.02$ ).

Evidence of Compensation

\begin{tabular}{cccccc|c}
\hline Removal Method & Yes & Yes $(\boldsymbol{\%})$ & No & No $(\boldsymbol{\%})$ & Total & \% of Total \\
\hline Physical & 16 & $25 \%$ & 47 & $75 \%$ & 63 & $65 \%$ \\
Chemical & 0 & $0 \%$ & 17 & $100 \%$ & 17 & $17 \%$ \\
Biocontrol & 0 & $0 \%$ & 13 & $100 \%$ & 13 & $13 \%$ \\
Combination & 0 & $0 \%$ & 5 & $100 \%$ & 5 & $5 \%$ \\
\hline Total & 16 & & 82 & & 98 & $100 \%$
\end{tabular}

The majority of physical removal efforts utilized electrofishing and targeted

closed systems that were $>1$ ha in size (Table 3.4). The logistic regression model for the full dataset showed significant relationships between evidence of compensation and both removal technique and connectivity (Table 3.5; full model output in Appendix C Table C.2-5). Additionally, there was a marginally significant relationship between evidence of 
compensation and removal area size. When I performed the post hoc multiple comparisons, evidence of compensation was found significantly more frequently among removal efforts primarily employing electrofishing compared to gillnetting, multiple techniques, or rare techniques (Table 3.5; full post hoc outputs Appendix C Table C.6-7). There were no significant or marginal differences between gillnetting, multiple, or rare removal techniques.

Compensation occurred at a significantly higher frequency in systems with variable connectivity compared to closed systems (Table 3.5). Though not statistically significant, evidence of compensation occurred more frequently among variable systems compared to open systems. Open and closed systems were not significantly different from each other.

Compensation occurred at a marginally higher frequency among sites $>1$ ha compared to sites $\leq 1$ ha (Table 3.5).

Of the 98 case studies I examined, 88 targeted fish populations, and 55 fish removal efforts utilized physical methods. All of the case studies that showed signs of compensation were from efforts targeting fish. While the model and post hoc analyses of this reduced dataset yielded nearly identical results as the analyses of the full dataset, there were three exceptions. First, the removal of the 7 non-fish case studies that utilized rare removal techniques resulted in there no longer being a significant difference in the compensation frequency between electrofishing and rare removal techniques (Table 3.5; full model and post hoc test outputs in Appendix C, Table C.8-13). Second, compensation occurred at a significantly higher frequency for sites $>1$ ha compared to 
sites $\leq 1$ ha rather than the marginal difference I found for the full dataset. Finally, the frequency of compensation at sites with variable connectivity became marginally higher compared to open systems, while it was previously not statistically higher.

Table 3.4 Cases with or without evidence that compensation occurred for each of 3 variables and their corresponding levels. The dataset is limited to removal efforts utilizing physical methods as there was no evidence of compensation in any of the other three methods of removals $(n=63)$.

Evidence of Compensation

\begin{tabular}{|c|c|c|c|c|c|c|c|}
\hline Variable & Level & Yes & Yes $(\%)$ & No & No $(\%)$ & Total & $\%$ of Total \\
\hline \multirow{5}{*}{$\begin{array}{l}\text { Physical } \\
\text { Removal } \\
\text { Technique }\end{array}$} & Electrofishing & 11 & $50 \%$ & 11 & $50 \%$ & 22 & $35 \%$ \\
\hline & Gillnetting & 1 & $6 \%$ & 16 & $94 \%$ & 17 & $27 \%$ \\
\hline & Multiple & 2 & $17 \%$ & 10 & $83 \%$ & 12 & $19 \%$ \\
\hline & Rare & 2 & $17 \%$ & 10 & $83 \%$ & 12 & $19 \%$ \\
\hline & Total & 16 & & 47 & & 63 & $100 \%$ \\
\hline \multirow{4}{*}{$\begin{array}{l}\text { Removal Site } \\
\text { Connectivity }\end{array}$} & Closed & 4 & $11 \%$ & 31 & $89 \%$ & 35 & $55 \%$ \\
\hline & Open & 7 & $39 \%$ & 11 & $61 \%$ & 18 & $29 \%$ \\
\hline & Variable & 5 & $50 \%$ & 5 & $50 \%$ & 10 & $16 \%$ \\
\hline & Total & 16 & & 47 & & 63 & $100 \%$ \\
\hline \multirow{3}{*}{$\begin{array}{c}\text { Removal Site } \\
\text { Area }\end{array}$} & $>1$ ha & 12 & $34 \%$ & 25 & $66 \%$ & 37 & $59 \%$ \\
\hline & $\leq 1$ ha & 4 & $15 \%$ & 22 & $85 \%$ & 26 & $41 \%$ \\
\hline & Total & 16 & & 47 & & 63 & $100 \%$ \\
\hline
\end{tabular}


Table 3.5 Statistical output of post hoc multiple comparisons analysis for frequency with which evidence of compensation was detected across physical removal technique and removal site connectivity. Two datasets were examined: All removal efforts utilizing physical methods $(n=63)$, and those physical removal efforts targeting fish $(\mathrm{n}=55)$. Efforts utilizing chemical, biocontrol, or a combination of methods were not included as there was no evidence of compensation from these methods. For both datasets, evidence of compensation was found generally more frequent among removal efforts using electrofishing, at sites with variable connectivity, and at sites $>1$ ha in area. Bold and italicized $p$-values are significant, while italicized alone are marginally significant.

\begin{tabular}{cccc|ccc} 
& \multicolumn{3}{c|}{ All Removals } & \multicolumn{3}{c}{ Fish Removals Only } \\
\hline Comparison & Coefficient \pm SE & $\boldsymbol{z}$ & $\boldsymbol{p}$ & Coefficient \pm SE & $\boldsymbol{z}$ & $\boldsymbol{p}$ \\
\hline Gillnetting - Electrofishing & $-3.22 \pm 1.34$ & -2.41 & $\mathbf{0 . 0 2}$ & $-3.76 \pm 1.55$ & -2.43 & $\mathbf{0 . 0 2}$ \\
Multiple - Electrofishing & $-2.10 \pm 1.00$ & -2.10 & $\mathbf{0 . 0 4}$ & $-2.29 \pm 1.07$ & -2.14 & $\mathbf{0 . 0 3}$ \\
Rare - Electrofishing & $-2.33 \pm 1.07$ & -2.17 & $\mathbf{0 . 0 3}$ & $-1.08 \pm 1.20$ & -0.90 & 0.37 \\
Multiple - Gillnetting & $1.13 \pm 1.42$ & 0.79 & 0.43 & $1.47 \pm 1.47$ & 1.00 & 0.32 \\
Rare - Gillnetting & $0.90 \pm 1.47$ & 0.61 & 0.54 & $2.67 \pm 1.75$ & 1.52 & 0.13 \\
Rare - Multiple & $-0.22 \pm 1.18$ & -0.19 & 0.85 & $1.21 \pm 1.34$ & 0.90 & 0.37 \\
\hline Open - Closed & $0.76 \pm 0.95$ & 0.80 & 0.42 & $0.17 \pm 1.14$ & 0.15 & 0.89 \\
Variable - Closed & $2.68 \pm 1.05$ & 2.55 & $\mathbf{0 . 0 1}$ & $2.95 \pm 1.20$ & 2.45 & $\mathbf{0 . 0 1}$ \\
Variable - Open & $1.92 \pm 1.22$ & 1.57 & 0.12 & $2.78 \pm 1.63$ & 1.71 & 0.09 \\
\hline$>1$ ha - $\leq 1$ ha & $1.62 \pm 0.95$ & 1.70 & 0.09 & $2.45 \pm 1.26$ & 1.95 & $\mathbf{0 . 0 5}$ \\
\hline
\end{tabular}

\section{Discussion}

Analysis of the literature helped identify several factors that are correlated with compensation in recruitment and so can help inform future decisions about removal.

Evidence for compensation was found in 16 of 98 removal efforts reviewed, most often (72\%) among failed removal efforts. In 5 cases studies, the increase in juvenile and overall abundance was sufficient to suggest overcompensation may have occurred (Smith et al. 1996, Meyer et al. 2006, Weidel et al. 2007, Thuesen et al. 2011, Shepard et al. 2014). All removal efforts containing evidence of compensation utilized only physical methods. While evidence of compensation was found for all physical removal techniques, it was most common among electrofishing efforts. While the majority of removal efforts occurred in closed systems, evidence of compensation was more frequent among removal 
efforts targeting sites with variable connectivity. There was a marginally significant relationship between compensation and size of removal site. These findings suggest that physical removal efforts, particularly those primarily or solely utilizing electrofishing, are the ones most likely to result in compensation as a response to removal efforts. While I found no evidence of compensation for removal efforts utilizing chemical, biocontrol, or a combination of methods, this only suggests that compensation is not an especially common outcome of these removal methods and not that these methods can never result in compensation.

Although my findings were consistent when I examined the 'all species' and 'only fish' datasets, it is important to note that in the 'all species' dataset the majority of the case studies examined targeted fish. As a result, the relationship between removal effort characteristics and the frequency of compensation may only be applicable to fish removal efforts. This is especially true for the physical removal techniques electrofishing and gillnetting as they are specifically designed for the capture of fish and would not be used to remove other aquatic non-native species such as mussels or ascidians. Therefore, the finding that electrofishing is correlated with compensation does not indicate fish are more likely to compensate than other organisms because gillnetting was also limited to fish but did not typically result in compensation.

While I only found evidence for compensation in $16 \%$ of removal efforts examined, the actual frequency with which compensation occurs may be higher. Harvest of a population can produce a continuum of recruitment responses, ranging from reductions to compensatory and even overcompensatory responses (De Roos et al. 2007, 
Zipkin et al. 2009). Large compensatory responses are more likely to complicate or derail removal efforts, and thus may account for the observed relationship between removal success and compensation. Removal efforts that result in a smaller compensatory response by the target population may be undetected due to sufficiently high removal rates, high inter-annual variation in recruitment, inadequate sampling of all age classes or inaccurate population estimates. Additionally, projects with successful outcomes are far more likely to be published and thus it may be difficult to obtain information on efforts resulting in a large compensatory response (Kolar et al. 2010). Regardless, the fact that roughly one-in-five published removal effort shows evidence of compensation, or even overcompensation, shows that compensation is a common enough outcome of removal that it must be considered and its likelihood evaluated during the planning stages for removal.

Among the case studies, only physical efforts showed evidence of compensation, suggesting that removal method influences the likelihood of compensation. Compared to chemical methods, physical removal of aquatic species are far more labor intensive and size-selective (Halfyard 2010). Chemical treatments can be applied relatively quickly, begin to take affect within a few hours, and can rapidly reduce the target species abundance (Sigler \& Sigler 1990, Lazur et al. 2006, Halfyard 2010). However, the applications of chemicals does not guarantee success, as highlighted in a review by Meronek et al. (1996) which found 13 of 55 chemical removal efforts examined were unsuccessful. Additionally, the generally high non-target mortality and high levels of public opposition associated with chemical applications may limit the applicability of this 
approach (Koehn et al. 2000, Halfyard 2010). Physical removal efforts can require several years to implement, providing multiple opportunities for surviving reproductive adults to spawn under less competitive conditions and for YOY to grow and mature under reduced threat of cannibalism (Claessen et al. 2004). Additionally, while chemical treatments generally affect all size classes of the target species equally (though concentration required may vary), physical methods can be size-selective (Sigler \& Sigler 1990). Electrofishing is biased towards larger fish, smaller individuals will often not enter traps containing larger conspecifics, and mesh size in gillnets determine the size range of fish that can be captured (Bayley \& Austen 2002, Prchalová et al. 2009, Muthmainnah et al. 2014). The removal of larger individuals has been known to result in maturation at smaller size for the remaining population (Funakoshi 1992, Trippel 1995, de Roos et al. 2006, Syslo et al. 2011, Bodin et al. 2012). Work by Karatayev et al. (2015) suggests that earlier maturation, combined with stage-specific harvest strategies could increase the chances of an overcompensatory response, and therefore could explain the higher frequency of compensation I observed among removal efforts primarily utilizing electrofishing.

The connectivity of a site can theoretically enhance or reduce a population's compensatory potential, and the analysis showed that compensation was most frequent among sites with variable connectivity. Open populations should have higher rates of immigration than closed systems, and thus compensation may occur due to increased recruitment from nearby populations when local abundance decreases. Closed populations should have greater larval or juvenile retention, thus creating a tighter stock- 
recruitment relationship compared to open systems. Populations with variable connectivity may have greater compensatory potential compared to closed or open populations since they switch between the two states and thus may experience periods of high immigration, including for adults, and periods of high larval retention

Alternatively, the recruitment increases that I took as evidence of compensation for sites with variable connectivity could result from access to more habitat and associated resources when the site switches from an effectively closed system to one that is more open. Several studies have shown that when aquatic species gain access to more habitat (e.g., dam removals, floodplain inundation) that abundance of the previously restricted population increases (Bajer \& Sorensen 2010, Marks et al. 2010, Phelps et al. 2015). One limitation of my analysis was that I could only estimate connectivity based on physical barriers. Other phenomenon, such as winter-hypoxia, can limit access to habitats as effectively as a physical barrier (Bajer \& Sorensen 2010). Given that environmental barriers can be seasonal, a habitat that appears open based on physical barriers may in fact have variable connectivity. Any future examinations on the relationship between connectivity and compensation should take non-physical barriers into account.

Compensation was more common among efforts targeting sites $>1$ ha, potentially due to increased costs in terms of effort and resources, particularly for physical removal methods which are generally labor intensive (Halfyard 2010). Additionally, the efficacy of removal methods such as electrofishing is reduced in larger and more complex systems (Sutherland 2006, Kolar et al. 2010). As a result, removal efforts targeting larger sites may be more likely to reduce abundances enough to result in a compensatory response 
through the reduction of intraspecific pressures but not enough to overcome the increase in recruitment and ultimately reduce the target population. However, because removal area size was missing from several case studies and was highly skewed overall, I categorized the case studies into two broad categories $(\leq 1 \mathrm{ha},>1 \mathrm{ha})$ and was unable to perform a more nuanced analysis. As a result, I suggest that the relationship between compensation and removal area size warrants further investigation provided sufficient, accurate site dimensions can be obtained.

Although a potentially powerful predictor of compensation, I did not include density-dependent recruitment as a predictor for several reasons. First, the outcome of removal efforts targeting species with density-dependent recruitment was quite variable. Many of the species with evidence for density-dependent recruitment (cannibalism of juveniles, density-dependent fecundity, density-dependent growth), including Cyprinus carpio (Carlander 1969), Micropterus dolomieu (Brown et al. 2009), Perca fluviatilis (Ludgate \& Closs 2003), Sylvanias fontinalis (Carlander 1969, Utz \& Hartman 2009), Salvelinus namaycush (Martin 1970, Healy 1978), showed evidence for compensation in some case studies but not in others. Given that the degree of density-dependent recruitment isn't reliably reported for all studies and differs for a given species across locations, I could not reasonably include it in my model even if it is an important predictor of compensation. Second, I found evidence of density-dependent fecundity for one species (Ictalurus punctatus), which showed evidence of compensation but for which I could not find evidence of density-dependent recruitment (Hines 2014). While fecundity is not always directly linked to recruitment, I would consider it weak evidence of density- 
dependent recruitment. Third, my inability to find strong evidence of density-dependent recruitment may result from a lack of research on the species rather than a true representation of the species recruitment process.

Lack of site-specific or removal-specific information prevented inclusion of additional, potentially important predictor variables. The effort employed by managers to remove a targeted species will influence if and when sufficient numbers of the target species have been removed from a population to a) trigger a compensatory increase in recruitment and b) for species with potential for moderate to strong Allee effects, reduce the population to a level where Allee effects will negate that response (Jonzén \& Lundberg 1999, Zipkin et al. 2009). However, removal efforts in the review often used measures of effort that were incomparable, even among those that employed the same removal techniques (e.g., time spent electrofishing, number of electrofishing passes, and area covered during electrofishing) (Smith et al. 1996, Meyer et al. 2006, Weidel et al. 2007). Although uniformity in measures of effort across all removal efforts is unlikely, access to additional information in supplemental documentation would improve comparisons across removals. Additionally, I suggest that managers record environmental data that influence local reproduction and survival (e.g., water temperature) and consider them as potentially influencing the success of removal (Mills et al. 1996, Van Der Kraak \& Pankhurst 1997, Beitinger et al. 2000, Xu et al. 2010, Fernández-Chacón et al. 2015). Finally, while the effect of removal site area was examined across broad categories in this study $(\leq 1$ ha $<)$, more detailed site data would have allowed for a more detailed and informative analysis. 
The potential for a population to compensate in response to removal efforts may be influenced by the timing of removal efforts. Removal efforts are often timed to occur prior to spawning in an effort to reduce the number of potential reproductive individuals and subsequently reduce recruitment (Ludgate \& Closs 2003, Britton et al. 2010, Pacas \& Taylor 2015). Timing of removal efforts that coincide with spawning events can take advantage of mating-associated aggregation behavior to increase catch rates (Rost 1989, Shepard et al. 2014). However, if the population is not sufficiently reduced prior to spawning, the removal effort may simply benefit the remaining reproductive individuals and their offspring through the reduction of negative density-dependent pressures. Pacas $\&$ Taylor (2015) suggested managers wishing to avoid compensatory recruitment should attempt intense efforts to remove all reproductive fish prior to reproduction. Additionally, the age of a population (time since establishment) could also influence its response to harvest. Older populations are more likely to be near their carrying capacity and thus should be more likely to compensate in response to reductions in abundance (Péron 2013). Although there was insufficient data for an in depth analysis of the role of removal effort timing in regards to the target population's reproduction and time since establishment, these variables warrant further investigation.

While my analysis shows that the majority of unsuccessful removal efforts showed signs of compensation, it is possible that my observations of high juvenile recruitment may instead result from the recovery of a population in response to an unsuccessful removal effort. However, I think this is unlikely for several reasons. While the opinions of the authors were not used to determine if a case study showed evidence of 
compensation, of the 13 case studies I classified as unsuccessful with evidence of compensation, the authors of 12 of the case studies mentioned compensation as a potential cause for the unsuccessful removal. Additionally, the measurements of abundance used to determine if compensation had occurred were taken while the removal efforts were still ongoing. As a result, these populations were still suffering enhanced mortality while increases in juvenile abundance occurred and not rebounding after the completion of removal efforts.

Compensatory recruitment by a population targeted for removal can lead to negative consequences for efforts to remove aquatic species. While recruitment must be density-dependent for a population to compensate in response to removal efforts, other factors influence whether or not compensation will occur. A full understanding of how a population will respond to harvest can be prohibitive in terms of time and data required (Rose et al. 2001). This review evaluated a number of potentially important factors and found several which were indeed significantly related to the occurrence of compensation. The findings of this review provide criteria for managers to determine the relative risk of compensation for a removal effort prior to the start of removal. Additionally, this review provides further evidence of the potential impacts of size-selective mortality on population growth rates. Increased availability of data on failed removal efforts and the inclusion of more site-specific details in future removal efforts would allow for a more detailed and beneficial examination of how data that is typically available to managers could be utilized to predict compensation resulting from removal efforts. 


\section{Conclusions}

The goal of my research was to examine how inter- and intraspecific interactions of non-native species may counteract lethal biotic factors that might otherwise prevent their establishment or limit their abundance. I tested if naïve specimens of an introduced species could recognize cues of risk of attack from novel recipient range predators that could be used to reduce their risk of predation through the expression of inducible defenses. Additionally, I developed and evaluated a series of experiments designed to measure intraspecific pressures of a non-native population and estimate the overcompensatory potential of the population in response to harvest. Finally, I performed a literature review to assess how compensatory recruitment in response to harvest affects the outcome of removal efforts and if typically available information on the target area and removal methodology could provide insight into the risk of compensation, or worse, overcompensation.

Unlike specimens of Nuttallia obscurata collected in the Northeast Pacific, specimens from their native range in Japan did not increase their burrowing depth in the presence of cues from the predatory Metacarcinus magister. However, in the absence of cues signaling the risk of predation, Japanese $N$. obscurata burrowed significantly deeper than their introduced counterparts, and thus newly introduced N. obscurata may have experienced reduced predation due to deeper, if less plastic, burrowing depth. While my findings suggest that it is unlikely that inducible defenses influenced the initial survival of newly arrived $N$. obscurata, inducible defenses may contribute to the continued success of N. obscurata in the Northeast Pacific. Non-natives species that respond to 
conspecific alarm cues or whose native predators are similar to those found in the recipient range may be better able to express inducible defenses, and thus gain protection during the initial stages of invasion. Previous findings have shown that the expression of anti-predator defenses can change over only a few generations (Thompson 1998, Yoshida et al. 2003, Nunes et al. 2014, Berthon 2015), and thus inducible defenses could easily change rapidly to enhance success. My novel approach of using specimens collected from the invaders native range provided evidence of the variable nature of inducible defenses throughout the invasion process. I encourage further investigation into changes into the expression of inducible defense across generations and the role inducible defenses may play in lag times of invasion.

My experiments with Carcinus maenas was the first attempt to my knowledge of the use of field experiments to determine if an invasive population would overcompensate as a result of removal efforts. The results of these experiments, in conjunction with previously recorded details on the life history of $C$. maenas, suggested overcompensation in Bodega Harbor was a possible, but unlikely, response to ongoing removal efforts. This conclusion was supported by a lack of any large increase in juvenile or overall abundance in Bodega Harbor compared to nearby bays where steps to remove C. maenas had not taken place. While the results of this analysis can only be confidently applied to Bodega Harbor, the general approach could be utilized to assess other populations of $C$. maenas targeted for removal or modified for use with other non-native species. The site specificity of these findings is supported by a possibly compensatory 
increase in juvenile abundance after a multi-year effort to remove $C$. maenas from Seadrift Lagoon, an artificial water body in Northern California (Grosholz pers. com.)

Given that best management practices for invasive species management promote rapid removal after detection, there may be insufficient data or time for statistical or experimental examination of the compensatory or overcompensatory potential of a population (Hobbs \& Humphriest 1995, Myers et al. 2000, Rejmánek \& Pitcairn 2002). My review of attempts to remove invasive aquatic animals showed a significant relationship between several variables, which are available to managers (e.g., removal method and techniques to be used, removal site area, and removal site connectivity, removal site connectivity), and evidence of compensation resulting from removal efforts. In particular, electrofishing had a strong association with compensation possibly because this method is biased towards the removal of larger individuals (Sigler \& Sigler 1990, Halfyard 2010, Kolar et al. 2010) allows maturation at a smaller size, potentially decreasing the size at maturation for the population (Funakoshi 1992, Trippel 1995, de Roos et al. 2006, Syslo et al. 2011, Bodin et al. 2012) and earlier onset of reproduction that increases the overall population growth rate (Karatayev et al. 2015). Factors such as removal technique and habitat connectivity could be used by managers to determine if a planned removal effort has an increased likelihood of resulting in compensation. More site-specific details should be included in future records of removal efforts to allow for the development of more detailed and powerful tools to predict compensation resulting from removal efforts. 
My research has contributed to our understanding of how populations of aquatic non-native species establish and endure in new locations while facing lethal pressures from predators and humans. Despite only having been applied thus far to a small subset of populations and species, the work presented here has the potential for wider development and use. By comparing responses of non-natives from their introduced and native ranges, we can gain further insight into how these species overcome biotic resistance. If the expression of inducible defenses changes throughout the invasion process it could alter not only the efficacy of biotic resistance but biocontrol efforts as well. My work expands upon our understanding of the effects of large scale mortality on population growth in aquatic systems. While much of what I examined is related to human-caused mortality, my conclusions could be applied to the response of other species (native or non-native) to other large scale sources of mortality (e.g., diseases). The results of my research further highlight the site-specific nature of compensation and overcompensation, but suggest that certain population and site specific characteristics may provide some indication of compensatory potential. The prospect of assessing compensatory and overcompensatory potential of a population prior to removal will allow for more informed planning, which in turn will increase the chances of successful mitigation efforts or avoid resource expenditure on unfeasible efforts. 


\section{References}

Abrams P (2009) When does greater mortality increase population size? The long history and diverse mechanisms underlying the hydra effect. Ecol Lett 12:462-74

Alpert P (2006) The advantages and disadvantages of being introduced. Biol Invasions $8: 1523-1534$

Auster PJ, Crockett LR (1984) Foraging tactics of several crustacean species for infaunal prey. J Shellfish Res 4:139-143

Bajer PG, Sorensen PW (2010) Recruitment and abundance of an invasive fish, the common carp, is driven by its propensity to invade and reproduce in basins that experience winter-time hypoxia in interconnected lakes. Biol Invasions 12:11011112

Bates D, Mächler M, Bolker B, Walker S (2015) Fitting Linear Mixed-Effects Models Using lme4. J Stat Softw 67

Bax N, Hayes K, Marshall A, Parry D, Thresher R (2000) Man-made marinas as sheltered islands for alien marine organisms : Establishment and eradication of an alien invasive marine species. In: Veitch CR, Clout MN (eds) Turning the tide: the eradication of invasive species. IUCN SSC Invasive Species Specialist Group., IUCN, Gland, Switzerland and Cambridge, UK., p 26-39

Bayley PB, Austen DJ (2002) Transactions of the American Fisheries Society Capture Efficiency of a Boat Electrofisher. Trans Am Fish Soc 131:435-451

Beeby A, Brennan A-M (2008) First ecology: Ecological principles and environmental issues. Oxford University Press

Beitinger TL, Bennet WA, McCauly RW (2000) Temperature Tolerances of North American Freshwater Fishes Exposed to Dynamic Changes in Temperature. Environ Biol Fishes 58:237-275

Bernatis JL, Warren GL (2014) Effectiveness of a Hand Removal Program for Management of Nonindigenous Apple Snails in an Urban Pond. Southeast Nat 13:607-618

Berthon K (2015) How do native species respond to invaders? Mechanistic and traitbased perspectives. Biol Invasions 17:2199-2211

Best AS, Johst K, Münkemüller T, Travis JMJ (2007) Which species will succesfully track climate change? The influence of intraspecific competition and density dependent dispersal on range shifting dynamics. Oikos 116:1531-1539 
Beverton RJH, Holt SJ (1957) On the Dynamics of Exploited Fish Populations. Fish Investig 2:533

Blackburn TM, Cassey P, Duncan RP, Evans KL, Gaston KJ (2004) Avian Extinction and Mammalian Introductions on Oceanic Islands. Science 305:1955-1958

Blundon JA, Kennedy VS (1982) Refuges for infaunal bivalves from blue crab, Callinectes sapidus, predation in Chesapeake Bay (USA). J Exp Mar Bio Ecol 65:67-82

Bodin M, Brännström Å, Dieckmann U (2012) A Systematic Overview of HarvestingInduced Maturation Evolution in Predator-Prey Systems with Three Different LifeHistory Tradeoffs. Bull Math Biol 74:2842-2860

Boogaard MA, Bills TD, Selgeby JH, Johnson DA (1996) Evaluation of piscicides for control of ruffe. North Am J Fish Manag 16:600-607

Borenstein M, Hedges LV, Higgins JPT, Rothstein HR (2009) Introduction to MetaAnalysis. John Wiley \& Sons, Ltd.

Bourdeau P (2009) Prioritized phenotypic responses to combined predators in a marine snail. Ecology 90:1659-1669

Bourdeau PE (2010) Cue reliability, risk sensitivity and inducible morphological defense in a marine snail. Oecologia 162:987-94

Bourdeau PE (2011) Constitutive and inducible defensive traits in co-occurring marine snails distributed across a vertical rocky intertidal gradient. Funct Ecol 25:177-185

Boyce MS, Sinclair ARE, White GC (1999) Seasonal compensation of predation and harvesting. Oikos 87:419-426

Brastrup TJ (2001) Knife Lake and Knife River Rehabilitation Project. Rotenone in Fisheries: Are the rewards worth the risks? 9-28

Britton JR, Brazier M (2006) Eradicating the invasive topmouth gudgeon, Pseudorasbora parva, from a recreational fishery in northern England. Fish Manag Ecol 13:329-335

Britton JR, Brazier M, Davies GD, Chare SI (2008) Case studies on eradicating the Asiatic cyprinid Pseudorasbora parva from fishing lakes in England to prevent their riverine dispersal. Aquat Conserv Mar Freshw Ecosyst 18:867-876

Britton JR, Davies GD, Brazier M (2010) Towards the successful control of the invasive Pseudorasbora parva in the UK. Biol Invasions 12:125-131

Britton JR, Gozlan RE, Copp GH (2011) Managing non-native fish in the environment. 
Fish and Fisheries 12:256-274

Broekhuysen GJ (1936) On development, growth and distribution of Carcinides Maenas (L.). Joh. Enschede en Zonen, Haarlem

Brown TG, Runciman B, Pollard S, Grant A, Bradford MJ (2009) Biological Synopsis of Smallmouth Bass (Micropterus dolomieu). Can Manuscr Rep Fish Aquat Sci 2884:318-322

Bruno JF, Fridley JD, Bromberg KD, Bertness MD (2005) Insights into Biotic Interactions from Studies of Species Invasions. In: Sax DF, Stachowicz JJ, Gaines SD (eds) Species Invasions: Insights into Ecology, Evolution, and Biogeography. Sinauer Associates. Inc

Bruno JF, O'Connor MI (2005) Cascading effects of predator diversity and omnivory in a marine food web. Ecol Lett 8:1048-1056

Buckley Y, Hinz H, Matthies D, Rees M (2001) Interactions between density-dependent processes, population dynamics and control of an invasive plant species, Tripleurospermum perforatum (scentless chamomile). Ecol Lett 4:551-558

Bückmann D, Adelung D (1964) Der Einfluß der Umweltfaktoren auf das Wachstum und den Häutungsrhythmus der Strandkrabbe Carcinides maenas. Helgoländer wissenschaftliche Meeresuntersuchungen 10:91-103

Buktenica MW, Hering DK, Girdner SF, Mahoney BD, Rosenlund BD (2013) Eradication of Nonnative Brook Trout with Electrofishing and Antimycin-A and the Response of a Remnant Bull Trout Population. North Am J Fish Manag 33:117-129

Byers J (2002) Physical habitat attribute mediates biotic resistance to non-indigenous species invasion. Oecologia 130:146-156

Carlander KD (1969) Handbook of Freshwater Fishery Biology, Vol. 1. Iowa State University Press, Ames

Carlton J, Cohen A (2003) Episodic global dispersal in shallow water marine organisms: the case history of the European shore crabs Carcinus maenas and C. aestuarii. J Biogeogr 30:1809-1820

Carlton J, Geller J (1993) Ecological roulette: the global transport of nonindigenous marine organisms. Science 261:78-82

Carmona-Catot G, Moyle PB, Aparicio E, Crain PK, Thompson LC, García-Berthou E (2010) Brook Trout Removal as a Conservation Tool to Restore Eagle Lake Rainbow Trout. North Am J Fish Manag 30:1315-1323 
Carriker MR (1955) Critical review of biology and control of oyster drills Urosalpinx and Eupleura. US Department of the Interior, Fish and Wildlife Service.

Carthey AJR, Banks PB (2014) Naïveté in novel ecological interactions: Lessons from theory and experimental evidence. Biol Rev 89:932-949

Case T (1990) Invasion resistance arises in strongly interacting species-rich model competition communities. Proc Natl Acad Sci 87:9610-9614

Caskey LL, Riedel RR, Costa-Pierce B, Butler J, Hurlbert SH (2007) Population dynamics, distribution, and growth rate of tilapia (Oreochromis mossambicus) in the Salton Sea, California, with notes on bairdiella (Bairdiella icistia) and orangemouth corvina (Cynoscion xanthulus). Hydrobiologia 576:185-203

Castorani MCN, Hovel KA (2016) Native predator chemical cues induce anti-predation behaviors in an invasive marine bivalve. Biol Invasions 18:169-181

Catford JA, Jansson R, Nilsson C (2009) Reducing redundancy in invasion ecology by integrating hypotheses into a single theoretical framework. Divers Distrib 15:22-40

Caudron A, Champigneulle A (2011) Multiple electrofishing as a mitigate tool for removing nonnative Atlantic brown trout (Salmo trutta L.) threatening a native Mediterranean brown trout population. Eur J Wildl Res 57:575-583

Chapman WM, Banner AH (1949) Contributions to the life history of the Japanese oyster drill, Tritonalia japonica, with notes on other enemies of the Olympia oyster, Ostrea lurida. State of Washington, Department of Fisheries.

Christensen SW, Goodyear CP (1988) Testing the validity of stock-recruitment curve fits. Am Fish Soc Monogr 4:219-231

Cisterne A, Vanderduys EP, Pike DA, Schwarzkopf L (2014) Wary invaders and clever natives: Sympatric house geckos show disparate responses to predator scent. Behav Ecol 25:604-611

Claessen D, Roos AM de, Persson L (2004) Population dynamic theory of size-dependent cannibalism. Proc R Soc London B 271:333-340

Coan EV, Scott PV, Bernard ER (2000) Bivalve seashells of western North America; Marine bivalve mollusks from Arctic Alaska to Baja California. Santa Barbara Museum Natural History, Santa Barbara, California, USA

Coggins Jr. LG, Yard MD, Pine III WE (2011) Nonnative Fish Control in the Colorado River in Grand Canyon, Arizona: An Effective Program or Serendipitous Timing? Trans Am Fish Soc 140:456-470 
Colautti RI, Ricciardi A, Grigorovich IA, MacIsaac HJ (2004) Is invasion success explained by the enemy release hypothesis? Ecol Lett 7:721-733

Cooper C, Hunt CD, Dingus C, Libby PS, Kirkbride G (2012) Assessing ballast treatment standards for effect on rate of establishment using a stochastic model of the green crab. Comput Ecol Softw 2:53-69

Coutts ADM, Forrest BM (2007) Development and application of tools for incursion response: Lessons learned from the management of the fouling pest Didemnum vexillum. J Exp Mar Bio Ecol 342:154-162

Cowen RK, Lwiza KM, Sponaugle S, Paris CB, Olson DB (2000) Connectivity of Marine Populations: Open or Closed? Science 287:857-859

Crawley MJ (2005) Statistics: An Introduction Using R. John Wiley \& Sons, Limited, Hoboken, NJ

Crooks J (2005) Lag times and exotic species: The ecology and management of biological invasions in slow-motion. Ecoscience 12:316-329

Culver CS, Kuris AM (2000) The apparent eradication of a locally established introduced marine pest. Biol Invasions 2:245-253

Curtis DL, Sauchyn L, Keddy L, Therriault TW, Pearce CM (2012) Prey Preferences and Relative Predation Rates of Adult European Green Crabs (Carcinus maenas) Feeding on Various Bivalve Species in British Columbia, Canada. Can Tech Rep Fish Aquat Sci 3014:iv + 14 p

Dana ED, López-Santiago J, García-de-Lomas J, García-Ocaña DM, Gámez V, Ortega F (2010) Long-term management of the invasive Pacifastacus leniusculus (Dana, 1852 ) in a small mountain stream. Aquat Invasions 5:317-322

Dao TS, Tran LTT, Vo TMC, Bui BT (2016) Toxicity of Zinc Dissolved In Saigon River to the Tropical Micro-Crustacean Daphnia Lumholtzi. Environ Manag Sustain Dev $5: 170$

Davidson TM, Rivera CE de (2012) Per Capita Effects and Burrow Morphology of a Burrowing Isopod (Sphaeroma quoianum) in Different Estuarine Substrata. J Crustac Biol 32:25-30

Delmott SE, Edds DR (2014) Zebra mussel maturation and seasonal gametogenesis in Marion Reservoir, Kansas, USA. BioInvasion Rec 3:247-260

Dennis B, Desharnais R, Cushing J, Costantino R (1997) Transitions in population dynamics: equilibria to periodic cycles to aperiodic cycles. J Anim Ecol 66:704-729 
DeWitt TJ, Sih A, Wilson DS (1998) Costs and limits of phenotypic plasticity. Trends Ecol Evol 13:77-81

DFO (2011) Ecological Assessment of the Invasive European Green Crab (Carcinus maenas) In Newfoundland 2007-2009.

Diggle J, Day J, Bax N (2004) Eradicating European carp from Tasmania and implications for national European carp eradication. Inland Fisheries Service, Hobart.

Dill LM (1974) The escape response of the zebra danio (Brachydanio rerio). I. The stimulus for escape. Anim Behav 22:711-722

Donald DB, Alger DJ (1989) Evaluation of exploitation as a means of improving growth in a stunted population of brook trout. North Am J Fish Manag 9:177-183

Donkers P, Patil JG, Wisniewski C, Diggle JE (2012) Validation of mark-recapture population estimates for invasive common carp, Cyprinus carpio, in Lake Crescent, Tasmania. J Appl Ichthyol 28:7-14

Dudas SE, McGaw IJ, Dower JF (2005) Selective crab predation on native and introduced bivalves in British Columbia. J Exp Mar Bio Ecol 325:8-17

Dumont CP, Gaymer CF, Thiel M (2011) Predation contributes to invasion resistance of benthic communities against the non-indigenous tunicate Ciona intestinalis. Biol Invasions 13:2023-2034

Duncombe LG (2014) Evaluating trapping as a method to control the European green crab, Carcinus maenas, population at Pipestem Inlet, British Columbia. Royal Roads University

Dunlop E, Shuter B, Ridgway M (2005) Isolating the influence of growth rate on maturation patterns in the smallmouth bass (Micropterus dolomieu). Can J Fish Aquat Sci 62:844-853

Dunstone N (1993) The mink. T. \& AD Poyser, London

Dzialowski AR, Lennon JT, O'Brien WJ, Smith VH (2003) Predator-induced phenotypic plasticity in the exotic cladoceran Daphnia lumholtzi. Freshw Biol 48:1593-1602

Earle JE, Lajeunesse BL (2007) Evaluation of a Brook Trout Removal Project to Establish Westslope Cutthroat Trout in Canmore Creek, Alberta. In: Wild Trout IX Sustaining Wild Trout in a Changing World.p 82-89

Edelaar P, Drent J, Goeij P De (2003) A double test of the parasite manipulation hypothesis in a burrowing bivalve. Oecologia 134:66-71 
Eilers JM, Truemper HA, Jackson LS, Eilers BJ, Loomis DW (2011) Eradication of an invasive cyprinid (Gila bicolor) to achieve water quality goals in Diamond Lake, Oregon (USA). Lake Reserv Manag 27:194-204

Everett R, Ruiz G (1993) Coarse woody debris as a refuge from predation in aquatic communities. Oecologia 93:475-486

Fernández-Chacón A, Genovart M, Álvarez D, Cano JM, Ojanguren AF, Rodriguez Muñoz R, Nicieza AG (2015) Neighbouring populations, opposite dynamics: influence of body size and environmental variation on the demography of streamresident brown trout (Salmo trutta). Oecologia 178:379-389

Ferner M, Smee D, Chang Y (2005) Cannibalistic crabs respond to the scent of injured conspecifics: danger or dinner? Mar Ecol Prog Ser 300:193-200

Finney S, Haines G (2008) Northern Pike Removal, Smallmouth Bass Monitoring, and Native Fish Monitoring in the Yampa River, Hayden to Craig Reach, 2004-2006. Upper Colorado River Basin Endangered Fish Recovery Program, Project 143.

Firth LB, Knights AM, Bell SS (2011) Air temperature and winter mortality: Implications for the persistence of the invasive mussel, Perna viridis in the intertidal zone of the south-eastern United States. J Exp Mar Bio Ecol 400:250-256

Flueck WT (2004) Observations of interactions between Puma, Puma concolor, and introduced European Red Deer, Cervus elaphus, in Patagonia. Can Field-Naturalist 118:132-134

Flueck WT, Smith-Flueck JM (1993) Über das in Argentinien angesiedelte Rotwild (Cervus elaphus L., 1758): Verbreitung und Tendenzen. Z Jagdwiss 39:153-160

Flynn AM, Smee DL (2010) Behavioral plasticity of the soft-shell clam, Mya arenaria (L.), in the presence of predators increases survival in the field. J Exp Mar Bio Ecol 383:32-38

Forrester GE, Steele MA (2004) Predators, Prey Refuges, and the Spatial Scaling of Density-Dependent Prey Mortality. Ecology 85:1332-1342

Forsyth R (1993) Nuttallia obscurata, an introduced bivalve (Psammobiidae) in British Columbia. Vancouver Shell News

Fox L (1975) Cannibalism in natural populations. Annu Rev Ecol Syst 6:87-106

Freeman AS, Byers JE (2006) Divergent Induced Responses to an Invasive Predator in Marine Mussel Populations. Science 313:831-833

Freeman AS, Meszaros J, Byers JE (2009) Poor phenotypic integration of blue mussel 
inducible defenses in environments with multiple predators. Oikos 118:758-766

Freeman M, Turnbill J, Yeomans W, Bean C (2010) Prospects for management strategies of invasive crayfish populations with an emphasis on biological control. Aquat Conserv Mar Freshw Ecosyst 20:211-223

Fuller MH (2009) Lower Yampa River Channel Catfish and Smallmouth Bass Control Program, Colorado, 2001-2006. US Fish and Wildlife Service, Vernal, Utah. Vernal, Utah

Funakoshi S (1992) Relationship between stock levels and the population structure of the Japanese anchovy. Mar Freshw Behav Phy 21:1-84

Galil B, Zenetos A (2002) A sea change - exotics in the eastern Mediterranean Sea. In: Leppäkoski E, Gollasch S, Olenin S (eds) Invasive aquatic species of Europe: distribution, impacts and management. Kluwer Academic Publishers, Dordrecht, Netherlands

Garner YL, Litvaitis MK (2013) Effects of injured conspecifics and predators on byssogenesis, attachment strength and movement in the blue mussel, Mytilus edulis. J Exp Mar Bio Ecol 448:136-140

Geller JB, Walton ED, Grosholz ED, Ruiz GM (1997) Cryptic invasions of the crab Carcinus detected by molecular phylogeography. Mol Ecol 6:901-906

Gherardi F, Aquiloni L, Diéguez-Uribeondo J, Tricarico E (2011) Managing invasive crayfish: Is there a hope? Aquat Sci 73:185-200

Gillespie GE, Parker M, Merilees W (1999) Distribution, abundance, biology and fisheries potential of the exotic varnish clam, (Nuttallia obscurata) in British Columbia. Department of Fisheries and Oceans.

Glude J (1955) The effects of temperature and predators on the abundance of the softshell clam, Mya arenaria, in New England. Trans Am Fish Soc 84:13-26

Goeij P De, Luttikhuizen P (1998) Deep-burying reduces growth in intertidal bivalves: Field and mesocosm experiments with Macoma balthica. J Exp Mar Bio Ecol 228:327-337

Goldschmidt T, Witte F, Wanink J (1993) Society for Conservation Biology Cascading Effects of the Introduced Nile Perch on the Detritivorous / Phytoplanktivorous Species in the Sublittoral Areas of Lake Victoria. Conserv Biol 7:686-700

Goodyear CP (1993) Spawning stock biomass per recruit in fisheries management: foundation and current use. In: Smith SJ, Hunt JJ, Rivard D (eds) Risk evaluation and biological reference points for fisheries management No. 120. Canadian Special 
Publication of Fisheries and Aquatic Sciences, p 67-82

Gotelli NJ (2008) A Primer of Ecology, Fourth Edition, 4th edn. Sinauer Associates. Inc, Sunderland, MA

Govindarajulu P, Altwegg R, Anholt B (2005) Matrix model investigation of invasive species control: bullfrogs on Vancouver Island. Ecol Appl 15:2161-2170

Grabowski J, Kimbro D (2005) Predator-avoidance behavior extends trophic cascades to refuge habitats. Ecology 86:1312-1319

Grason EW, Miner BG (2012) Behavioral plasticity in an invaded system: non-native whelks recognize risk from native crabs. Oecologia 169:105-15

Gresswell R (1991) Use of antimycin for removal of brook trout from a tributary of Yellowstone Lake. North Am J Fish Manag 11:83-90

Griffiths CL, Richardson CA (2006) Chemically induced predator avoidance behaviour in the burrowing bivalve Macoma balthica. J Exp Mar Bio Ecol 331:91-98

Grosholz E (2002) Ecological and evolutionary consequences of coastal invasions. Trends Ecol Evol 17:22-27

Grosholz E, Lovell S, Besedin E, Katz M (2011) Modeling the impacts of the European green crab on commercial shellfisheries. Ecol Appl 21:915-924

Grosholz E, Ruiz G, Dean C, Shirley K, Maron J, Connors P (2000) The impacts of a nonindigenous marine predator in a California bay. Ecology 81:1206-1224

Halfyard E (2010) A review of options for the containment, control and eradication of illegally introduced smallmouth bass (Micropterus dolomieu). Department of Fisheries and Oceans, Gulf Region, Oceans and Science Branch.

Harvell CD (1990) The ecology and evolution of inducible defenses. Q Rev Biol 65:323340

Harvey BC, White JL, Nakamoto RJ (2004) An emergent multiple predator effect may enhance biotic resistance in a stream fish assemblage. Ecology 85:127-133

Havel JE, Mabee WR, Jones JR (1995) Invasion of the exotic cladoceran Daphnia lumholtzi into North American reservoirs. Can J Fish Aquat Sci 52:151-160

Hawkins J, Walford C, Hill A (2009) Smallmouth Bass control in the middle Yampa River, 2003-2007. Final Report to the Upper Colorado River Endangered Fish Recovery Program, Project 125. 
Healy MC (1978) Dynamics of exploited lake trout populations and implications for management. J Wildl Manage 42:307-328

Heck K, Thoman T (1981) Experiments on predator-prey interactions in vegetated aquatic habitats. J Exp Mar Bio Ecol 53:125-134

Hein CL, Roth BM, Ives AR, Zanden JM Vander (2006) Fish predation and trapping for rusty crayfish (Orconectes rusticus) control: a whole-lake experiment. Can J Fish Aquat Sci 63:383-393

Hewitt CL, Campbell ML (2007) Mechanisms for the prevention of marine bioinvasions for better biosecurity. Mar Pollut Bull 55:395-401

Hierro JL, Maron JL, Callaway RM (2005) A biogeographical approach to plant invasions: The importance of studying exotics in their introduced and native range. $\mathrm{J}$ Ecol 93:5-15

Hill JE, Sowards J (2015) Successful eradication of the non-native loricariid catfish Pterygoplichthys disjunctivus from the Rainbow River, Florida. Manag Biol Invasions 6:311-317

Hines B (2014) Endangered Fish Monitoring and Nonnative Fish Control in the Lower San Juan River 2013, Final Report. Utah Division of Wildlife Resources for San Juan River Basin Recovery Implementation Program, US Fish and Wildlife Service, Albuquerque, New Mexico. Albuquerque, New Mexico

Hines A, Ruiz G (1995) Temporal variation in juvenile blue crab mortality: nearshore shallows and cannibalism in Chesapeake Bay. Bull Mar Sci 57:884-901

Hobbs RJ, Humphriest SE (1995) An Integrated Approach to the Ecology and Management of Plant Invasions. Conserv Biol 9:761-770

Holling CS (1959) The Components of Predation as Revealed by a Study of SmallMammal Predation of the European Pine Sawfly. Can Entomol 91:293-320

Holling CS (1961) Principles of Insect Predation. Annu Rev Entomol 6:163-182

Holling CS (1966) The functional response of invertebrate predators to prey density. Mem Entomol Soc Canada 98:5-86

Holling CS (1973) Resilience and Stability of Ecological Systems. Annu Rev Ecol Syst $4: 1-23$

Holt R, Cordingley A (2011) Eradication of the non-native carpet ascidian (sea squirt) Didemnum vexillum in Holyhead Harbour: Progress, methods and results to spring 2011. Bangor CCW 112 
Hopkins GA, Forrest BM, Jiang W, Gardner JPA (2011) Successful eradication of a nonindigenous marine bivalve from a subtidal soft-sediment environment. J Appl Ecol 48:424-431

Howard RD (1981) Sexual Dimorphism in Bullfrogs. Ecology 62:303-310

Hunt C, Yamada S (2003) Biotic resistance experienced by an invasive crustacean in a temperate estuary. Biol Invasions 5:33-43

Hutchings PAT (1993) Ballast water introductions of exotic marine organisms into Australia: current status and management options P. Hutchings, Marine Pollution Bulletin, 25(5-8), 1992, pp 196-199. Biol Conserv 25:196-199

Jamieson GS, Grosholz ED, Armstrong DA, Elner RW (1998) Potential ecological implications from the introduction of the European green crab, Carcinus maenas (Linneaus), to British Columbia, Canada, and Washington, USA. J Nat Hist 32:1587-1598

Jensen GC, Asplen MK (1998) Omnivory in the diet of juvenile dungeness crab, Cancer magister Dana. J Exp Mar Bio Ecol 226:175-182

Jensen GC, McDonald PS, Armstrong DA (2007) Biotic resistance to green crab, Carcinus maenas, in California bays. Mar Biol 151:2231-2243

Jiang W, Meng T, Chen R, Wei S (1997) Diet of Charybdis japonica (A. MilineEdwards) and portunus trituberculatus (Miers) in the Bohai Sea. Mar Fish Res 19:53-59

Johnstone I, Coffey B (1985) The role of recreational boat traffic in interlake dispersal of macrophytes: a New Zealand case study. J Environ 20:263-279

Jonzén N, Lundberg P (1999) Temporally structured density-dependence and population management. Ann Zool Fennici 36:39-44

Karatayev VA, Kraft CE, Zipkin E (2015) Racing through life : maturation rate plasticity regulates overcompensation and increases persistence. Ecosphere 6:1-12

Keane RM, Crawley MJ (2002) Exotic plant invasions and the enemy release hypothesis. Trends Ecol Evol 17:164-170

Kelso JRM, Shuter BJ (1989) Validity of the Removal Method for Fish Population Estimation in a Small Lake. North Am J Fish Manag 9:471-476

Kimbro DL, Cheng BS, Grosholz ED (2013) Biotic resistance in marine environments. Ecol Lett 16:821-833 
Kimbro DL, Grosholz ED, Baukus AJ, Nesbitt NJ, Travis NM, Attoe S, Coleman-Hulbert C (2009) Invasive species cause large-scale loss of native California oyster habitat by disrupting trophic cascades. Oecologia 160:563-75

Kishida O, Nishimura K (2005) Multiple inducible defences against multiple predators in the anuran tadpole, Rana pirica. Evol Ecol Res 7:619-631

Kishida O, Trussell G, Nishimura K (2009) Top-down effects on antagonistic inducible defense and offense. Ecology 90:1217-1226

Klassen G, Locke A (2007) A Biological Synopsis of the European Green Crab, Carcinus maenas. Can Manuscr Rep Fish Aquat Sci 2818:1-82

Knapp RA, Boiano DM, Vredenburg VT (2007) Removal of nonnative fish results in population expansion of a declining amphibian (mountain yellow-legged frog, Rana muscosa). Biol Conserv 135:11-20

Knapp RA, Matthews KR (1998) Eradication of nonnative fish by gill-netting from a small mountain lake in California. Restor Ecol 6:207-213

Koehn J, Brumley A, Gehrke P (2000) Managing the impacts of Carp. Bureau of Rural Sciences.

Koenig MK, Meyer K a., Kozfkay JR, DuPont JM, Schriever EB (2015) Evaluating the Ability of Tiger Muskellunge to Eradicate Brook Trout in Idaho Alpine Lakes. North Am J Fish Manag 35:659-670

Kolar CS, Courtenay Jr. WR, Nico LG (2010) Managing undesired or invading species. In: Hubert WA, Quist MC (eds) Inland fisheries management in North America, Third. American Fisheries Society, Bethesda, Mayland, p 213-258

Kosior M, Wandzel T (2001) Comparison of fecundity of pikeperch (Stizostedion lucioperca ) in three lagoons in the southern Baltic Sea. Bull Sea Fish Inst 3:3-27

Kraak G Van Der, Pankhurst NW (1997) Temperature effects on the reproductive performance of fish. In: Wood CM, McDonald DG (eds) Global Warming: Implications for Freshwater and Marine Fish. Cambridge University Press, p 159174

Kulp M, Moore S (2000) Multiple electrofishing removals for eliminating rainbow trout in a small southern Appalachian stream. North Am J Fish Manag 20:259-266

Langerhans RB, DeWitt TJ (2002) Plasticity constrained: Over-generalized induction cues cause maladaptive phenotypes. Evol Ecol Res 4:857-870

Lappalainen J, Dorner H, Wysujack K (2003) Reproduction biology of pikeperch (Sander 
lucioperca (L.)) - a review. Ecol Freshw Fish 12:95-106

Lazur A, Early S, Jacobs JM (2006) Acute Toxicity of 5\% Rotenone to Northern Snakeheads. North Am J Fish Manag 26:628-630

Lee DP (2001) Northern pike control at Lake Davis, California. Rotenone in Fisheries: Are the rewards worth the risks?55-61

León R de, Vane K, Bertuol P, Chamberland V, Simal F, Imms E, Vermeij M (2013) Effectiveness of lionfish removal efforts in the southern Caribbean. Endanger Species Res 22:175-182

Leonard GH, Bertness MD, Yund PO, Jan N (1999) Crab predation, waterborne cues, and inducible defenses in the blue mussel, Mytilus edulis. Ecology 80:1-14

Leppäkoski E, Olenin S, Gollasch S (2002) The Baltic Sea - a Biology, field laboratory for invasion. In: Leppäkoski E, Gollasch S, Olenin S (eds) Invasive aquatic species of Europe: distribution, impacts and management. Kluwer Academic Publishers, Dordrecht, Netherlands

Levine JM, Adler PB, Yelenik SG (2004) A meta-analysis of biotic resistance to exotic plant invasions. Ecol Lett 7:975-989

Lincoln GA (1971) Puberty in a seasonally breeding male, the red deer stag (Cervus elaphus L.). J Reprod Fertil 25:41-54

Lintermans M, Raadik T (2001) Local eradication of trout from streams using rotenone : the Australian experience. Managing invasive freshwater fish in New Zealand. Proceedings of a workshop hosted by Department of Conservation. Manag invasive Freshw fish New Zeal:95-111

Lively CM (1986) Canalization versus develomental conversion in a spatially variable environment. Am Nat 128:561-572

Locke A, Carman M, Editors G, Locke A, Hanson JM (2009) Rapid response to nonindigenous species. 1. Goals and history of rapid response in the marine environment. Aquat Invasions 4:237-247

Lockwood JL, Cassey P, Blackburn T (2005) The role of propagule pressure in explaining species invasions. Trends Ecol Evol 20:223-228

Lockwood JL, Hoopes MF, Marchetti MP (2007) Invasion Ecology. Blackwell Publishing Ltd, Carlton, Victoria, Australia

Lodge DM, Stein R a, Brown KM, Covich AP, Bronmark C, Garvey JE, Klosiewski SP (1998) Predicting impact of freshwater exotic species on native biodiversity: 
challenges in spatial scaling. Aust J Ecol 23:53-67

Loppnow GL, Vascotto K, Venturelli PA (2013) Nonnative, predatory fish removal and native fish response, upper Verde River, Arizona: Preliminary results. Manag Biol Invasions 4:191-206

Lourdes Lozano-Vilano M de, Contreras-Balderas AJ, García-Ramírez ME (2006) Eradication of Spotted Jewelfish, Hemichromis Guttatus, From Poza San José Del Anteojo, Cuatro Ciénegas Bolsón, Coahuila, Mexico. Southwest Nat 51:553-555

Lucy F (2006) Early life stages of Dreissena polymorpha (zebra mussel): The importance of long-term datasets in invasion ecology. Aquat Invasions 1:171-182

Ludgate B, Closs G (2003) Responses of fish communities to sustained removals of perch (Perca fluviatilis). Sci Conserv 210:1-38

Macarthur R, Levins R (1967) The Limiting Similarity, Convergence, and Divergence of Coexisting Species. Am Nat 101:377-385

Macdonald K (1969) Quantitative studies of salt marsh mollusc faunas from the North American Pacific coast. Ecol Monogr 39:33-59

Mack R, Simberloff D, Lonsdale W, Evans H, Clout M, Bazzas F (2000) Biotic Invasions : Causes, Epidemiology, Global Consequences , and Control. Ecol Appl 10:689-710

Mallison CT, Hestand RS, Thompson BZ (1995) Removal of Triploid Grass Carp with an Oral Rotenone Bait in Two Central Florida Lakes. Lake Reserv Manag 11:337-342

Marks JC, Haden GA, O’Neill M, Pace C (2010) Effects of Flow Restoration and Exotic Species Removal on Recovery of Native Fish: Lessons from a Dam Decommissioning. Restor Ecol 18:934-943

Markula A, Csurhes S (2009) Pest animal risk assessment Asian house gecko. Queens1 Prim Ind Fish 3:1-23

Martin N (1970) Long-term effects of diet on the biology of the lake trout and the fishery in Lake Opeongo, Ontario. J Fish Board Canada 27:125-146

McDonald JH (2014) Handbook of Biological Statistics, 3rd edn. Sparky House Publishing, Baltimore, Maryland

McKillup SC, McKillup RV (1992) Inhibition of feeding in response to crushed conspecifics by the pebble crab Philyra laevis (Bell). J Exp Mar Bio Ecol 161:33-43

Meronek TG, Bouchard PM, Buckner ER, Burri TM, Demmerly KK, Hatleli DC, Klumb 
RA, Schmidt SH, Coble DW (1996) A Review of Fish Control Projects. North Am J Fish Manag 16:63-74

Meyer KA, Lamansky Jr. JA, Schill DJ (2006) Evaluation of an Unsuccessful Brook Trout Electrofishing Removal Project in a Small Rocky Mountain Stream. North Am J Fish Manag 26:849-860

Mills E, Rosenberg G, Spindle A, Ludyanskiy M, Pligin Y, May B (1996) A review of the biology and ecology of the quagga mussel (Dreissena bugensis), a second species of freshwater dreissenid introduced to North America. Am Zool 36:271-286

Mistri M (2002) Ecological Characteristics of the Invasive Asian Date Mussel, Musculista senhousia, in the Sacca di Goro (Adriatic Sea, Italy). Estuaries 25:431440

Mitchell CE, Power AG (2003) Release of invasive plants from fungal and viral pathogens. Nature 421:625-7

Moe S, Stenseth N, Smith R (2002) Density-dependent compensation in blowfly populations give indirectly positive effects of a toxicant. Ecology 83:1597-1603

Moir F, Weissburg MJ (2009) Cautious cannibals: Behavioral responses of juvenile and adult blue crabs to the odor of injured conspecifics. J Exp Mar Bio Ecol 369:87-92

Moksnes P (2004) Self-regulating mechanisms in cannibalistic populations of juvenile shore crabs Carcinus maenas. Ecology 85:1343-1354

Moksnes P, Lipcius R, Pihl L, Montfrans J van (1997) Cannibal-prey dynamics in young juveniles and postlarvae of the blue crab. J Exp Mar Bio Ecol 215:157-187

Moore SE, Kulp MA, Hammonds J, Rosenlund B (2005) Restoration of Sams Creek and an Assessment of Brook Trout Restoration Methods Great Smoky Mountains National Park. Water Resources Division, National Park Service, Department of the Interior.

Muthmainnah D, Subagdja M, Atminarso D, Sawestri S, Makmur S (2014) Selectivity and effectiveness of different gillnet mesh sizes used in ranau lake of Sumatra. $\mathbf{J}$ Biodivers Environ Sci 5:82-89

Myers RA (2002) Recruitment: Understanding Density-Dependence in Fish Populations. In: Hart PJB, Reynolds JD (eds) Handbook of Fish Biology and Fisheries. Blackwell Publishing Ltd, Oxford, UK, p 123-148

Myers JH, Simberloff D, Kuris AM, Carey JR (2000) Eradication revisited: Dealing with exotic species. Trends Ecol Evol 15:316-320 
Naddafi R, Rudstam L (2013) Predator-induced behavioural defences in two competitive invasive species: the zebra mussel and the quagga mussel. Anim Behav 86:12751284

Nicholson A (1954) An outline of the dynamics of animal populations. Aust J Zool 2:965

Nico LG, Walsh SJ (2011) Non-indigenous freshwater fishes on tropical Pacific islands : a review of eradication efforts. In: Veitch CR, Clout MN, Towns DR (eds) Island invasives: eradication and management. IUCN, Gland, Switzerland, p 97-107

Nowak RM (1991) Walker's Mammals of the World. The Johns Hopkins University Press, Baltimore and London

Nunes AL, Orizaola G, Laurila A, Rebelo R (2014) Rapid evolution of constitutive and inducible defenses against an invasive predator. Ecology 95:1520-1530

Nussbaum R, Brodie E, Storm R (1983) Amphibians and reptiles of the Pacific Northwest. Idaho Research Foundation, Moscow, ID

Ohlberger J, Langangen Ø, Edeline E (2011) Stage-specific biomass overcompensation by juveniles in response to increased adult mortality in a wild fish population. Ecology 92:2175-2182

Ojaveer H, Galil BS, Campbell ML, Carlton JT, Canning-Clode J, Cook EJ, Davidson AD, Hewitt CL, Jelmert A, Marchini A, McKenzie CH, Minchin D, OcchipintiAmbrogi A, Olenin S, Ruiz G (2015) Classification of Non-Indigenous Species Based on Their Impacts: Considerations for Application in Marine Management. PLoS Biol 13:1-13

Pacas C, Taylor MK (2015) Nonchemical Eradication of an Introduced Trout from a Headwater Complex in Banff National Park, Canada. North Am J Fish Manag $35: 748-754$

Padilla DK, Williams SL (2004) Beyond ballast water:aquarium and ornamental trades as sources of invasive species in aquatic ecosystems. Front Ecol Env 3:131-138

Pardini EA, Drake JM, Chase JM, Knight TM (2009) Complex population dynamics and control of the invasive biennial Alliaria petiolata (garlic mustard). Ecol Appl 19:387-97

Parker JD, Burkepile DE, Hay ME (2006) Opposing Effects of Native and Exotic Herbivores on Plant Invasions. Science 311:1459-1461

Parker JD, Hay ME (2005) Biotic resistance to plant invasions? Native herbivores prefer non-native plants. Ecol Lett 8:959-967 
Parker BR, Schindler DW, Donald DB, Anderson RS (2001) The effects of stocking and removal of a nonnative salmonid on the plankton of an alpine lake. Ecosystems $4: 334-345$

Parkes JP, Panetta FD (2009) Eradication of invasive species: progress and emerging issues in the 21st century. In: Clout M, Williams P (eds) Invasive Species Management: A Handbook of Principles and Techniques. Oxford University Press, Oxford, New York, USA

Paul AJ, Post JR, Stelfox JD (2003) Can anglers influence the abundance of native and nonnative salmonids in a stream from the Canadian Rocky mountains? North Am J Fish Manag 23:109-119

Payne CM, Tillberg CV, Suarez AV (2004) Recognition systems and biological invasions. Ann Zool Fennici 41:843-858

Pearl CA, Adams MJ, Schuytema GS, Nebeker AV (2003) Behavioral Responses of Anuran Larvae to Chemical Cues of Native and Introduced Predators in the Pacific Northwestern United States. J Herpetol 37:572-576

Péron G (2013) Compensation and additivity of anthropogenic mortality: Life-history effects and review of methods. J Anim Ecol 82:408-417

Persson L, Amundsen PA, Roos AM De, Klemetsen A, Knudsen R, Primicerio R (2007) Culling prey promotes predator recovery--alternative states in a whole-lake experiment. Science 316:1743-6

Persson L, Bystrom P, Wahlstrom E (2000) Cannibalism and competition in Eurasian Perch: Population dynamics of anontogenetic omnivore. Ecology 81:1058-1071

Peterson C, Black R (1994) An experimentalist's challenge: when artifacts of intervention interact with treatments. Mar Ecol Prog Ser 111:289-297

Pham L, West D, Closs GP (2013) Reintroduction of a native galaxiid (Galaxias fasciatus) following piscicide treatment in two streams: Response and recovery of the fish population. Ecol Freshw Fish 22:361-373

Phelps QE, Tripp SJ, Herzog DP, Garvey JE (2015) Temporary connectivity: The relative benefits of large river floodplain inundation in the lower Mississippi River. Restor Ecol 23:53-56

Pinto L, Chandrasena N, Pera J, Hawkins P, Eccles D, Sim R (2005) Managing invasive carp (Cyprinus carpio L.) for habitat enhancement at Botany Wetlands, Australia. Aquat Conserv Mar Freshw Ecosyst 15:447-462

Postma JF, Buckert-de Jong MC, Staats N, Davids C (1994) Chronic toxicity of cadmium 
to Chironomus riparius (Diptera: Chironomidae) at different food levels. Arch Environ Contam Toxicol 26:143-148

Prchalová M, Kubečka J, Ř́ha M, Mrkvička T, Vašek M, Jůza T, Kratochvíl M, Peterka J, Draštík V, Krrížek J (2009) Size selectivity of standardized multimesh gillnets in sampling coarse European species. Fish Res 96:51-57

Preisser E, Bolnick D, Benard M (2005) Scared to death? The effects of intimidation and consumption in predator-prey interactions. Ecology 86:501-509

R Development Core Team (2012) R: a language and environment for statistical computing. R Foundation for Statistical Computing, Vienna, Austria. URL http://www.R-project.org/.

R Development Core Team (2014) R: a language and environment for statistical computing. R Foundation for Statistical Computing, Vienna, Austria. URL http://www.R-project.org/.

Ratcliffe PJ, Jones NV, Walters NJ (1981) The survival of Macoma balthica (L.) in mobile sediments. In: Jones NV, Wolff WJ (eds) Feeding and survival strategies of estuarine organisms. Plenum, p 91-108

Rayner TS, Creese RG (2006) A review of rotenone use for the control of non- indigenous fish in Australian fresh waters, and an attempted eradication of the noxious fish, Phalloceros caudimaculatus. New Zeal J Mar Freshw Res 40:477-486

Reading CJ, McGrorty S (1978) Seasonal variations in the burying depth of Macoma balthica (L.) and its accessibility to wading birds. Estuar Coast Mar Sci 6:135-144

Rejmánek M, Pitcairn MJ (2002) When is eradication of exotic pest plants a realistic goal? Turn tide Erad invasive species:249-253

Ricker W (1954) Stock and recruitment. J Fish Board Canada 11:559-623

Ricker WE (1975) Computation and interpretation of biological statistics of fish populations. Bull Fish Res Board Canada:401

Rivera C de, Grosholz E, Ruiz G (2011) Multiple and long-term effects of an introduced predatory crab. Mar Ecol Prog Ser 429:145-155

Rivera CE de, Grosholz ED, Ruiz GM, Turner BC, Brown CW, Steves BP, Larson AL (2010) Final Report for Pacific States Marine Fisheries Commission Green crab control methods, Phase $3 \& 3 \mathrm{~b}$ : Expanding capacity to control European Green Crab populations in the Northeast Pacific.

Rivera C de, Ruiz G, Hines A, Jivoff P (2005) Biotic resistance to invasion: native 
predator limits abundance and distribution of an introduced crab. Ecology 86:33643376

Roberts D, Rittschof D, Gerhart D, Shmidt A, Hill L (1989) Vertical Migration of the Clam Mercenaria-Mercenaria (L.) (Mollusca, Bivalvia): Environmental Correlates and Ecological Significance. J Exp Mar Bio Ecol 126:271-280

Rockwood LL (2006) Introduction to Population Ecology. Blackwell Publishing Ltd, Carlton, Victoria, Australia

Rodríguez G (2007) Lecture Notes on Generalized Linear Models. URL: http://data.princeton.edu/wws509/notes/.

Roos AM de, Boukal DS, Persson L (2006) Evolutionary regime shifts in age and size at maturation of exploited fish stocks. Proc Biol Sci 273:1873-80

Roos A De, Schellekens T, Kooten T van, Wolfshaar K van de, Claessen D, Persson L (2007) Idependent growth leads to overcompensation in stage-specific biomass when mortality increases: the influence of maturation versus reproduction regulation. Am Nat 170:E59-76

Rose KA, Cowan JH (2000) Predicting fish population dynamics: compensation and the importance of site-specific considerations. Environ Sci Policy 3:433-443

Rose KA, Cowan JH, Winemiller KO, Myers RA, Hilborn R (2001) Compensatory density dependence in fish populations: Importance, controversy, understanding and prognosis.

Rost RA (1989) Water quality and restoration of the Lower Oconto River, Oconto County, Wisconsin. Technical bulletin (USA). :1-36

Ruiz-Navarro A, Verdiell-Cubedo D, Torralva M, Oliva-Paterna F (2013) Removal control of the highly invasive fish Gambusia holbrooki and effects on its population biology: learning by doing. Wildl Res 40:82-89

Salo P, Nordström M, Thomson RL, Korpimäki E (2008) Risk induced by a native top predator reduces alien mink movements. J Anim Ecol 77:1092-1098

Saunders WC, Budy P, Thiede GP (2015) Demographic changes following mechanical removal of exotic brown trout in an Intermountain West (USA), high-elevation stream. Ecol Freshw Fish 24:252-263

Scarnecchia DL (1988) Evaluation of Fish Eradication and Game-fish Restocking in a Central Iowa Pond. J Iowa Acad Sci 95:55-59

Schaufler G, Stögner C, Gassner H, Kaiser R, Schabetsberger R (2015) How to contain a 
tapeworm epidemic-testing the efficiency of different catch methods to reduce the translocated final host Esox lucius in an alpine lake. Int Rev Hydrobiol 100:169-176

Schröder A, Leeuwen A van, Cameron TC (2014) When less is more: Positive population-level effects of mortality. Trends Ecol Evol 29:614-624

Seno H (2008) A paradox in discrete single species population dynamics with harvesting/thinning. Math Biosci 214:63-9

Shanks A, Roegner G (2007) Recruitment limitation in Dungeness crab populations is driven by variation in atmospheric forcing. Ecology 88:1726-1737

Shepard BB, Nelson LM, Taper ML, Zale AV (2014) Factors Influencing Successful Eradication of Nonnative Brook Trout from Four Small Rocky Mountain Streams Using Electrofishing. North Am J Fish Manag 34:988-997

Shroyer SM (2007) Induced winterkill as a management tool for reclaiming Minnesota walleye rearing ponds. Minnesota Department of Natural Resources Report 547:47

Shurin JB, Borer ET, Seabloom EW, Anderson K, Blanchette CA, Broitman BR, Cooper SD, Halpern BS (2002) A cross-ecosystem compariuson of the strength of trophic cascades. Ecol Lett 5:785-791

Sigler W, Sigler J (1990) Recreational fisheries: management, theory, and application. University of Nevada Press

Sih A (1986) Antipredator responses and the perception of danger by mosquito larvae. Ecology 67:434-441

Sih A, Bolnick DI, Luttbeg B, Orrock JL, Peacor SD, Pintor LM, Preisser E, Rehage JS, Vonesh JR (2010) Predator-prey naïveté, antipredator behavior, and the ecology of predator invasions. Oikos 119:610-621

Simberloff D (2014) Biological invasions: What's worth fighting and what can be won? Ecol Eng 65:112-121

Sissenwine MP (1984) Why do fish populations vary? In: May RM (ed) Exploitation of Marine Communities. Springer-Verlag, New York, p 59-94

Smith PW (1979) The Fishes of Illinois. University of Illinois Press, Urbana

Smith P, Leah R, Eaton J (1996) Removal of pikeperch (Stizostedion lucioperca) from a British Canal as a management technique to reduce impact on prey fish populations. Ann Zool Fennici 33:537-545

Sorensen KH, Sterner RW (1992) Extreme cyclomorphosis in Daphnia lumholtzi. Freshw 
Biol 28:257-262

Stanley SM (1970) Relation of shell form to life habits of the Bivalvia (Mollusca). Geol Soc Am 125

Stevens B, Armstrong D, Cusimano R (1982) Feeding habits of Dungeness crab Cancer magister as determined by the index of relative importance. Mar Biol 72:135-145

Sutherland WJ (1982) Spatial Variation in the Predation of Cockles by Oystercatchers at Traeth Melynog, Anglesey. I. The Cockle Population. J Anim Ecol 51:481-489

Sutherland WJ (2006) Ecological census techniques: A handbook. Cambridge University Press

Syslo JM, Guy CS, Bigelow PE, Doepke PD, Ertel BD, Koel TM (2011) Response of non-native lake trout (Salvelinus namaycush) to 15 years of harvest in Yellowstone National Park. Can J Fish Aquat Sci 68:2132-2145

Tallqvist M (2001) Burrowing behaviour of the Baltic clam Macoma balthica: effects of sediment type, hypoxia and predator presence. Mar Ecol Prog Ser 212:183-191

Thompson JN (1998) Rapid evolution as an ecological process. Trends Ecol Evol $13: 329-32$

Thompson PD, Rahel FJ (1996) Evaluation of Depletion-Removal Electrofishing of Brook Trout in Small Rocky Mountain Streams. North Am J Fish Manag 16:332339

Thuesen P, Russell D, Thomson F, Pearce M, Vallance T, Hogan A (2011) An evaluation of electrofishing as a control measure for an invasive tilapia (Oreochromis mossambicus) population in northern Australia. Mar Freshw Res 62:110-118

Tollrian R, Harvell CD (1998) The Ecology and Evolution of Inducible Defenses. Princeton University Press, Princeton, NJ

Torchin M, Lafferty K, Dobson A (2003) Introduced species and their missing parasites. Nature 421

Torchin M, Mitchell C (2004) Parasites, pathogens, and invasions by plants and animals. Front Ecol Environ 2:183-190

Trammel M, Meismer S, Speas D (2004) Nonnative cyprinid removal in the lower Green and Colorado rivers, Utah Prepared by Nonnative cyprinid removal in the lower Green and Colorado rivers, Utah.

Travis J (1993) Invader Threatens Black, Azov Seas. Science 262:1366-1367 
Trewavas E (1983) Tialpine fishes of the genera Sarotherodon, Oreochromis and Danakilia. Cornell University Press, Ithaca

Trippel EA (1995) Age at Maturity as a Stress Indicator in Fisheries. Bioscience 45:759771

Trussell G, Ewanchuk P, Bertness M (2003) Trait-mediated effects in rocky intertidal food chains: predator risk cues alter prey feeding rates. Ecology 84:629-640

Trussell G, Nicklin M (2002) Cue sensitivity, inducible defense, and trade-offs in a marine snail. Ecology 83:1635-1647

Tsolaki E, Diamadopoulos E (2010) Technologies for ballast water treatment: A review. J Chem Technol Biotechnol 85:19-32

Turgeon K, Kramer DL (2016) Immigration rates during population density reduction in a coral reef fish. PLoS One 11:1-17

Turner BC, Rivera CE de, Grosholz ED, Ruiz GM (2016) Assessing population increase as a possible outcome to management of invasive species. Biol Invasions 18:533548

Urabe J, Suzuki T, Nishita T, Makino W (2013) Immediate ecological impacts of the 2011 Tohoku earthquake tsunami on intertidal flat communites. PLoS One 8:e62779

Utz RM, Hartman KJ (2009) Density-dependent individual growth and size dynamics of central Appalachian brook trout (Salvelinus fontinalis). Can J Fish Aquat Sci 66:1072-1080

Veitch C, Clout M (2002) Turning the tide: the eradication of invasive species. Proc Int Conf Erad Isl Invasives:155-164

Vredenburg VT (2004) Reversing introduced species effects: Experimental removal of introduced fish leads to rapid recovery of a declining frog. Proc Natl Acad Sci U S A 101:7646-7650

Watanuki A, Aota T, Otsuka E, Kawai T, Iwahashi Y, Kuwahara H, Fujita D (2010) Restoration of kelp beds on an urchin barren : Removal of sea urchins by citizen divers in southwestern Hokkaido. Bull Fish Res Agen 32:83-87

Weidel BC, Josephson DC, Kraft CE (2007) Littoral Fish Community Response to Smallmouth Bass Removal from an Adirondack Lake. Trans Am Fish Soc 136:778789

Weiher E, Keddy PA (1995) Assembly Rules, Null Models, and Trait Dispersion: New Questions from Old Patterns. Oikos 74:159-164 
Werner S, Rothhaupt KO (2008) Mass mortality of the invasive bivalve Corbicula fluminea induced by a severe low-water event and associated low water temperatures. Hydrobiologia 613:143-150

Whitlow WL (2009) Changes in survivorship, behavior, and morphology in native softshell clams induced by invasive green crab predators. Mar Ecol 31:418-430

Whitlow WL, Rice NA, Sweeney C (2003) Native species vulnerability to introduced predators: testing an inducible defense and a refuge from predation. Biol Invasions $5: 23-31$

Wilson K, Heck K, Able K (1987) Juvenile blue crab, Callinectes sapidus, survival: an evaluation of eelgrass, Zostera marina, as refuge. Fish Bull 85:53-58

Wimbush J, Frischer ME, Zarzynski JW, Nierzwicki-Bauer SA (2009) Eradication of colonizing populations of zebra mussels (Dreissena polymorpha) by early detection and SCUBA removal: Lake George, NY. Aquat Conserv Mar Freshw Ecosyst 19:703-713

Wolfe LM (2002) Why alien invaders succeed: support for the escape-from-enemy hypothesis. Am Nat 160:705-11

Xu CL, Letcher BH, Nislow KH (2010) Size-dependent survival of brook trout Salvelinus fontinalis in summer: Effects of water temperature and stream flow. $\mathrm{J}$ Fish Biol 76:2342-2369

Yamada S (2001) Global invader: the European Green Crab. Oregon Sea Grant

Yamada SB, Boulding EG (1998) Claw morphology, prey size selection and foraging efficiency in generalist and specialist shell-breaking crabs. J Exp Mar Bio Ecol 220:191-211

Yamada S, Gillespie G (2008) Will the European green crab (Carcinus maenas) persist in the Pacific Northwest? ICES J Mar Sci 65:725-729

Yamada SB, Kosro PM (2009) Linking ocean conditions to year class strength of the invasive European green crab, Carcinus maenas. Biol Invasions 12:1791-1804

Yamada SB, Navarrete S, Needham C (1998) Predation induced changes in behavior and growth rate in three populations of the intertidal snail, Littorina sitkana(Philippi). J Exp Mar Bio Ecol 220:213-226

Yoshida T, Jones LE, Ellner SP, Fussmann GF, Hairston NG (2003) Rapid evolution drives ecological dynamics in a predator-prey system. Nature 424:303-306

Zagata C, Young C, Sountis C, Kuehl M (2008) "Mytilus edulis". Animal Diversity Web. 
animaldiversity.org/accounts/Mytilus_edulis (accessed 25 Sept 2016).

Zaklan SD, Ydenberg R (1997) The body size-burial depth relationship in the infaunal clam Mya arenaria. J Exp Mar Bio Ecol 215:1-17

Zangerl AR, Rutledge CE (1996) The Probability of Attack and Patterns of Constitutive and Induced Defense : A Test of Optimal Defense Theory. Am Nat 147:599-608

Zaret TM, Paine RT (1973) Species introduction in a tropical lake. Science 182:449-455

Zimmer-Faust R, Fielder D, Heck K (1994) Effects of tethering on predatory escape by juvenile blue crabs. Mar Ecol Prog Ser 111:299-303

Zipkin EF, Kraft CE, Cooch EG, Sullivan PJ (2009) When can efforts to control nuisance and invasive species backfire? Ecol Appl 19:1585-95

Zipkin EF, Sullivan PJ, Cooch EG, Kraft CE, Shuter BJ, Weidel BC (2008)

Overcompensatory response of a smallmouth bass (Micropterus dolomieu) population to harvest: release from competition? Can J Fish Aquat Sci 65:22792292

Zwarts L, Wanink J (1989) Siphon size and burying depth in deposit- and suspensionfeeding benthic bivalves. Mar Biol 100:227-240 


\section{Appendix A: Supplemental tables and figures, R-scripts with additional output for Chapter 1}

Table A.1 Tanks excluded from the statistical analysis due to high predation ( $>1$ clam per tank) for each treatment across Experiments 1-3

\begin{tabular}{llll}
\hline Experiment & Treatment & $\begin{array}{l}\text { Tanks } \\
\text { Excluded }\end{array}$ & $\begin{array}{l}\text { Tanks } \\
\text { Remaining }\end{array}$ \\
\hline 1 & USA N. obscurata, C. productus + crushed N. obscurata & 2 & 6 \\
1 & USA N. obscurata, C. maenas + crushed N. obscurata & 1 & 7 \\
1 & USA N. obscurata, M. magister + crushed N. obscurata & 1 & 7 \\
2 & USA N. obscurata, Crushed N. obscurata & 2 & 8 \\
3 & USA N. obscurata, Roaming M. magister & 2 & 8 \\
3 & Canadian N. obscurata, Roaming M. magister & 1 & 9 \\
3 & Japanese $N$. obscurata, Roaming $M$. magister & 1 & 9 \\
\hline
\end{tabular}
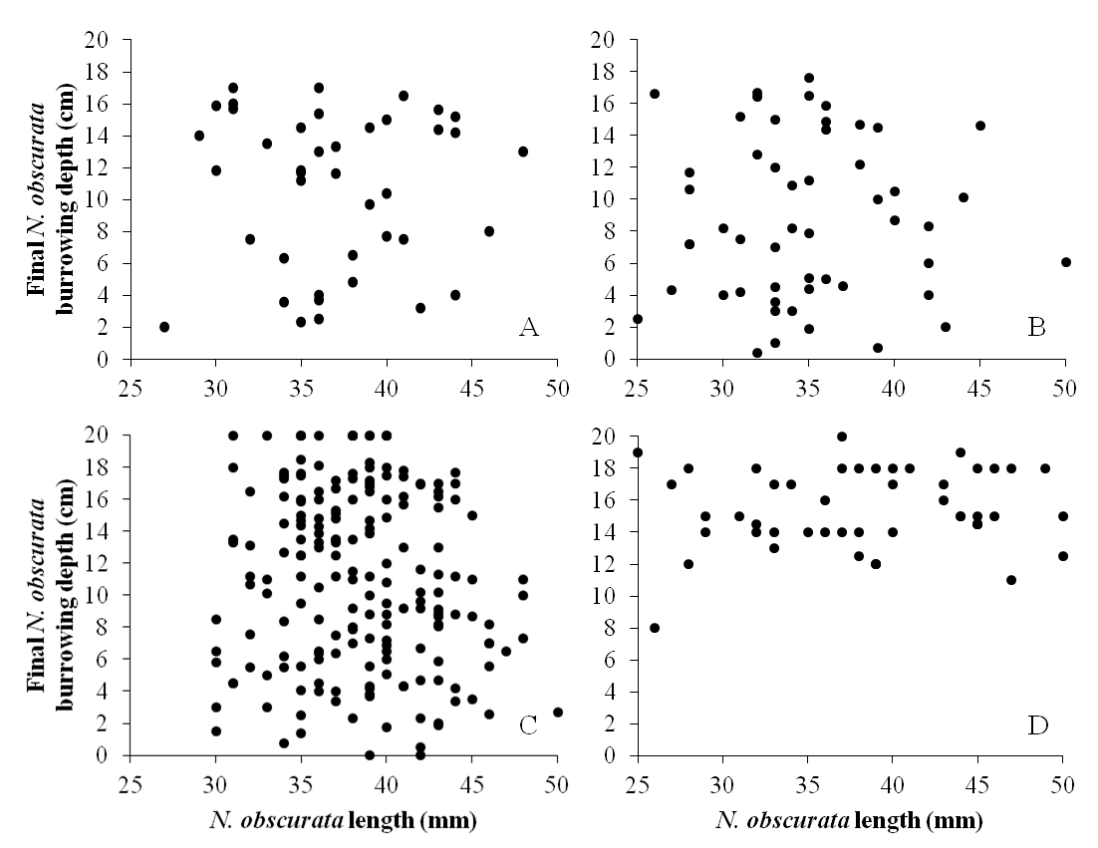

Figure A.1 Burrowing depth $(\mathrm{cm})$ and body length $(\mathrm{mm})$ for Nuttallia obscurata in Experiment $1(\mathrm{~A} ; \mathrm{N}=$ 41), Experiment $2(\mathrm{~B} ; \mathrm{N}=52)$, Experiment $3(\mathrm{C} ; \mathrm{N}=194)$, and clams collected in the field at Sand Lake, OR (D; $\mathrm{N}=49)$. 
Figure A.2: Images of collection efforts for Nuttallia obscurata at Sand Lake, Oregon, USA (Top) and Hiroura Bay, Miyagi Prefecture, Japan (Bottom). Sediment was more inundated and slightly denser in Japan compared to the Oregon site.
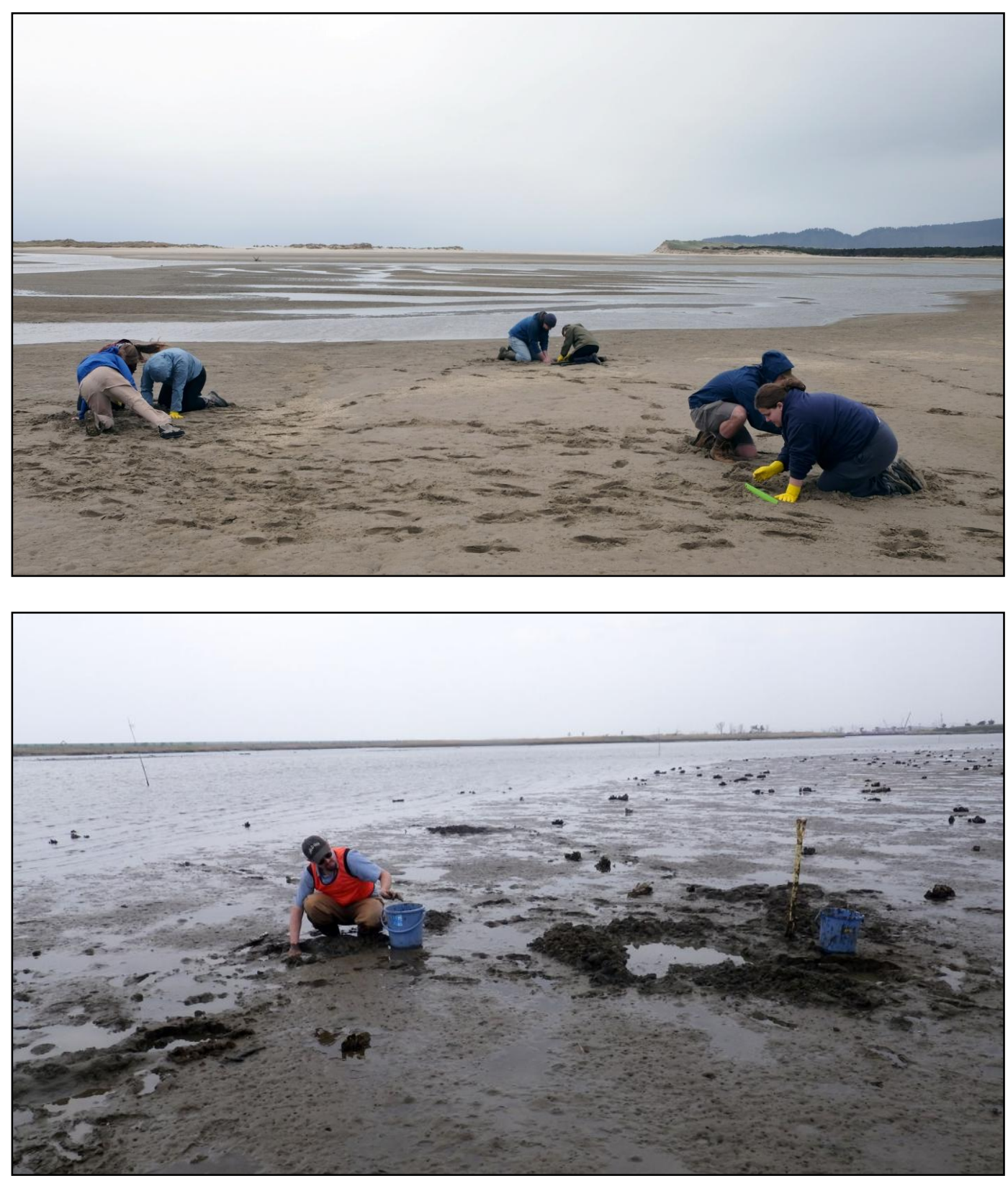
Supplement A.1: Linear mixed-effects model rationale

We originally considered using analysis of variance (ANOVA) or ANCOVA to analyze our experimental results but ultimately chose to use generalized linear mixedeffects models (GLMM) based on two criteria. First, GLMM is recommended for models with both fixed and random categorical exploratory variables (Crawley 2005). Cue treatment (Experiments 1-3), Country (Experiment 3) and Location (Location test) were fixed effects in our model. Time Block, Tank, and Clam Position (nested within Tank) were random effects in our models. Additionally, our chosen R-function (lmer) allowed us to easily specify the different relationships between our random effects (nested vs. independent).

Second, the goal of our study was not to compare the differences among means for all groups within a given category, as with an ANOVA, but instead to compare the mean of a selected group to all other groups within the category. For example, in Experiment 1 we wanted to determine if specimens of $N$. obscurata from Oregon would increase their burrowing depth in the presence of Cancer productus, Metacarcinus magister, or Carcinus maenas compared to our Control. However, we were not specifically interested in if $N$. obscurata burrows deeper in the presence of $C$. productus versus $M$. magister versus $C$. maenas. In Experiment 3, we were not interested in testing for differences in burrowing depths of $N$. obscurata between every combination of Treatment (Control, Caged M. magister, Roaming M. magister) and Country (USA, Canada, and Japan). We chose specifically to compare the burrowing depths of $N$. 
obscurata in USA Control treatments from Canada and Japan. Additionally, we examined if differences in burrowing depth of $N$. obscurata in the presence of Caged or Roaming M. magister versus our Control treatments differed between clams from Canada or Japan compared to those from the USA. Using an analysis with fewer computations improves the statistical power while allowing us to make the comparisons of interest.

R script A.1: Generalized linear mixed-effects model R script for Experiment 1; produced using package "Ime4" and data set "Experiment.1"

lmer ( Final.Clam.Depth..cm. Cue.Treatment + ( $1 \mid$ Time.Block ) +

( 1 | Tank / Clam.Position $)$, data $=$ Experiment.1)

Table A.2: Experiment 1 generalized linear mixed-effects model scaled residuals

\begin{tabular}{|c|c|c|c|c|}
\hline Min & 1Q & Median & 3Q & Max \\
\hline-2.7395 & -0.7404 & 0.1967 & 0.6404 & 2.0699 \\
\hline
\end{tabular}

Table A.3: Experiment 1 generalized linear mixed-effects model output for fixed effects; model fit by restricted maximum likelihood (REML); t-tests use Satterthwaite approximations to degrees of freedom

\begin{tabular}{r|c|c|c|c|c|} 
& \multicolumn{1}{c}{$\begin{array}{c}\text { Estimate } \\
\text { (Coefficient) }\end{array}$} & \multicolumn{1}{c}{$\begin{array}{c}\text { Standard } \\
\text { error }\end{array}$} & df & $t$ & $p$ \\
\cline { 2 - 6 } $\begin{array}{r}\text { Control } \\
\text { (Intercept) }\end{array}$ & 10.63735 & 1.23567 & 9.32 & 8.609 & $9.8 \mathrm{e}-06$ \\
\cline { 2 - 6 } $\begin{array}{r}\text { Cancer productus }+ \\
\text { crushed N. obscurata }\end{array}$ & -0.06136 & 0.89908 & 104.23 & -0.068 & 0.9457 \\
\cline { 2 - 6 } $\begin{array}{r}\text { Metacarcinus magister }+ \\
\text { crushed N. obscurata }\end{array}$ & 2.23476 & 0.98901 & 103.62 & 2.260 & 0.0259 \\
\cline { 2 - 6 } $\begin{array}{r}\text { Carcinus maenas }+ \\
\text { crushed N. obscurata }\end{array}$ & 2.06272 & 0.91737 & 102.39 & 2.249 & 0.0267 \\
\cline { 2 - 6 } & & & & &
\end{tabular}

Table A.4: Experiment 1 generalized linear mixed-effects model output for random effects

\begin{tabular}{r|c|c|}
\multicolumn{1}{c}{} & \multicolumn{1}{c}{ Variance } & Standard deviation \\
\cline { 2 - 3 } Clam.Position:Tank & 0.3020 & 0.5495 \\
\cline { 2 - 3 } Time.Block & 7.2640 & 2.6952 \\
\cline { 2 - 3 } Tank & 0.5398 & 0.7347 \\
\cline { 2 - 3 } Residual & 13.8105 & 3.7162 \\
\cline { 2 - 3 } & &
\end{tabular}


Table A.5: Experiment 1 generalized linear mixed-effects model correlation of fixed effects

\begin{tabular}{r|c|c|c|} 
& \multicolumn{1}{c}{$\begin{array}{c}\text { Control } \\
\text { (Intercept) }\end{array}$} & \multicolumn{1}{c}{$\begin{array}{c}\text { Cancer productus }+ \\
\text { crushed N. obscurata }\end{array}$} & $\begin{array}{c}\text { Metacarcinus magister }+ \\
\text { crushed N. obscurata }\end{array}$ \\
\cline { 2 - 4 } $\begin{array}{r}\text { Cancer productus }+ \\
\text { crushed N. obscurata }\end{array}$ & -0.297 & & \\
\cline { 2 - 4 } $\begin{array}{r}\text { Metacarcinus magister }+ \\
\text { crushed N. obscurata }\end{array}$ & -0.284 & 0.359 & \\
\cline { 2 - 4 } $\begin{array}{r}\text { Carcinus maenas }+ \\
\text { crushed N. obscurata }\end{array}$ & -0.307 & 0.383 & 0.353 \\
\cline { 2 - 4 } & & &
\end{tabular}

R script A.2: Generalized linear mixed-effects model R script for Experiment 2; produced using package "Ime4" and data set "Experiment.2"

lmer ( Final.Clam.Depth..cm. Cue.Treatment $+(1 \mid$ Time.Block $)+$ ( 1 | Tank / Clam.Position, data $=$ Experiment.2 $)$

Table A.6: Experiment 2 generalized linear mixed-effects model scaled residuals

\begin{tabular}{|c|c|c|c|c|}
\hline Min & 1Q & Median & 3Q & Max \\
\hline-2.0689 & -0.7729 & 0.0051 & 0.8271 & 1.8522 \\
\hline
\end{tabular}

Table A.7: Experiment 2 generalized linear mixed-effects model output for fixed effects; model fit by restricted maximum likelihood (REML); t-tests use Satterthwaite approximations to degrees of freedom

\begin{tabular}{|c|c|c|c|c|c|}
\hline & $\begin{array}{c}\text { Estimate } \\
\text { (Coefficient) }\end{array}$ & $\begin{array}{c}\text { Standard } \\
\text { error }\end{array}$ & df & $t$ & $p$ \\
\hline Control (Intercept) & 8.8166 & 0.8789 & 34.09 & 10.032 & $1.04 \mathrm{e}-11$ \\
\hline $\begin{array}{r}\text { Crushed Nuttallia } \\
\text { obscurata }\end{array}$ & 0.5191 & 1.0043 & 168.94 & 0.517 & 0.6059 \\
\hline $\begin{array}{r}\text { Caged Metacarcinus } \\
\text { magister }\end{array}$ & 1.3110 & 0.9712 & 170.76 & 1.350 & 0.1788 \\
\hline $\begin{array}{r}\text { Roaming Metacarcinus } \\
\text { magister }\end{array}$ & 2.1841 & 1.1076 & 176.10 & 1.972 & 0.502 \\
\hline
\end{tabular}

Table A.8: Experiment 2 generalized linear mixed-effects model output for random effects

\begin{tabular}{r|c|c|} 
& \multicolumn{1}{c}{ Variance } & Standard deviation \\
\cline { 2 - 3 } Clam.Position:Tank & 0.03232 & 0.1798 \\
\cline { 2 - 3 } Time.Block & 2.43413 & 1.5602 \\
\cline { 2 - 3 } Tank & 0.00000 & 0.0000 \\
\cline { 2 - 3 } Residual & 23.66714 & 4.8649 \\
\cline { 2 - 3 } & &
\end{tabular}


Table A.9: Experiment 2 generalized linear mixed-effects model correlation of fixed effects

\begin{tabular}{|c|c|c|c|}
\hline & $\begin{array}{c}\text { Control } \\
\text { (Intercept) }\end{array}$ & $\begin{array}{c}\text { Crushed } \\
\text { Nuttallia obscurata }\end{array}$ & $\begin{array}{c}\text { Caged } \\
\text { Metacarcinus magister }\end{array}$ \\
\hline $\begin{array}{r}\text { Crushed } \\
\text { Nuttallia obscurata }\end{array}$ & -0.601 & & \\
\hline $\begin{array}{r}\text { Caged } \\
\text { Metacarcinus magister }\end{array}$ & -0.618 & 0.544 & \\
\hline $\begin{array}{r}\text { Roaming } \\
\text { Metacarcinus magister }\end{array}$ & -0.551 & 0.487 & 0.497 \\
\hline
\end{tabular}

R script A.3: Generalized linear mixed-effects model R script for Experiment 3; produced using package "Ime4" and data set "Experiment.3"

lmer ( Final.Clam.Depth..cm. Cue.Treatment $*$ Country $+(1 \mid$ Time.Block $)+$ ( 1 | Tank / Clam.Position, data $=$ Experiment. 3 )

Table A.10: Experiment 1 generalized linear mixed-effects model scaled residuals

\begin{tabular}{|c|c|c|c|c|}
\hline Min & 1Q & Median & 3Q & Max \\
\hline-2.47979 & -0.78888 & 0.05131 & 0.77469 & 2.06582 \\
\hline
\end{tabular}


Table A.11: Experiment 3 generalized linear mixed-effects model output for fixed effects; model fit by restricted maximum likelyhood (REML); t-tests use Satterthwaite approximations to degrees of freedom

\begin{tabular}{|c|c|c|c|c|c|}
\hline & $\begin{array}{c}\text { Estimate } \\
\text { (Coefficient) }\end{array}$ & $\begin{array}{l}\text { Standard } \\
\text { error }\end{array}$ & df & $t$ & $p$ \\
\hline $\begin{array}{l}\text { USA N. obscurata, } \\
\text { Control (Intercept) }\end{array}$ & 10.3022 & 0.8392 & 55.8 & 12.276 & $<2 \mathrm{e}-16$ \\
\hline $\begin{array}{l}\text { USA } N . \text { obscurata, } \\
\text { Caged } M . \text { magister }\end{array}$ & -0.2418 & 0.9378 & 434.4 & -0.258 & 0.7966 \\
\hline $\begin{array}{l}\text { USA } N \text {. obscurata, } \\
\text { Roaming } M \text {. magister }\end{array}$ & 1.9172 & 1.0092 & 437.4 & 1.900 & 0.0581 \\
\hline $\begin{array}{r}\text { Canadian N. obscurata, } \\
\text { Control }\end{array}$ & 0.2862 & 0.9344 & 432.2 & 0.306 & 0.7596 \\
\hline $\begin{array}{r}\text { Japanese } N . \text { obscurata, } \\
\text { Control }\end{array}$ & 2.1649 & 0.9293 & 432.1 & 2.330 & 0.0203 \\
\hline $\begin{array}{l}\text { (Canadian N. obscurata, } \\
\text { l vs. Caged M. magister) }\end{array}$ & 0.9802 & 1.3284 & 432.8 & 0.738 & 0.4610 \\
\hline $\begin{array}{l}\text { (Canadian N. obscurata, } \\
\text { s. Roaming M. magister) }\end{array}$ & -0.5210 & 1.3921 & 434.0 & -0.374 & 0.7084 \\
\hline $\begin{array}{l}\text { (Japanese } N \text {. obscurata, } \\
\text { l vs. Caged M. magister) }\end{array}$ & -0.2181 & 1.3430 & 434.5 & -0.162 & 0.8711 \\
\hline $\begin{array}{l}\text { (Japanese } N \text {. obscurata, } \\
\text {. Roaming } M . \text { magister) }\end{array}$ & -3.4643 & 1.3947 & 434.8 & -2.484 & 0.0134 \\
\hline
\end{tabular}

Table A.12: Experiment 3 generalized linear mixed-effects model output for random effects

\begin{tabular}{|c|c|c|}
\hline \multirow{3}{*}{$\begin{array}{r}\text { Clam.Position:Tank } \\
\text { Time.Block }\end{array}$} & Variance & Standard deviation \\
\hline & 0.000 & 0.000 \\
\hline & 1.202 & 1.097 \\
\hline Tank & 1.386 & 1.177 \\
\hline Residual & 23.305 & 4.828 \\
\hline
\end{tabular}


Table A.13: Experiment 3 generalized linear mixed-effects model correlation of fixed effects

\begin{tabular}{|c|c|c|c|c|c|c|c|c|}
\hline & $\begin{array}{c}\text { USA } \\
\text { N. obscurata, } \\
\text { Control } \\
\text { (Intercept) }\end{array}$ & $\begin{array}{c}\text { USA } \\
\text { N. obscurata, } \\
\text { Caged } \\
\text { M. magister }\end{array}$ & $\begin{array}{c}\text { USA } \\
\text { N. obscurata, } \\
\text { Roaming } \\
\text { M. magister }\end{array}$ & $\begin{array}{c}\text { Canadian } \\
\text { N. obscurata, } \\
\text { Control }\end{array}$ & $\begin{array}{l}\text { Japanese } \\
\text { N. obscurata, } \\
\text { Control }\end{array}$ & $\begin{array}{c}\text { Interaction } \\
\text { (Canadian } \\
\text { N. obscurata, } \\
\text { Control vs. } \\
\text { Caged } \\
\text { M. magister) }\end{array}$ & $\begin{array}{c}\text { Interaction } \\
\text { (Canadian } \\
\text { N. obscurata, } \\
\text { Control vs. } \\
\text { Roaming } \\
\text { M. magister) }\end{array}$ & $\begin{array}{c}\text { Interaction } \\
\text { (Japanese } \\
\text { N. obscurata, } \\
\text { Control vs. } \\
\text { Caged } \\
\text { M. magister) }\end{array}$ \\
\hline $\begin{array}{r}\text { USA } \\
\text { N. obscurata, } \\
\text { Caged } \\
\text { M. magister }\end{array}$ & -0.548 & & & & & & & \\
\hline $\begin{array}{r}\text { USA } \\
\text { N. obscurata, } \\
\text { Roaming } \\
\text { M. magister }\end{array}$ & -0.509 & 0.448 & & & & & & \\
\hline $\begin{array}{r}\text { Canadian } N . \\
\text { obscurata, } \\
\text { Control }\end{array}$ & -0.547 & 0.488 & 0.457 & & & & & \\
\hline $\begin{array}{r}\text { Japanese } \\
\text { N. obscurata, } \\
\text { Control }\end{array}$ & -0.552 & 0.494 & 0.459 & 0.494 & & & & \\
\hline $\begin{array}{r}\text { Interaction } \\
\text { (Canadian } \\
\text { N. obscurata, } \\
\text { Control vs. } \\
\text { Caged } \\
\text { M. magister) }\end{array}$ & 0.386 & -0.704 & -0.315 & -0.702 & -0.348 & & & \\
\hline $\begin{array}{r}\text { Interaction } \\
\text { (Canadian } \\
\text { N. obscurata, } \\
\text { Control vs. } \\
\text { Roaming } \\
\text { M. magister) }\end{array}$ & 0.369 & -0.324 & -0.723 & -0.673 & -0.332 & 0.469 & & \\
\hline $\begin{array}{r}\text { Interaction } \\
\text { (Japanese } \\
\text { N. obscurata, } \\
\text { Control vs. } \\
\text { Caged } \\
\text { M. magister) }\end{array}$ & 0.381 & -0.700 & -308 & -0.339 & -0.691 & 0.493 & 0.222 & \\
\hline $\begin{array}{r}\text { Interaction } \\
\text { (Japanese } \\
\text { N. obscurata, } \\
\text { Control vs. } \\
\text { Roaming } \\
\text { M. magister) }\end{array}$ & 0.369 & -0.330 & -0.719 & -0.333 & -0.667 & 0.234 & 0.520 & 0.461 \\
\hline
\end{tabular}


R script A.4: Generalized linear mixed-effects model R script for comparing burrowing depth of Nuttallia obscurata in tanks housed on water tables or lab shelves (hereafter Location Test); produced using package "Ime4" and data set "Location.data"

$$
\begin{aligned}
& \text { lmer }(\text { Final.Clam.Depth..cm. } \sim \text { Location }+(1 \mid \text { Time.Block })+ \\
& (1 \mid \text { Tank / Clam.Position, data = Location.data })
\end{aligned}
$$

Table A.14: Location Test generalized linear mixed-effects model scaled residuals

\begin{tabular}{|c|c|c|c|c|}
\hline Min & 1Q & Median & 3Q & Max \\
\hline-2.29198 & -0.72246 & -0.1852 & 0.70260 & 2.49529 \\
\hline
\end{tabular}

Table A.15: Location Test generalized linear mixed-effects model output for fixed effects; model fit by restricted maximum likelihood (REML); t-tests use Satterthwaite approximations to degrees of freedom

\begin{tabular}{r|c|c|c|c|c|}
\multicolumn{1}{c}{} & \multicolumn{1}{c}{$\begin{array}{c}\text { Estimate } \\
\text { (Coefficient) }\end{array}$} & \multicolumn{1}{c}{$\begin{array}{c}\text { Standard } \\
\text { error }\end{array}$} & \multicolumn{1}{c}{ df } & \multicolumn{1}{c|}{$t$} \\
\cline { 2 - 6 } $\begin{array}{r}\text { Water Table } \\
\text { (Intercept) }\end{array}$ & 6.1209 & 0.7951 & 3.6990 & 7.698 & 0.00209 \\
\cline { 2 - 6 } Lab Shelves & 2.0095 & 0.9428 & 1.9890 & 2.131 & 0.16745 \\
\cline { 2 - 6 } & & &
\end{tabular}

\begin{tabular}{|c|c|c|}
\hline \multirow{3}{*}{$\begin{array}{r}\text { Clam.Position:Tank } \\
\text { Time.Block }\end{array}$} & Variance & Standard deviation \\
\hline & 0.03395 & 0.5827 \\
\hline & 1.6730 & 1.2934 \\
\hline Tank & 0.5191 & 0.7205 \\
\hline Residual & 15.4587 & 3.9318 \\
\hline
\end{tabular}

Table A.16: Location Test generalized linear mixed-effects model output for random effects

Table A.17: Location Test generalized linear mixed-effects model correlation of fixed effects

\begin{tabular}{cc|} 
& $\begin{array}{c}\text { Water Table } \\
\text { (Intercept) }\end{array}$ \\
Lab Shelves & -0.595 \\
\hline
\end{tabular}




\section{Appendix B: Carcinus maenas survey data, $\mathbf{R}$ scripts with additional output, and Supplemental figures for Chapter 2}

Table B.1: Data from Carcinus maenas surveys from 2004 - 2009; in R script as "Carcinus.catch"

\begin{tabular}{|c|c|c|c|c|c|c|c|c|}
\hline $\begin{array}{c}\text { Bay. } \\
\text { ID }\end{array}$ & Year & Period & $\begin{array}{c}\text { Bay. } \\
\text { Treatment }\end{array}$ & Site & Adult & Juvenile & $\begin{array}{l}\text { Trap. } \\
\text { Dates }\end{array}$ & $\begin{array}{l}\text { Trap. } \\
\text { Count }\end{array}$ \\
\hline Bodega Harbor & 2004 & Before & Removal & 1 & 19 & 2 & 1 & 6 \\
\hline Bodega Harbor & 2004 & Before & Removal & 2 & 10 & 0 & 1 & 6 \\
\hline Bodega Harbor & 2004 & Before & Removal & 3 & 0 & 0 & 1 & 9 \\
\hline Elkhorn Slough & 2004 & Before & Reference & 1 & 54 & 61 & 3 & 6 \\
\hline Elkhorn Slough & 2004 & Before & Reference & 2 & 89 & 15 & 3 & 6 \\
\hline Elkhorn Slough & 2004 & Before & Reference & 3 & 35 & 46 & 3 & 6 \\
\hline Tomales Bay & 2004 & Before & Reference & 1 & 56 & 2 & 1 & 12 \\
\hline Tomales Bay & 2004 & Before & Reference & 2 & 54 & 56 & 1 & 12 \\
\hline Tomales Bay & 2004 & Before & Reference & 3 & 14 & 3 & 1 & 20 \\
\hline Bodega Harbor & 2005 & Before & Removal & 1 & 22 & 4 & 1 & 8 \\
\hline Bodega Harbor & 2005 & Before & Removal & 2 & 8 & 1 & 1 & 8 \\
\hline Bodega Harbor & 2005 & Before & Removal & 3 & 0 & 0 & 1 & 5 \\
\hline Elkhorn Slough & 2005 & Before & Reference & 1 & 37 & 23 & 3 & 6 \\
\hline Elkhorn Slough & 2005 & Before & Reference & 2 & 4 & 11 & 3 & 6 \\
\hline Elkhorn Slough & 2005 & Before & Reference & 3 & 6 & 30 & 3 & 6 \\
\hline Tomales Bay & 2005 & Before & Reference & 1 & 65 & 4 & 1 & 4 \\
\hline Tomales Bay & 2005 & Before & Reference & 2 & 18 & 0 & 1 & 4 \\
\hline Tomales Bay & 2005 & Before & Reference & 3 & 1 & 0 & 1 & 4 \\
\hline Bodega Harbor & 2006 & Before & Removal & 1 & 295 & 6 & 3 & 10 \\
\hline Bodega Harbor & 2006 & Before & Removal & 2 & 58 & 1 & 3 & 10 \\
\hline Bodega Harbor & 2006 & Before & Removal & 3 & 53 & 3 & 3 & 10 \\
\hline Elkhorn Slough & 2006 & Before & Reference & 1 & 173 & 2 & 3 & 6 \\
\hline Elkhorn Slough & 2006 & Before & Reference & 2 & 29 & 0 & 3 & 10 \\
\hline Elkhorn Slough & 2006 & Before & Reference & 3 & 6 & 0 & 3 & 10 \\
\hline Tomales Bay & 2006 & Before & Reference & 1 & 94 & 5 & 3 & 10 \\
\hline Tomales Bay & 2006 & Before & Reference & 2 & 5 & 4 & 3 & 10 \\
\hline Tomales Bay & 2006 & Before & Reference & 3 & 1 & 0 & 3 & 10 \\
\hline Bodega Harbor & 2007 & After & Removal & 1 & 19 & 21 & 3 & 10 \\
\hline Bodega Harbor & 2007 & After & Removal & 2 & 4 & 7 & 3 & 10 \\
\hline Bodega Harbor & 2007 & After & Removal & 3 & 4 & 14 & 3 & 10 \\
\hline Elkhorn Slough & 2007 & After & Reference & 1 & 24 & 29 & 3 & 10 \\
\hline Elkhorn Slough & 2007 & After & Reference & 2 & 8 & 14 & 3 & 10 \\
\hline Elkhorn Slough & 2007 & After & Reference & 3 & 0 & 4 & 3 & 10 \\
\hline Tomales Bay & 2007 & After & Reference & 1 & 2 & 29 & 3 & 10 \\
\hline
\end{tabular}




\begin{tabular}{|c|c|c|c|c|c|c|c|c|}
\hline Tomales Bay & 2007 & After & Reference & 2 & 0 & 3 & 3 & 10 \\
\hline Tomales Bay & 2007 & After & Reference & 3 & 2 & 2 & 3 & 10 \\
\hline Bodega Harbor & 2008 & After & Removal & 1 & 48 & 2 & 3 & 10 \\
\hline Bodega Harbor & 2008 & After & Removal & 2 & 38 & 0 & 3 & 10 \\
\hline Bodega Harbor & 2008 & After & Removal & 3 & 20 & 2 & 3 & 10 \\
\hline Elkhorn Slough & 2008 & After & Reference & 1 & 3 & 2 & 3 & 10 \\
\hline Elkhorn Slough & 2008 & After & Reference & 2 & 1 & 2 & 3 & 10 \\
\hline Elkhorn Slough & 2008 & After & Reference & 3 & 0 & 0 & 3 & 10 \\
\hline Tomales Bay & 2008 & After & Reference & 1 & 2 & 0 & 3 & 10 \\
\hline Tomales Bay & 2008 & After & Reference & 2 & 1 & 6 & 3 & 10 \\
\hline Tomales Bay & 2008 & After & Reference & 3 & 5 & 3 & 3 & 10 \\
\hline Bodega Harbor & 2009 & After & Removal & 1 & 16 & 103 & 3 & 10 \\
\hline Bodega Harbor & 2009 & After & Removal & 2 & 7 & 3 & 3 & 10 \\
\hline Bodega Harbor & 2009 & After & Removal & 3 & 1 & 0 & 3 & 10 \\
\hline Elkhorn Slough & 2009 & After & Reference & 1 & 1 & 6 & 3 & 10 \\
\hline Elkhorn Slough & 2009 & After & Reference & 2 & 3 & 33 & 3 & 10 \\
\hline Elkhorn Slough & 2009 & After & Reference & 3 & 3 & 12 & 3 & 10 \\
\hline Tomales Bay & 2009 & After & Reference & 1 & 6 & 34 & 3 & 10 \\
\hline Tomales Bay & 2009 & After & Reference & 2 & 1 & 10 & 3 & 10 \\
\hline Tomales Bay & 2009 & After & Reference & 3 & 21 & 9 & 3 & 10 \\
\hline
\end{tabular}

R script B.1: Generalized linear mixed model R script; Produced using package "Ime4" and data set "Carcinus.catch"

glmer ( cbind ( Juveniles , Adults ) Bay.Treatment + Period + Bay.Treatment:Period + $(1 \mid$ Year $)+(1 \mid$ Bay.ID $)+(1 \mid$ Bay.ID $:$ Year $)$, data $=$ Carcinus.catch, weights $=$ Scale, family $=$ binomial )

R script B.2: R script for creation of weight function "Scale"

Carcinus.catch \$ Effort <- with ( Carcinus.catch, Trap.Dates * Trap.Count )

Carcinus.catch \$ Scale < - with ( Carcinus.catch, max ( Effort ) / Effort )

Table B.2: Generalized linear mixed model output for fixed effects

\begin{tabular}{r|c|c|c|c|} 
& \multicolumn{1}{c}{ Estimate } & Standard Error & $z$ & $p$ \\
\cline { 2 - 5 } (Intercept) & -1.7682 & 0.6632 & -2.666 & 0.00767 \\
\cline { 2 - 5 } Bay.Treatment & -0.9855 & 0.8338 & -1.182 & 0.23723 \\
\cline { 2 - 5 } Period & 2.6404 & 0.9507 & 2.777 & 0.00548 \\
\cline { 2 - 5 } Bay.Treatment:Period & -0.2771 & 1.1912 & -0.233 & 0.81604 \\
\cline { 2 - 5 } & & & &
\end{tabular}


Table B.3: Generalized linear mixed model output for random effects

\begin{tabular}{r|c|c|}
\multicolumn{1}{c}{} & \multicolumn{1}{c}{ Variance } & Standard Deviation \\
\cline { 2 - 3 } Bay.ID & 1.308 & 1.144 \\
\cline { 2 - 3 } Year & $6.314 \mathrm{E}-01$ & $7.946 \mathrm{E}-01$ \\
\cline { 2 - 3 } Bay.ID:Year & $1.401 \mathrm{E}-09$ & $3.743 \mathrm{E}-05$ \\
\cline { 2 - 3 } & &
\end{tabular}

Table B.4: Correlation of Fixed Effects

\begin{tabular}{|c|c|c|c|} 
& \multicolumn{1}{c}{$($ Intercept $)$} & Bay.Treatment & \multicolumn{1}{c}{ Period } \\
\cline { 2 - 4 } Bay.Treatment & -0.415 & & \\
\cline { 2 - 4 } Period & -0.698 & 0.289 & \\
\cline { 2 - 4 } Bay.Treatment:Period & 0.291 & -0.700 & -0.427 \\
\cline { 2 - 4 } & & &
\end{tabular}

Table B.5: Generalized linear mixed model additional information

\begin{tabular}{|c|c|c|c|c|}
\multicolumn{1}{r|}{ AIC } & \multicolumn{1}{c}{ BIC } & \multicolumn{1}{c}{ Log likelihood } & \multicolumn{1}{c}{ Deviance } & DF residual \\
\hline 636 & 650 & -311 & 622 & 47 \\
\hline
\end{tabular}




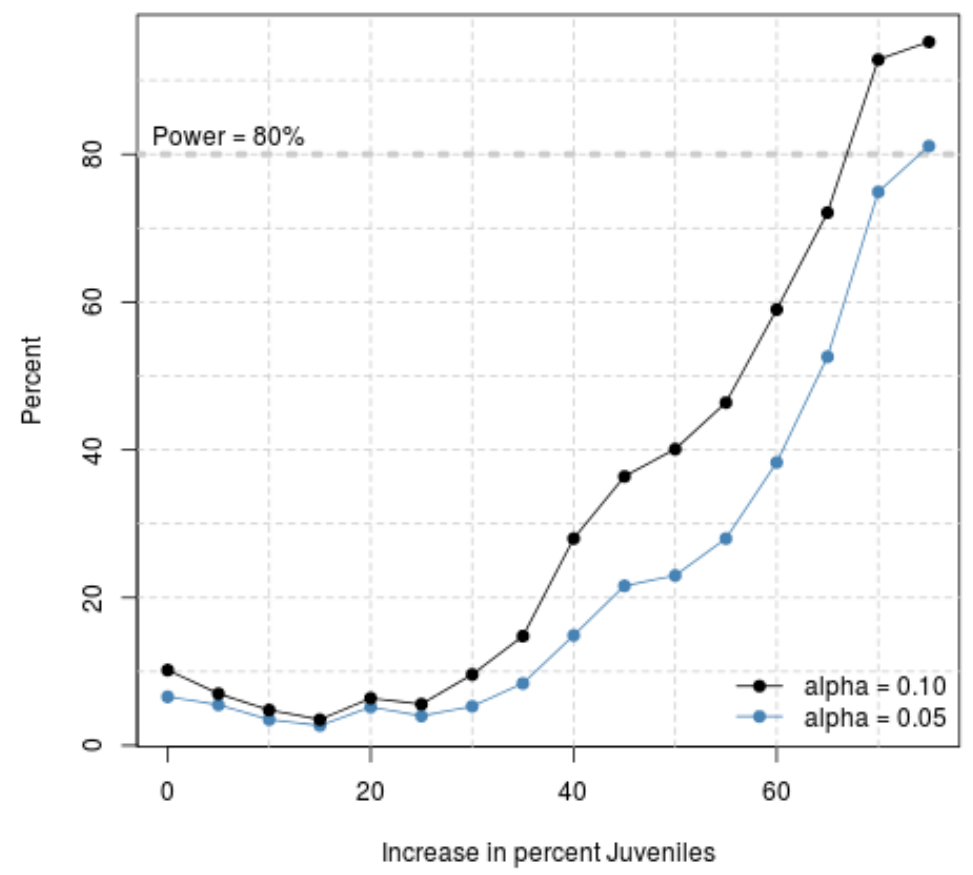

Figure B.2 Percent of simulated survey data sets with significant increases in juvenile Carcinus maenas abundance in Bodega Harbor post-removal with $\alpha=0.05$ and $\alpha=0.1$. The percentages of data sets with significant results were calculated across increasing effect size (post-removal increase in percent juveniles). An increase in juvenile abundance was considered detectible when $\geq 80 \%$ of simulated data sets (1000 for each 5\% increase in percent juveniles) had significant increases. With $\alpha=0.05$, the juvenile percentage of our catch data required an increase of $>70 \%$ before there were detectable increases in juvenile abundance for Bodega Harbor post-removal. The required increase in juvenile percentage was only slightly lower when $\alpha=0.1(>65 \%)$. 


\section{Appendix C: Supplemental tables and R-scripts with additional output for Chapter 3}

Table C.1 Data from the compensation literature review; in R script as "Comp.Rev"

\begin{tabular}{|c|c|c|c|c|c|c|c|c|c|}
\hline $\begin{array}{c}\text { Case. } \\
\text { Study. } \\
\text { ID }\end{array}$ & $\begin{array}{c}\text { Compensation. } \\
\text { Evidence }\end{array}$ & $\begin{array}{l}\text { Species. } \\
\text { Targeted }\end{array}$ & $\begin{array}{l}\text { Fish. } \\
\text { Species }\end{array}$ & $\begin{array}{l}\text { Removal. } \\
\text { Outcome }\end{array}$ & $\begin{array}{c}\text { Removal. } \\
\text { Method }\end{array}$ & $\begin{array}{l}\text { Removal. } \\
\text { Technique }\end{array}$ & $\begin{array}{c}\text { Area. } \\
\text { Connectivity }\end{array}$ & $\begin{array}{l}\text { Area. } \\
\text { Size..ha }\end{array}$ & $\begin{array}{c}\text { Area. } \\
\text { Size. } \\
\text { Binary }\end{array}$ \\
\hline 1 & Yes & Cyprinus carpio & Yes & Reduction & Physical & Multiple & Open & 58.00 & $>1$ \\
\hline 2 & Yes & Esox lucius & Yes & Unsuccessful & Physical & Electrofishing & Open & NA & $>1$ \\
\hline 3 & Yes & $\begin{array}{l}\text { Ictalurus } \\
\text { punctatus }\end{array}$ & Yes & Unsuccessful & Physical & Electrofishing & Open & NA & $>1$ \\
\hline 4 & Yes & $\begin{array}{l}\text { Micropterus } \\
\text { dolomieu }\end{array}$ & Yes & Unsuccessful & Physical & Electrofishing & Open & NA & $>1$ \\
\hline 5 & Yes & $\begin{array}{l}\text { Micropterus } \\
\text { dolomieu }\end{array}$ & Yes & Unsuccessful & Physical & Electrofishing & Closed & 271.00 & $>1$ \\
\hline 6 & Yes & $\begin{array}{l}\text { Oreochromis } \\
\text { mossambicus }\end{array}$ & Yes & Unsuccessful & Physical & Electrofishing & Open & 11.00 & $>1$ \\
\hline 7 & Yes & Perca fluviatilis & Yes & Unsuccessful & Physical & Multiple & Variable & 0.79 & $\leq 1$ \\
\hline 8 & Yes & Salmo trutta & Yes & Unsuccessful & Physical & Electrofishing & Open & 2.72 & $>1$ \\
\hline 9 & Yes & Salmo trutta & Yes & Unsuccessful & Physical & Electrofishing & Variable & 2.41 & $>1$ \\
\hline 10 & Yes & $\begin{array}{l}\text { Salvelinus } \\
\text { fontinalis }\end{array}$ & Yes & Reduction & Physical & Electrofishing & Variable & 0.34 & $\leq 1$ \\
\hline 11 & Yes & $\begin{array}{l}\text { Salvelinus } \\
\text { fontinalis }\end{array}$ & Yes & Unsuccessful & Physical & Rare & Variable & 0.48 & $\leq 1$ \\
\hline 12 & Yes & $\begin{array}{l}\text { Salvelinus } \\
\text { fontinalis }\end{array}$ & Yes & Unsuccessful & Physical & Electrofishing & Closed & 2.18 & $>1$ \\
\hline 13 & Yes & $\begin{array}{l}\text { Salvelinus } \\
\text { fontinalis }\end{array}$ & Yes & Unsuccessful & Physical & Rare & Open & 2.34 & $>1$ \\
\hline 14 & Yes & $\begin{array}{l}\text { Salvelinus } \\
\text { fontinalis }\end{array}$ & Yes & Eradication & Physical & Electrofishing & Closed & 0.58 & $\leq 1$ \\
\hline 15 & Yes & $\begin{array}{l}\text { Salvelinus } \\
\text { namaycush }\end{array}$ & Yes & Unsuccessful & Physical & Gillnetting & Closed & 34020.00 & $>1$ \\
\hline 16 & Yes & $\begin{array}{l}\text { Stizostedion } \\
\text { lucioperca }\end{array}$ & Yes & Unsuccessful & Physical & Electrofishing & Variable & 28.93 & $>1$ \\
\hline 17 & No & Cyprinus carpio & Yes & Eradication & Chemical & Rotenone & Closed & 490.22 & $>1$ \\
\hline 18 & No & Cyprinus carpio & Yes & Reduction & Physical & Multiple & Closed & 2365.00 & $>1$ \\
\hline 19 & No & Cyprinus carpio & Yes & Reduction & Physical & Multiple & Closed & 4770.00 & $>1$ \\
\hline 20 & No & Cyprinus carpio & Yes & Eradication & Physical & Multiple & Closed & 2365.00 & $>1$ \\
\hline 21 & No & Cyprinus carpio & Yes & Eradication & Chemical & Rotenone & Closed & 0.25 & $\leq 1$ \\
\hline 22 & No & Esox lucius & Yes & Reduction & Chemical & $\begin{array}{c}\text { Rotenone \& } \\
\text { Nusyn- } \\
\text { noxfish }\end{array}$ & Variable & 1619.00 & $>1$ \\
\hline 23 & No & Esox lucius & Yes & Reduction & Physical & Multiple & Open & 410.00 & $>1$ \\
\hline
\end{tabular}




\begin{tabular}{|c|c|c|c|c|c|c|c|c|c|}
\hline 24 & No & $\begin{array}{l}\text { Gambusia } \\
\text { holbrooki }\end{array}$ & Yes & Eradication & Physical & Multiple & Closed & NA & $\leq 1$ \\
\hline 25 & No & Gila bicolor & Yes & Eradication & Combination & $\begin{array}{c}\text { Chemical \& } \\
\text { Physical }\end{array}$ & Open & 1226.00 & $>1$ \\
\hline 26 & No & $\begin{array}{l}\text { Hemichromis } \\
\text { guttatus }\end{array}$ & Yes & Reduction & Physical & Rare & Variable & 0.06 & $\leq 1$ \\
\hline 27 & No & Ictalurus melas & Yes & Eradication & Chemical & Rotenone & Closed & 0.25 & $\leq 1$ \\
\hline 28 & No & $\begin{array}{l}\text { Ictalurus } \\
\text { punctatus }\end{array}$ & Yes & Unsuccessful & Physical & Electrofishing & Open & NA & $>1$ \\
\hline 29 & No & $\begin{array}{l}\text { Ictalurus } \\
\text { punctatus }\end{array}$ & Yes & Eradication & Chemical & Rotenone & Closed & 0.25 & $\leq 1$ \\
\hline 30 & No & $\begin{array}{l}\text { Ictiobus } \\
\text { cyprinellus }\end{array}$ & Yes & Eradication & Chemical & Rotenone & Closed & 0.25 & $\leq 1$ \\
\hline 31 & No & $\begin{array}{l}\text { Micropterus } \\
\text { dolomieu }\end{array}$ & Yes & Unsuccessful & Physical & Electrofishing & Open & NA & $>1$ \\
\hline 32 & No & $\begin{array}{l}\text { Oncorhynchus } \\
\text { mykiss }\end{array}$ & Yes & Reduction & Physical & Electrofishing & Open & 136.80 & $>1$ \\
\hline 33 & No & $\begin{array}{c}\text { Oncorhynchus } \\
\text { mykiss }\end{array}$ & Yes & Eradication & Physical & Gillnetting & Closed & 11.70 & $>1$ \\
\hline 34 & No & $\begin{array}{c}\text { Oncorhynchus } \\
\text { mykiss }\end{array}$ & Yes & Eradication & Physical & Gillnetting & Closed & 1.60 & $>1$ \\
\hline 35 & No & $\begin{array}{c}\text { Oncorhynchus } \\
\text { mykiss }\end{array}$ & Yes & Reduction & Physical & Electrofishing & Closed & 0.27 & $\leq 1$ \\
\hline 36 & No & $\begin{array}{l}\text { Oncorhynchus } \\
\text { mykiss }\end{array}$ & Yes & Eradication & Chemical & Rotenone & Closed & 0.36 & $\leq 1$ \\
\hline 37 & No & $\begin{array}{c}\text { Oncorhynchus } \\
\text { mykiss }\end{array}$ & Yes & Eradication & Chemical & Rotenone & Variable & 4.00 & $>1$ \\
\hline 38 & No & $\begin{array}{l}\text { Oncorhynchus } \\
\text { mykiss }\end{array}$ & Yes & Reduction & Combination & $\begin{array}{c}\text { Chemical \& } \\
\text { Physical }\end{array}$ & Closed & 1.68 & $>1$ \\
\hline 39 & No & $\begin{array}{l}\text { Oncorhynchus } \\
\text { mykiss hybrids }\end{array}$ & Yes & Eradication & Physical & Gillnetting & Closed & 3.10 & $>1$ \\
\hline 40 & No & $\begin{array}{l}\text { Oncorhynchus } \\
\text { mykiss hybrids }\end{array}$ & Yes & Reduction & Physical & Gillnetting & Open & 1.60 & $>1$ \\
\hline 41 & No & $\begin{array}{l}\text { Oncorhynchus } \\
\text { mykiss hybrids }\end{array}$ & Yes & Reduction & Physical & Gillnetting & Open & 2.00 & $>1$ \\
\hline 42 & No & Perca fluviatilis & Yes & Reduction & Physical & Multiple & Variable & 0.17 & $\leq 1$ \\
\hline 43 & No & Perca fluviatilis & Yes & Reduction & Physical & Multiple & Variable & 0.46 & $\leq 1$ \\
\hline 44 & No & $\begin{array}{c}\text { Phalloceros } \\
\text { caudimaculatus }\end{array}$ & Yes & Reduction & Chemical & Rotenone & Closed & 500.00 & $>1$ \\
\hline 45 & No & Pomoxis spp. & Yes & Eradication & Chemical & Rotenone & Closed & 0.25 & $\leq 1$ \\
\hline 46 & No & $\begin{array}{c}\text { Pseudorasbora } \\
\text { parva }\end{array}$ & Yes & Eradication & Chemical & Rotenone & Variable & 2.20 & $>1$ \\
\hline 47 & No & $\begin{array}{c}\text { Pseudorasbora } \\
\text { parva }\end{array}$ & Yes & Eradication & Combination & $\begin{array}{c}\text { Chemical \& } \\
\text { Physical }\end{array}$ & Variable & 1.13 & $>1$ \\
\hline 48 & No & $\begin{array}{c}\text { Pseudorasbora } \\
\text { parva }\end{array}$ & Yes & Reduction & Chemical & Rotenone & Variable & 5.63 & $>1$ \\
\hline 49 & No & $\begin{array}{c}\text { Pseudorasbora } \\
\text { parva }\end{array}$ & Yes & Reduction & Physical & Rare & Closed & 0.30 & $\leq 1$ \\
\hline 50 & No & $\begin{array}{c}\text { Pterygoplichthys } \\
\text { disjunctivus }\end{array}$ & Yes & Eradication & Physical & Rare & Open & 42.32 & $>1$ \\
\hline 51 & No & Salmo trutta & Yes & Reduction & Physical & Electrofishing & Closed & 0.16 & $\leq 1$ \\
\hline
\end{tabular}




\begin{tabular}{|c|c|c|c|c|c|c|c|c|c|}
\hline 52 & No & Salmo trutta & Yes & Eradication & Chemical & Rotenone & Variable & 4.00 & $>1$ \\
\hline 53 & No & Salmo trutta & Yes & Reduction & Chemical & Rotenone & Closed & 0.08 & $\leq 1$ \\
\hline 54 & No & Salmo trutta & Yes & Reduction & Chemical & Rotenone & Closed & 0.15 & $\leq 1$ \\
\hline 55 & No & $\begin{array}{l}\text { Salvelinus } \\
\text { fontinalis }\end{array}$ & Yes & Eradication & Combination & $\begin{array}{c}\text { Chemical \& } \\
\text { Physical }\end{array}$ & Closed & 5.11 & $>1$ \\
\hline 56 & No & $\begin{array}{l}\text { Salvelinus } \\
\text { fontinalis }\end{array}$ & Yes & Eradication & Chemical & Antimycin & Variable & NA & $>1$ \\
\hline 57 & No & $\begin{array}{l}\text { Salvelinus } \\
\text { fontinalis }\end{array}$ & Yes & Eradication & Physical & Gillnetting & Closed & 11.70 & $>1$ \\
\hline 58 & No & $\begin{array}{l}\text { Salvelinus } \\
\text { fontinalis }\end{array}$ & Yes & Eradication & Physical & Gillnetting & Closed & 1.50 & $>1$ \\
\hline 59 & No & $\begin{array}{l}\text { Salvelinus } \\
\text { fontinalis }\end{array}$ & Yes & Eradication & Physical & Gillnetting & Variable & 1.20 & $>1$ \\
\hline 60 & No & $\begin{array}{l}\text { Salvelinus } \\
\text { fontinalis }\end{array}$ & Yes & Eradication & Physical & Gillnetting & Closed & 1.60 & $>1$ \\
\hline 61 & No & $\begin{array}{l}\text { Salvelinus } \\
\text { fontinalis }\end{array}$ & Yes & Eradication & Biocontrol & $\begin{array}{l}\text { Stocking } \\
\text { Predators }\end{array}$ & Closed & 2.60 & $>1$ \\
\hline 62 & No & $\begin{array}{l}\text { Salvelinus } \\
\text { fontinalis }\end{array}$ & Yes & Eradication & Biocontrol & $\begin{array}{l}\text { Stocking } \\
\text { Predators }\end{array}$ & Closed & 10.50 & $>1$ \\
\hline 63 & No & $\begin{array}{l}\text { Salvelinus } \\
\text { fontinalis }\end{array}$ & Yes & Reduction & Biocontrol & $\begin{array}{l}\text { Stocking } \\
\text { Predators }\end{array}$ & Closed & 1.00 & $\leq 1$ \\
\hline 64 & No & $\begin{array}{l}\text { Salvelinus } \\
\text { fontinalis }\end{array}$ & Yes & Reduction & Biocontrol & $\begin{array}{l}\text { Stocking } \\
\text { Predators }\end{array}$ & Closed & 1.00 & $\leq 1$ \\
\hline 65 & No & $\begin{array}{l}\text { Salvelinus } \\
\text { fontinalis }\end{array}$ & Yes & Reduction & Biocontrol & $\begin{array}{l}\text { Stocking } \\
\text { Predators }\end{array}$ & Closed & 2.60 & $>1$ \\
\hline 66 & No & $\begin{array}{l}\text { Salvelinus } \\
\text { fontinalis }\end{array}$ & Yes & Reduction & Biocontrol & $\begin{array}{l}\text { Stocking } \\
\text { Predators }\end{array}$ & Closed & 3.50 & $>1$ \\
\hline 67 & No & $\begin{array}{l}\text { Salvelinus } \\
\text { fontinalis }\end{array}$ & Yes & Reduction & Biocontrol & $\begin{array}{l}\text { Stocking } \\
\text { Predators }\end{array}$ & Closed & 5.10 & $>1$ \\
\hline 68 & No & $\begin{array}{l}\text { Salvelinus } \\
\text { fontinalis }\end{array}$ & Yes & Reduction & Biocontrol & $\begin{array}{l}\text { Stocking } \\
\text { Predators }\end{array}$ & Closed & 5.10 & $>1$ \\
\hline 69 & No & $\begin{array}{l}\text { Salvelinus } \\
\text { fontinalis }\end{array}$ & Yes & Reduction & Biocontrol & $\begin{array}{l}\text { Stocking } \\
\text { Predators }\end{array}$ & Closed & 8.40 & $>1$ \\
\hline 70 & No & $\begin{array}{l}\text { Salvelinus } \\
\text { fontinalis }\end{array}$ & Yes & Reduction & Biocontrol & $\begin{array}{l}\text { Stocking } \\
\text { Predators }\end{array}$ & Closed & 10.90 & $>1$ \\
\hline 71 & No & $\begin{array}{l}\text { Salvelinus } \\
\text { fontinalis }\end{array}$ & Yes & Reduction & Biocontrol & $\begin{array}{l}\text { Stocking } \\
\text { Predators }\end{array}$ & Closed & 15.80 & $>1$ \\
\hline 72 & No & $\begin{array}{l}\text { Salvelinus } \\
\text { fontinalis }\end{array}$ & Yes & Reduction & Biocontrol & $\begin{array}{l}\text { Stocking } \\
\text { Predators }\end{array}$ & Closed & 16.00 & $>1$ \\
\hline 73 & No & $\begin{array}{l}\text { Salvelinus } \\
\text { fontinalis }\end{array}$ & Yes & Unsuccessful & Biocontrol & $\begin{array}{l}\text { Stocking } \\
\text { Predators }\end{array}$ & Closed & 2.60 & $>1$ \\
\hline 74 & No & $\begin{array}{l}\text { Salvelinus } \\
\text { fontinalis }\end{array}$ & Yes & Eradication & Physical & Multiple & Closed & 2.17 & $>1$ \\
\hline 75 & No & $\begin{array}{l}\text { Salvelinus } \\
\text { fontinalis }\end{array}$ & Yes & Eradication & Physical & Multiple & Closed & 32.80 & $>1$ \\
\hline 76 & No & $\begin{array}{l}\text { Salvelinus } \\
\text { fontinalis }\end{array}$ & Yes & Eradication & Physical & Gillnetting & Closed & 21.00 & $>1$ \\
\hline 77 & No & $\begin{array}{l}\text { Salvelinus } \\
\text { fontinalis }\end{array}$ & Yes & Eradication & Physical & Electrofishing & Closed & 0.40 & $\leq 1$ \\
\hline 78 & No & $\begin{array}{l}\text { Salvelinus } \\
\text { fontinalis }\end{array}$ & Yes & Eradication & Physical & Electrofishing & Closed & 0.58 & $\leq 1$ \\
\hline 79 & No & $\begin{array}{l}\text { Salvelinus } \\
\text { fontinalis }\end{array}$ & Yes & Eradication & Physical & Electrofishing & Closed & 0.72 & $\leq 1$ \\
\hline
\end{tabular}




\begin{tabular}{|c|c|c|c|c|c|c|c|c|c|}
\hline 80 & No & $\begin{array}{l}\text { Salvelinus } \\
\text { fontinalis }\end{array}$ & Yes & Reduction & Physical & Electrofishing & Closed & 0.16 & $\leq 1$ \\
\hline 81 & No & $\begin{array}{l}\text { Salvelinus } \\
\text { fontinalis }\end{array}$ & Yes & Reduction & Physical & Electrofishing & Closed & 0.30 & $\leq 1$ \\
\hline 82 & No & $\begin{array}{l}\text { Salvelinus } \\
\text { fontinalis }\end{array}$ & Yes & Reduction & Physical & Electrofishing & Closed & 0.48 & $\leq 1$ \\
\hline 83 & No & $\begin{array}{l}\text { Salvelinus } \\
\text { fontinalis }\end{array}$ & Yes & Eradication & Physical & Gillnetting & Closed & 0.18 & $\leq 1$ \\
\hline 84 & No & $\begin{array}{l}\text { Salvelinus } \\
\text { fontinalis }\end{array}$ & Yes & Eradication & Physical & Gillnetting & Closed & 0.25 & $\leq 1$ \\
\hline 85 & No & $\begin{array}{l}\text { Salvelinus } \\
\text { fontinalis }\end{array}$ & Yes & Eradication & Physical & Gillnetting & Closed & 0.27 & $\leq 1$ \\
\hline 86 & No & $\begin{array}{l}\text { Salvelinus } \\
\text { fontinalis }\end{array}$ & Yes & Reduction & Physical & Gillnetting & Closed & 0.38 & $\leq 1$ \\
\hline 87 & No & $\begin{array}{l}\text { Salvelinus } \\
\text { fontinalis }\end{array}$ & Yes & Reduction & Physical & Gillnetting & Closed & 0.29 & $\leq 1$ \\
\hline 88 & No & $\begin{array}{l}\text { Salvelinus } \\
\text { namaycush }\end{array}$ & Yes & Eradication & Physical & Gillnetting & Closed & 11.70 & $>1$ \\
\hline 89 & No & $\begin{array}{l}\text { Carcinus } \\
\text { maenas }\end{array}$ & No & Reduction & Physical & Rare & Open & 500.00 & $>1$ \\
\hline 90 & No & $\begin{array}{l}\text { Didemnum } \\
\text { vexillum }\end{array}$ & No & Unsuccessful & Physical & Rare & Open & NA & $\leq 1$ \\
\hline 91 & No & $\begin{array}{l}\text { Didemnum } \\
\text { vexillum }\end{array}$ & No & Unsuccessful & Combination & $\begin{array}{l}\text { Chemical \& } \\
\text { Physical }\end{array}$ & Open & 0.61 & $\leq 1$ \\
\hline 92 & No & $\begin{array}{c}\text { Dreissena } \\
\text { polymorpha }\end{array}$ & No & Reduction & Physical & Rare & Open & 0.39 & $\leq 1$ \\
\hline 93 & No & Mytilopsis sp. & No & Eradication & Chemical & Chlorine & Variable & NA & $\leq 1$ \\
\hline 94 & No & $\begin{array}{c}\text { Orconectes } \\
\text { rusticus }\end{array}$ & No & Reduction & Physical & Rare & Closed & 64.00 & $>1$ \\
\hline 95 & No & $\begin{array}{l}\text { Pacifastacus } \\
\text { leniusculus }\end{array}$ & No & Reduction & Physical & Multiple & Open & 0.34 & $\leq 1$ \\
\hline 96 & No & Perna perna & No & Eradication & Physical & Rare & Closed & 12.60 & $>1$ \\
\hline 97 & No & $\begin{array}{c}\text { Pomacea } \\
\text { canaliculata }\end{array}$ & No & Eradication & Physical & Rare & Variable & 1.60 & $>1$ \\
\hline 98 & No & $\begin{array}{l}\text { Terebrasabella } \\
\text { heterouncinata }\end{array}$ & No & Eradication & Physical & Rare & Closed & 0.01 & $\leq 1$ \\
\hline
\end{tabular}

R script C.1: Table generation and Fisher Exact Test R scripts for categorical variables

"Removal.Outcome" and "Compensation.Evidence"; produced using data set "Comp.Rev"

outcome.table <- table ( Comp.Rev \$ Removal.Outcome, Comp.Rev \$ Compensation.Evidence )

fisher.test ( outcome.table ) 
R script C.2: Table generation and Fisher Exact Test R scripts for categorical variables

"Removal.Method" and "Compensation.Evidence"; produced using data set "Comp.Rev"

method.table <- table ( Comp.Rev \$ Removal.Method, Comp.Rev \$ Compensation.Evidence )

fisher.test ( method.table )

R.script C.3: Generation of data set "Phys.Comp.Rev"; produced using package "dplyr" and data set "Comp.Rev"

Phys.Comp.Rev <- Comp.Rev \% . \% filter ( Removal.Method == " Physical " )

R script C.4: Table generation R script for categorical variables "Removal.Technique" and

"Compensation.Evidence"; produced using data set "Phys.Comp.Rev"

tech.table <- table ( Phys.Comp.Rev \$ Removal.Technique, Phys.Comp.Rev \$

Compensation.Evidence )

R script C.5: Table generation R script for categorical variables "Area.Connectivity" and "Compensation.Evidence"; produced using data set "Phys.Comp.Rev"

area.table <- table ( Phys.Comp.Rev \$ Area.Connectivity, Phys.Comp.Rev \$ Compensation.Evidence )

R script C.6: Table generation R script for categorical variables "Area.Size.Binary" and "Compensation.Evidence"; produced using data set "Phys.Comp.Rev"

conn.table <- table ( Phys.Comp.Rev \$ Area.Size.Binary, Phys.Comp.Rev \$

Compensation.Evidence )

R script C.7: Binomial logistic regression model R script for model "Comp.glm"; produced using data set "Phys.Comp.Rev"

Comp.glm <- glm ( Compensation.Evidence Area.Connectivity + Removal.Technique + Area.Size.Binary, data $=$ Phys.Comp.Rev, family $=\operatorname{binomial}\left(\operatorname{link}={ }^{\prime} \operatorname{logit}{ }^{\prime}\right)$ ) 
Table C.2: Binomial logistic regression scaled residuals for model "Comp.glm"

\begin{tabular}{|c|c|c|c|c|}
\hline Min & 1Q & Median & 3Q & Max \\
\hline-1.5660 & -0.6341 & -0.2959 & 0.1055 & 2.5101 \\
\hline
\end{tabular}

Table C.3: Binomial logistic regression model summary output for model "Comp.glm"; levels for the intercept are as follows: Removal.Technique = "Electrofishing"; Area.Connectivity = "Closed";

Area.Size.Binary $=$ " $\leq 1$ "

\begin{tabular}{|c|c|c|c|c|}
\hline & $\begin{array}{c}\text { Estimate } \\
\text { (Coefficient) }\end{array}$ & $\begin{array}{l}\text { Standard } \\
\text { error }\end{array}$ & $z$ & $p$ \\
\hline (Intercept) & -1.5021 & 0.7671 & -1.958 & 0.0502 \\
\hline $\begin{array}{l}\text { Removal.Technique: } \\
\text { "Gillnetting" }\end{array}$ & -3.2231 & 1.3369 & -2411 & 0.0159 \\
\hline $\begin{array}{l}\text { Removal.Technique: } \\
\text { "Multiple" }\end{array}$ & -2.0979 & 0.9993 & -2.099 & 0.0358 \\
\hline $\begin{array}{l}\text { Removal.Technique: } \\
\text { "Other" }\end{array}$ & -2.3253 & 1.0695 & -2.174 & 0.0297 \\
\hline $\begin{array}{r}\text { Area.Connectivity: } \\
\text { "Open" }\end{array}$ & 0.7622 & 0.9486 & 0.803 & 0.4217 \\
\hline $\begin{array}{l}\text { Area.Connectivity: } \\
\text { "Variable" }\end{array}$ & 2.6817 & 1.0509 & 2.552 & 0.0107 \\
\hline $\begin{array}{r}\text { Area.Size.Binary: } \\
">1 "\end{array}$ & 1.6187 & 0.9517 & 1.701 & 0.0890 \\
\hline
\end{tabular}

Table C.4: Binomial logistic regression model summary output null and residual deviance for model "Comp.glm"

\begin{tabular}{|c|c|c|}
\hline & Deviance & $\mathrm{df}$ \\
\hline $\begin{array}{r}\text { Null } \\
\text { Deviance }\end{array}$ & 71.398 & 62 \\
\hline $\begin{array}{l}\text { Residual } \\
\text { Deviance }\end{array}$ & 48.176 & 56 \\
\hline
\end{tabular}


Table C.5: Binomial logistic regression model summary output AIC for model “Comp.glm”

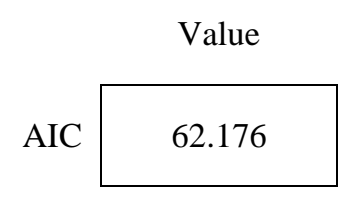

R script C.8: Multiple comparisons of means R script for variable "Removal.Technique"; produced using function "glht" from R package "multcomp" and model "Comp.glm"; model was rerun to exclude $p$ value adjustment

$$
\begin{aligned}
& \text { library ( multcomp }) \\
& \text { Mult.Tech <- ( glht }(\text { Comp.glm , mcp }(\text { Removal.Technique }=\text { " Tukey " })) \text { ) } \\
& \text { summary ( Mult.Tech }, \text { test }=\text { adjusted }(" \text { none " }))
\end{aligned}
$$

Table C.6: Multiple comparisons of means summary output for "Mult.Tech"; $p$ - values are unadjusted

\begin{tabular}{c|c|c|c|c|} 
& \multicolumn{1}{c}{$\begin{array}{c}\text { Estimate } \\
\text { (Coefficient) }\end{array}$} & \multicolumn{2}{c}{$\begin{array}{c}\text { Standard } \\
\text { error }\end{array}$} \\
\cline { 2 - 5 } Gillnetting - Electrofishing & -3.2231 & 1.3369 & -2.411 & 0.0159 \\
\cline { 2 - 5 } Multiple - Electrofishing & -2.0979 & 0.9993 & -2.099 & 0.0358 \\
\cline { 2 - 5 } Other - Electrofishing & -2.3253 & 1.0695 & -2.174 & 0.0297 \\
\cline { 2 - 5 } Multiple - Gillnetting & 1.1252 & 1.4210 & 0.762 & 0.4285 \\
\cline { 2 - 5 } Other - Gillnetting & 0.8978 & 1.4672 & 0.612 & 0.5406 \\
\cline { 2 - 5 } Other - Multiple & -0.2274 & 1.1780 & -0.193 & 0.8469 \\
\cline { 2 - 5 } & & & & \\
\cline { 2 - 5 } & & &
\end{tabular}

R script C.9: Multiple comparisons of means R script for variable "Area.Connectivity"; produced using function "glht" from R package "multcomp" and model "Comp.glm"; model was rerun to exclude $p$ value adjustment

library ( multcomp )

Conn.Tech <- ( glht ( Comp.glm, mcp (Area.Connectivity = " Tukey " ) ) )

summary ( Conn.Tech, test $=$ adjusted $($ " none " $)$ ) 
Table C.7: Multiple comparisons of means summary output for “Conn.Tech"; $p$ - values are unadjusted

\begin{tabular}{cc|c|c|c|}
\multicolumn{1}{c}{$\begin{array}{c}\text { Estimate } \\
\text { (Coefficient) }\end{array}$} & \multicolumn{2}{c}{$\begin{array}{c}\text { Standard } \\
\text { error }\end{array}$} & \multicolumn{2}{c}{$z$} \\
\cline { 2 - 5 } Open - Closed & 0.7622 & 0.9486 & 0.803 & 0.4217 \\
\cline { 2 - 5 } Variable - Closed & 2.6817 & 1.0509 & 2.552 & 0.0107 \\
\cline { 2 - 5 } Variable - Open & 1.9195 & 1.2245 & 1.568 & 0.1170 \\
\cline { 2 - 5 } & & & &
\end{tabular}

R script C.10: Generation of data set "Fish.Phys.Comp.Rev"; produced using package "dplyr" and data set "Phys.Comp.Rev"

Fish.Phys.Comp.Rev <- Phys.Comp.Rev \% . \% filter ( Fish.Species == " Yes " )

R script C.11: Binomial logistic regression model R script for model "Fish.Comp.glm"; produced using data set "Fish.Phys.Comp.Rev"

Fish.Comp.glm <- glm ( Compensation.Evidence Area.Connectivity + Removal.Technique + Area.Size.Binary, data $=$ Fish.Phys.Comp.Rev, family $=$ binomial $(\operatorname{link}=$ ' logit ' $)$ )

Table C.8: Binomial logistic regression scaled residuals for model "Fish.Comp.glm"

\begin{tabular}{|c|c|c|c|c|}
\hline Min & 1Q & Median & 3Q & Max \\
\hline-1.5574 & -0.5864 & -0.3025 & 0.4768 & 2.4928 \\
\hline
\end{tabular}


Table C.9: Binomial logistic regression model summary output for model "Fish.Comp.glm"; levels for the intercept are as follows: Removal.Technique = "Electrofishing"; Area.Connectivity = "Closed";

Area.Size.Binary $=$ " $\leq 1$ "

\begin{tabular}{|c|c|c|c|c|}
\hline & $\begin{array}{c}\text { Estimate } \\
\text { (Coefficient) }\end{array}$ & $\begin{array}{c}\text { Standard } \\
\text { error }\end{array}$ & $z$ & $p$ \\
\hline (Intercept) & -1.7533 & 0.8602 & -2.038 & 0.0415 \\
\hline $\begin{array}{l}\text { Removal.Technique: } \\
\text { "Gillnetting" }\end{array}$ & -3.7546 & 1.5474 & -2.426 & 0.0152 \\
\hline $\begin{array}{l}\text { Removal.Technique: } \\
\text { "Multiple" }\end{array}$ & -2.2894 & 1.0703 & -2.139 & 0.0324 \\
\hline $\begin{array}{l}\text { Removal.Technique: } \\
\text { "Other" }\end{array}$ & -1.0844 & 1.2019 & -0.902 & 0.3669 \\
\hline $\begin{array}{r}\text { Area.Connectivity: } \\
\text { "Open" }\end{array}$ & 0.1665 & 1.1376 & 0.146 & 0.8837 \\
\hline $\begin{array}{l}\text { Area.Connectivity: } \\
\text { "Variable" }\end{array}$ & 2.9509 & 1.2048 & 2.449 & 0.0143 \\
\hline $\begin{array}{r}\text { Area.Size.Binary: } \\
\text { "> 1" }\end{array}$ & 2.4465 & 1.2568 & 1.947 & 0.0516 \\
\hline
\end{tabular}

Table C.10: Binomial logistic regression model summary output null and residual deviance for model "Fish.Comp.glm"

\begin{tabular}{|c|c|c|}
\hline & Deviance & df \\
\hline $\begin{array}{r}\text { Null } \\
\text { Deviance }\end{array}$ & 66.326 & 54 \\
\hline $\begin{array}{l}\text { Residual } \\
\text { Deviance }\end{array}$ & 43.130 & 48 \\
\hline
\end{tabular}

Table C.11: Binomial logistic regression model summary output AIC for model "Fish.Comp.glm"

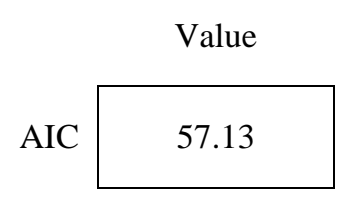


R script C.12: Multiple comparisons of means R script for variable "Removal.Technique"; produced using function "glht" from R package "multcomp" and model "Fish.Comp.glm"; model was rerun to exclude $p$ value adjustment

library ( multcomp )

Fish.Mult.Tech <- $($ glht $($ Fish.Comp.glm, mcp $($ Removal.Technique $=$ " Tukey " $))$ summary ( Fish.Mult.Tech , test $=$ adjusted $($ " none " $))$

Table C.12: Multiple comparisons of means summary output for "Fish.Mult.Tech"; $p$ - values are unadjusted

\begin{tabular}{c|c|c|c|c|} 
& \multicolumn{1}{c}{$\begin{array}{c}\text { Estimate } \\
\text { (Coefficient) }\end{array}$} & \multicolumn{1}{c}{$\begin{array}{c}\text { Standard } \\
\text { error }\end{array}$} & \multicolumn{1}{c}{$z$} \\
\cline { 2 - 5 } Gillnetting - Electrofishing & -3.755 & 1.547 & -2.426 & 0.0152 \\
\cline { 2 - 5 } Multiple - Electrofishing & -2.289 & 1.070 & -2.139 & 0.0324 \\
\cline { 2 - 5 } Other - Electrofishing & -1.084 & 1.202 & -0.902 & 0.3669 \\
\cline { 2 - 5 } Multiple - Gillnetting & 1.465 & 1.473 & 0.995 & 0.3198 \\
\cline { 2 - 5 } Other - Gillnetting & 2.670 & 1.752 & 1.524 & 0.1274 \\
\cline { 2 - 5 } Other - Multiple & 1.205 & 1.343 & 0.897 & 0.3696 \\
\cline { 2 - 5 } & &
\end{tabular}

R script C.13: Multiple comparisons of means R script for variable "Area.Connectivity"; produced using function "glht" from R package "multcomp" and model "Fish.Comp.glm"; model was rerun to exclude $p$ value adjustment

library ( multcomp )

Fish.Conn.Tech <- $($ glht $($ Fish.Comp.glm, mcp $($ Area.Connectivity = " Tukey " $))$

summary $($ Fish.Conn.Tech, test $=$ adjusted $($ " none " ) ) 
Table C.13: Multiple comparisons of means summary output for "Fish.Conn.Tech"; $p$ - values are unadjusted

\begin{tabular}{c|c|c|c|c|}
\multicolumn{1}{c}{} & \multicolumn{1}{c}{$\begin{array}{c}\text { Estimate } \\
\text { (Coefficient) }\end{array}$} & \multicolumn{2}{c}{$\begin{array}{c}\text { Standard } \\
\text { error }\end{array}$} & \multicolumn{1}{c}{$z$} \\
\cline { 2 - 5 } Open - Closed & 0.1665 & 1.1376 & 0.146 & 0.8837 \\
\cline { 2 - 5 } Variable - Closed & 2.9509 & 1.2048 & 2.449 & 0.0143 \\
\cline { 2 - 5 } Variable - Open & 2.7845 & 1.6326 & 1.706 & 0.0881 \\
\cline { 2 - 5 } & & & &
\end{tabular}




\title{
Appendix D: Cascades to Coast GK-12 Curriculum
}
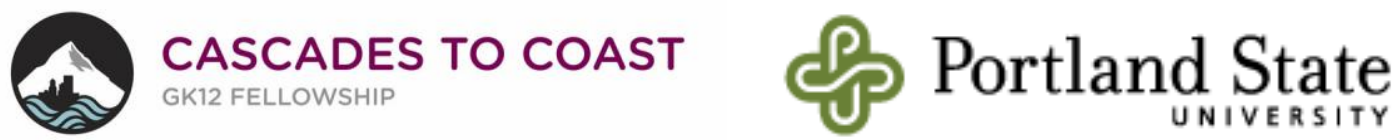

\author{
Defining Invasive Species and Understanding \\ Natural Resistance to Their Expansion \\ Cascades to Coast GK-12 Curriculum
}

Fellow: Brian Turner (PSU Environmental Science)

Teacher: Laurie McDowell (Lent School)

Advisor: Catherine de Rivera (PSU Environmental Science)

\section{Learning goal:}

Over a series of three activities, students will be introduced to the concept of invasive species, learn how abiotic and biotic conditions in a habitat can prevent the establishment and spread of invasive species, and how human impacts on those conditions can facilitate the invasion of new species.

\section{Introduction:}

Invasive species, non-native organisms that cause economic or ecological harm, are an ever growing topic of concern among scientists, governments, farmers and nature lovers. These organisms are generally introduced to new regions through human activities, either intentionally or as a byproduct of other activities. Invasive species are a major threat to biodiversity, second only to habitat destruction, and threaten $\sim 42 \%$ of species on the endangered species list (Pimentel et al. 2005). Costs to agriculture, fisheries, forestry, ecological tourism and other industries by introduced species are estimated at $\$ 120$ billion per year to the U.S. economy alone (Pimentel et al. 2005).

Despite the risk invasive species pose, not all habitats are equally vulnerable to invasion. Numerous factors such as the tolerances of invasive species to environmental conditions and the biodiversity of a habitat will influence how vulnerable it is to invasion. An understanding of what makes a habitat more resistant to invasion can aid in the prioritization of resources and efforts for managing invasive species.

\section{Invasive Species Information Resources:}

- https://www.nwf.org/Wildlife/Threats-to-Wildlife/Invasive-Species.aspx 
- https://www.fws.gov/invasives/faq.html

- https://www.fws.gov/verobeach/PythonPDF/CostofInvasivesFactSheet.pdf

- http://oceanservice.noaa.gov/facts/invasive.html

- http://www.nature.org/ourinitiatives/habitats/forests/explore/invasives-101.xml

\section{References:}

[1] D. Pimentel, R. Zuniga, and D. Morrison, "Update on the environmental and economic costs associated with alien-invasive species in the United States," Ecol. Econ., vol. 52, no. 3 SPEC. ISS., pp. 273-288, 2005. 


\author{
Defining Invasive Species Activity \\ Cascades to Coast GK-12 Curriculum
}

\title{
Learning goal:
}

Students will be introduced to the concept of invasive species, learn the criteria used to categorize a species as invasive and then use these criteria to categorize local species as native, non-native, pest, or invasive.

\section{Students Learning Objectives:}

- Understand the concept of invasive species

- Using a species point of origin and their ecological/economic impacts, categorize local species as native, non-native, pest, or invasive

\section{Target Grade:}

$6^{\text {th }}$

\section{Next Generation Science Standards:}

- 5-ESS3-1. Obtain and combine information about ways individual communities use science ideas to protect the Earth's resources and environment.

- MS-ESS3-3. Apply scientific principles to design a method for monitoring and minimizing a human impact on the environment.

\section{Curriculum Summary:}

Students will be introduced to the concept of invasive species and the criteria necessary for a species to be considered invasive. Based on these criteria, groups of students will be asked to categorize a selection of species found in Oregon as native, nonnative, pest or invasive. These organisms represent a variety of species ranging from mammals to single celled plants across three different habitat types (marine, freshwater, and terrestrial). Each species is represented by a card with a picture and information to aid students in selecting a category (native, non-native, pest or invasive). There are 36 species cards in total, 12 for each of the three habitats, and 3 for each category per 
habitat. After the students have divided the cards into categories, the class will discuss the rationale for choices. Particular emphasis should be placed on discussing those species where different groups chose different categories. The decision to categorize a species as invasive is often complicated and the rationale behind each group's choice can be discussed.

\section{Definitions:}

Organism: An individual living thing such as a single plant, animal, bacteria, or fungus.

Invasive Species: A species that is non-native (evolved elsewhere) in relation to the location under consideration and whose introduction causes or is likely to cause economic or environmental harm or harm to human health.

Marine: Found in or produced in the ocean. In this activity, it referees to organisms that live in the ocean.

Terrestrial: Found on or related to the Earth. In this activity, it referees to organisms that live on land.

Freshwater: Found in or produced in fresh water. In this activity, it referees to organisms that live in lakes, ponds, and rivers.

\section{Background:}

While most people agree that invasive species are a problem, there has been debate on what species should be considered invasive. Some people think any species that causes problems should be considered invasive, while some think it should be based only on where a species is originally from. On February 3, 1999, then President Bill Clinton signed Executive Order 13112 which clarified the definition of what the United States government would consider an invasive species. The order defined an invasive species as a species that is:

1) non-native (or alien) to the ecosystem under consideration and

2) whose introduction causes or is likely to cause economic or environmental harm or harm to human health.

It is important to remember that for a species to be invasive it must fulfill both of the criteria stated put forward in Executive Order 13112. A species may originally be from somewhere else, but not cause any problems in its new habitat. Some species are grown commercially and are of great economic importance, even though they may originally be from another part of the world. Additionally, there are many species that are native to a region but cause problems similarly to invasive species. Based on the criteria presented in Executive Order 12112, a species can be classified into one of four categories.

1) Native: The species is from the location under consideration and has positive/neutral impacts. An example for the Pacific Northwest is Chinook 
salmon. Chinook salmon are native to the region and are of economic and ecological importance.

2) Pest: The species from the location under consideration and has negative impacts. An example for the Pacific Northwest is deer ticks. Deer ticks are native to the region, but are a vector for Lyme disease.

3) Non-Native: The species is not from the location under consideration and has positive/neutral impacts. An example for the Pacific Northwest is llamas. Llamas are raised as livestock, do not cause problems in the region, and are native to South America.

4) Invasive: The species is not from the location under consideration and has negative impacts. An example for the Pacific Northwest is English ivy. English ivy is originally from Europe, overgrows native ground cover, and can damage trees.

\section{Materials:}

- Additional information:

○ https://www.invasivespeciesinfo.gov/laws/execorder.shtml

- Defining Invasive Species Answer Key (for instructors use)

- Available at https://www.pdx.edu/soe-gk12/curriculum

- Handouts and worksheets:

- Available at https://www.pdx.edu/soe-gk12/curriculum

- Invasive Species Cards (36 in total, one set per group)

○ Invasive Species Sorting Sheet (1 per group)

\section{Activity Plan:}

1) Ask the class if they have ever heard about invasive species and what the students think it means before giving the official definition put forth in Executive Order 13112.

2) Provide an example of an invasive species, being sure to highlight the impact of the species and its point of origin.

3) Introduce the definitions and provide examples for native, pest, and non-native species. Be sure to highlight the impact of the species and its point of origin.

4) Divide the class into groups (2-4) and provide each group with a Sorting Sheet and a set of Invasive Species Cards. Explain that all of these organisms can currently be found in Oregon (though they may not be from here originally) and 
that the colors of their names represent their habitats (green $=$ freshwater, blue $=$ marine, red $=$ terrestrial $)$.

5) Have the students place each card onto one of the fours squares on the sorting sheet depending on if they think the species should be classified as native, nonnative, pest, or invasive. They should use their own knowledge of the species and the information on the cards to make this decision.

6) Once completed, go through the list and ask the class which category they put each species in and why. If a species has been assigned to more than one category, ask the students to explain their choice.

\section{Related Concepts:}

- Biology: competition, predation, food webs

- Agriculture: transplanting crops and livestock, crop pests

- Government: Presidential powers

- Historical: European colonization

- Economics: Global trade

\section{Extensions:}

- What is or is not invasive changes entirely depending on your global perspective. Organisms that are native to the United States may be very destructive if introduced to a new location. Have the students make new Invasive Species Sorting Sheet, replacing the word "Oregon" with "Miyagi, Japan". Miyagi is a Japanese prefecture. Have them categorize the species again, only this time from the perspective of someone in Miyagi. Have the students assume the species have the same impacts in Miyagi as they do in Oregon. Discuss with the students what has changed about the classification of the species. Discuss if it is reasonable to assume a species will have the same impacts abroad as it does in its native range. Spoiler alert, it is not.

- There is constant debate on whether or not to classify a species as invasive. This is especially the case with domesticated species. These species have numerous positive impacts for humans (companionship, labor, food, etc) but can have negative consequences when released into the wild. Below are examples of three such species. Have student's list the positive impacts of these species on their lives, and then provide information on the negative impacts of wild populations. Have the class discuss and ultimately classify these species as invasive or nonnative.

- Himalayan Blackberry 
- http://www.invasive.org/gist/moredocs/rubarm01.pdf

○ Housecats

- http://wildlife.org/wp-content/uploads/2014/05/Feral-Cats.pdf

○ Horses

- http://wildlife.org/wp-content/uploads/2014/05/Feral-Horse-andBurro.pdf 


\section{Abiotic Resistance to Invasive Species Activity Cascades to Coast GK-12 Curriculum}

\section{Learning goal:}

Students will be introduced to the concept of transport vectors and how technological innovations have increased the spread of invasive species. They will then learn about abiotic resistance, how invasive species are more likely to survive in habitats similar to their native range, and how the time of year a species is introduced changes if they will survive or not. Finally, they will examine that as climate change alters abiotic conditions, the potential ranges of invasive species will also change.

\section{Students Learning Objectives:}

- Understand what is a transport vector and how it relates to invasive species

- Understand abiotic resistance and how it prevents the establishment of some invasive species

- Understand how climate change may affect abiotic resistance

\section{Target Grade:}

$6^{\text {th }}$

\section{Oregon State Standards:}

- MS-ESS3-5. Ask questions to clarify evidence of the factors that have caused the rise in global temperatures over the past century.

- MS-LS2-4. Construct an argument supported by empirical evidence that changes to physical or biological components of an ecosystem affect populations.

\section{Curriculum Summary:}

Students will be introduced to the concept of transport vectors and how they relate to the spread of invasive species. The class will then discuss how one specific type of vector, ballast water, transports aquatic larvae throughout the world. The zebra mussel (Dreissena polymorpha) will be discussed as an example of an invasive species introduced via ballast. The students will then be introduced to the concept of abiotic resistance and how it can prevent the establishment of an invasive species in a new 
habitat. The students will then play a game where they are asked to create a species of marine larvae and to choose the temperature tolerance of the species. Using a map of global ports along with temperature data, the students will mimic the transport of larvae around the world and examine how frequently their larvae survive. They will then repeat the activity using temperatures that have been increased to mimic global warming.

\section{Background:}

Every day goods and people are transported around the globe and invasive species are along for the ride. Planes, boats, cars, and even our boots all act as transport vectors, moving invasive species from one location to another. Although invasive species can spread naturally, by hitching a ride with us they are able to spread much further and much, much faster than they ever could otherwise. For example, the zebra mussel, Dreissena polymorpha, is a species of freshwater mussel that is native to southern Russia. It was transported from Russia to the Great Lakes in the ballast water of a cargo ship. Sincere it's arrival in the 1980's, this species has clogged hydro-electric and other water intake pipes, costing businesses and communities billions in damages.

Despite the dangers of transporting invasive species, it is important to remember that not all organisms survive long enough to cause problems. Many die in transit; though as boats and planes become faster and faster it increases the chances species will survive the trip. Of those that do survive the trip, many will die off due to abiotic resistance. This occurs when abiotic (non-living) conditions such as temperature are not suitable for the organism. For example, cargo ships transport numerous species via ballast water. The ship will collect ballast water in one location, bringing along any swimming aquatic larvae with it. When they reach a new location and need to drop ballast, they will dump any surviving larvae in this new location. If the temperature or salinity of this new location is not suitable for the larvae, they will die. However, as abiotic conditions change due to events like global warming, previously inhospitable locations may become suitable for invasive species.

\section{Definitions:}

- Transport vector: A means by which invasive species are transported from one location to another. Examples include man-made vectors like ships (via ballast water, in cargo, or on the boar), airplanes (cargo or intentional shipping) and natural vectors like animals (attached to fur or inside body).

- Abiotic resistance: Non-living aspects of a location that may prevent an invasive species from establishing. These include temperature, water availability, salinity (if aquatic), etc. It is generally predicted that the more dissimilar the abiotic conditions are between a species native habitat and a habitat to which it has been introduced, the less likely it is the species will successfully invade. 
- Ballast water: Water carried in ships' ballast tanks to improve stability, balance and trim. It is taken up when cargo is unloaded and discharged when cargo loaded.

- Larvae: An immature form of animals that undergo metamorphosis to an adult form. For example, a caterpillar is the larvae of butterfly, and a tadpole is the larvae of a frog.

- $\quad$ Salinity: The measure of the amount of salt dissolved in water, usually measured in parts per thousand (ppt). The average ocean salinity is around $35 \mathrm{ppt}$ and the average river water salinity is $\leq 0.5 \mathrm{ppt}$.

\section{Materials:}

- Additional Information:

○ http://www.adfg.alaska.gov/index.cfm?adfg=invasive.pathways

○ http://www.biol.wwu.edu/peterson/vectors\&pathways.pdf

○ https://www.nwf.org/What-We-Do/Protect-Wildlife/InvasiveSpecies/Ballast-Water.aspx

○ http://www.epa.vic.gov.au/your-environment/water/ballast-water

○ https://www.nwf.org/Wildlife/Threats-to-Wildlife/InvasiveSpecies/InvasiveMussels.aspx

- Abiotic Resistance - Ballast Water and Marine Larvae Slides

- 20-sided die (one per group); alternatively can use Random Number Sheet (see below)

- Colored pencils (2 colors per student)

- Handouts and worksheets:

- Available at https://www.pdx.edu/soe-gk12/curriculum

- Abiotic Resistance - Port Abiotic Conditions Sheets (Pre and Post Global Warming; one set per group)

- Abiotic Resistance - Port Map (one per student)

- Random Number Sheet (one per group); alternatively can use 20-sided die (see above)

- Abiotic Resistance - Larvae Cards (one card per student)

\section{Activity Plan:}

1) Briefly review with students the concept of invasive species.

2) Define the term transport vector. Ask students to list possible vectors. Emphasize how these vectors have changed throughout history in terms of speed and frequency.

3) Explain what ballast is and how it can act as a vector for marine larvae. Show the students the Abiotic Resistance - Ballast Water and Marine Larvae Slides to highlight what ballast water is and the variety of shape and form of marine larvae. 
4) Hand out a larvae card and port map to each student. Ask them to name their larva, draw a picture of it, and decide its temperature tolerance. This tolerance will be the range the larva can survive. They can only circle one option and must use one of the options on the card.

5) Hand out the Abiotic Resistance - Pre-Global Warming Port Abiotic Conditions Sheet and Random Number Sheet or 20-sided die to each table. Have each student select a port to which their larva is native. This location must have a temperature in their larva can survive in the February column (e.g., Can survive in Dubai in February).

6) Each student will take turns using the random number sheet/die to select a number. They will need to roll the die or close their eyes and point randomly at the random number sheet. The number they choose is the port their larva is transported to. If the temperature in the February column is within their larva's tolerance range then it survives and they will draw a line using a colored pencil from their starting port to the new port. On their next turn, they will select a number twice, once for each port. They will do this for every port they spread to.

7) If the temperature in the February column is not in their larva's tolerance range then the larva dies. They will put a small " $\mathrm{X}$ " on their card and try again next turn.

8) If any student has larvae go to port \#20, Detroit, their larvae dies. Because Detroit is a freshwater port, the marine larvae of the students will be unable to survive no matter the temperature.

9) After 6 turns (or whatever is reasonable for the situation) have the students switch to using the June column for temperatures. Have the students switch colors and start again from their home port. Depending, you may want the students to use a new map.

10) After 6 turns, have the students compare the differences between the February and June paths. Were they different? Were they different across students?

\section{Related Concepts:}

- Biology: habitat suitability

- Economics: global trade

\section{Extensions:}

- Climate change stands to change a lot of things about our world, including the spread of invasive species. As global temperatures rise, areas that was previously too cold for a given species may become habitable. Re-run the activity using the Post-Global Warming Port Abiotic Conditions Sheet and have the students compare the results. Are there locations that you larvae can now survive in where it could not before? 


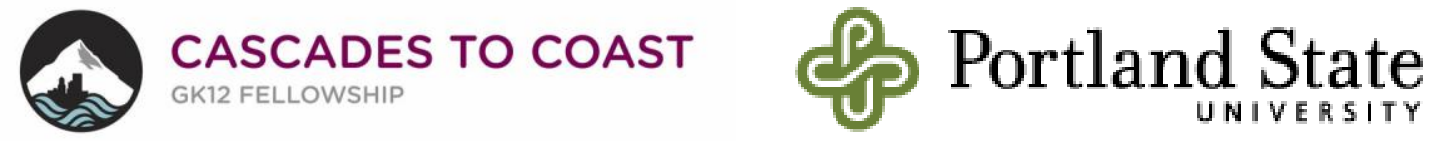 \\ Biotic Resistance to Invasive Species Activity Cascades to Coast GK-12 Curriculum}

\section{Learning goal:}

Students will be introduced to the concept of biotic resistance and the role it plays in the establishment of invasive species. They will then examine how the efficacy of biotic resistance is influenced by the characteristics of the invasive species and the predator diversity in the habitat to which it is being introduced. Finally, they will examine how impacts from humans can alter the efficacy of biotic resistance.

\section{Students Learning Objectives:}

- Understand the concept of biotic resistance

- Examine how the efficacy of biotic resistance to prevent invasion is determined by the characteristics of the invasive species and the predator community present in the invaded habitat

\section{Target Grade:}

$6^{\text {th }}$

\section{Oregon State Standards:}

- MS-ESS3-3. Apply scientific principles to design a method for monitoring and minimizing a human impact on the environment.

- MS-LS2-2. Construct an explanation that predicts patterns of interactions among organisms across multiple ecosystems

- MS-LS2-4. Construct an argument supported by empirical evidence that changes to physical or biological components of an ecosystem affect populations.

\section{Curriculum Summary:}

Students will be introduced to the concept of biotic resistance, how biotic resistance can prevent or limit the spread of invasive species, and how invasive species can overcome biotic resistance. The class will participate in a game in which they design 
their own clam species, in particular determining the defense mechanism it possess. A starting population of three of these clams is then introduced to a Pacific Northwest (PNW) estuary. The student's clams will "encounter" predators found in PNW estuaries via a slideshow. Each predator is best suited to consuming clams with specific defenses, and a student's clam will need to have certain traits in order to survive. For each predator, a student's clams will either survive or one clam will be consumed by the predator. If the student goes through the whole slideshow and has any clams remaining then their species has overcome biotic resistance and successfully invades the estuary.

\section{Background:}

Although invasive species can be destructive, most species that are introduced to a new region will not survive. Some will be unable to cope with the abiotic conditions present (temperature, etc). Another barrier to invasion is biotic resistance, or the living aspects of a new habitat. The strongest biotic factor that can limit invasions is predation. Predators will consume introduced species, which can reduce their number, wiping them out or limiting their range. For example, the invasive purple varnish clam, Nuttallia obscurata, is forced to live in the high intertidal as a result of predation by the Dungeness crab, Metacarcinus magister.

One important thing to remember is just because there are predators in a habitat does not mean that invasive species cannot establish. If an invasive species has the right kind of defenses, it will lessen the impact by predators and allow it to establish.

Alternatively, impacts from natural or human activities may reduce or eliminate predator populations, reducing predation pressure and allowing invasive species to establish.

\section{Definitions:}

- Biotic resistance: Living aspects of a location that may prevent an invasive species from establishing. This includes predation by local predators, infection by parasites or diseases, and competition with other species for resources. It is generally predicted that more diverse habitats are going to be more resistant to invasion, as there should be more potential predators and competitors.

- Clam: Aquatic organism of the Class Bivalvia (two-shelled) with shells of equal size. The majority of clams are filter feeders that use a pair of siphons to pull in water (siphon 1), remove organic particles and oxygen, then discharge the water along with waste materials (siphon 2). Most burrow and live in soft-substrates such sand or mud. There are marine and freshwater clams.

- Estuary: A partially enclosed coastal body of brackish water that has a least one river flowing into it and a connection with the open ocean. Estuaries are a transition zone between freshwater and marine environments. 


\section{Materials:}

- Additional Information:

- http://campus.lakeforest.edu/menke/PDFs/Bio131/Byers_Oecol_2002.pdf

- https://www.researchgate.net/profile/P_Sean_Mcdonald/publication/22578 7328_Biotic_resistance_to_green_crab_Carcinus_maenas_in_California_b ays/links/54c7adc50cf22d626a36d813.pdf

- https://www.researchgate.net/profile/P_Sean_Mcdonald/publication/22578 7328_Biotic_resistance to to green_crab_Carcinus_maenas_in_California_b ays/links/54c7adc50cf22d626a36d813.pdf

- Biotic Resistance - Clam Defense Slideshow

- Available at https://www.pdx.edu/soe-gk12/curriculum

- Biotic Resistance - Clam Defense Slideshow After Crab Harvest

- Available at https://www.pdx.edu/soe-gk12/curriculum

- Handouts and worksheets:

- Available at https://www.pdx.edu/soe-gk12/curriculum

- Biotic Resistance - Clam Species Cards (one card per student)

\section{Activity Plan:}

1) Briefly review with students the concepts of invasive species and abiotic resistance.

2) Introduce the concept of biotic resistance. Be sure to emphasize that although this is not as strong of a deterrent as abiotic resistance, it can still prevent or limit the spread of invasive species.

3) Show students the Clam Defense Slideshow, highlighting the 3 major ways clams defend themselves.

a. Burrowing Depth - Most clams live in sand or other soft-substrates. The deeper a clam burrows in this material, the more difficult it is for a predator to reach and capture it.

b. Shell Thickness - A clams soft tissues are housed within two shells (valves) joined together by a hinge (ligament). The thicker a clams shells, the harder it is for predators to penetrate the shell.

c. Muscle Strength - Clams posses an adductor muscle which, when contracted, pulls its two halves together. The larger and stronger the adductor muscle, the harder it is for predators to pull the shells apart.

4) Hand out a Clam Species Card to each student and tell them they will be creating their own clam species. Have them name the species and select how strong their defense will be in each of the 3 categories. The numbers cannot be changed during the game, and the sum of all three categories must equal 6. 
5) Explain to the students that three of each of their clam species has been introduced to the Pacific Northwest. These 3 clams are represented by the three clam icons on the species card.

6) Show the students the Pacific Northwest Predator Parade Slideshow. Each time a slide of a new predator comes up, read the appropriate description form below.

a. Red Rock Crab - This crab has long, strong claws which allow it to pull open or crush all but the toughest of clams. To survive an encounter with the Red Rock Crab, your clams must have a Burrowing Depth $=3$ or a Shell Thickness $=3$.

b. Moon Snail - This snail uses a spine-covered, tongue-like structure called a radula to drill a hole through a clams shell. To survive an encounter with the Moon Snail, your clams must have a Burrowing Depth $\geq 2$

c. Spotted Rock Crab - This crab has massive claws which can break a man's finger and crush even the toughest clams shell. To survive an encounter with the Spotted Rock Crab, your clams must have a Burrowing Depth $=3$.

d. Dungeness crab - This crab has fairly tough claws, but prefers to burrow into the sand after thinner shelled clams. To survive an encounter with the Dungeness crab, your clams need to have a Muscle Strength $=3$ or Shell Thickness $\geq 2$.

e. Pink Sea Star - This sea star can dig deep and pull clams open using structures called tube feet which cover the bottom of this colorful critter. To survive an encounter with the Pink Sea Star, your clams need a Muscle Strength $=3$.

f. Leopard Shark - Unlike some other sharks, this shark has flat teeth which it uses to crush the shells of shallow burrowing clams. To survive an encounter with a Leopard Shark, your clams need to have a Burrowing Depth $=3$ or a Shell Thickness $=3$.

7) Once you have read the description move to the next slide which shows the levels of a particular defense a clam needs to survive and encounter with this predator. If a student's clam does not survive, have them cross out one of the lives on their Clam Species Card.

8) Continue through the slide show in the same manner. If a student crosses out all three clams, the clam species has been wiped out. If the student makes it through all 6 predators with 1 or more clams remaining, then their species has survived and has invaded a new habitat.

9) Talk with the students about the traits of the surviving clams. Which traits seemed most beneficial, which the least? Would the outcome have been different if there were more clams in your starting population? Fewer clams? 


\section{Related Concepts:}

- Biology: interactions between predator and prey species, biodiversity

\section{Extensions:}

- Changes in the predator community can change how resistant a location is to invasion. Tell the students you are going to play the game again, only something has happened where the clams will be introduced. Crab fishermen have been very busy and as a result there are no crabs left in the area. Play the game a second time, making sure the students use the same clam they made during the first play through. This time, use the Biotic Resistance - Clam Defense Slideshow After Crab Harvest document as the slideshow. No crabs are present in this slideshow, as they have all been removed by fishermen. Ask the students if any survived this time that were killed off before. Discuss how the outcome of the game might change if more predators were added. The addition of predators to control invasive species does occur and is called biological control. 